\title{
Histologische Untersuchungen am Sehlappen der Cephalopoden.
}

\author{
Von \\ Michael v. Lenhossék in Tübingen.
}

Hierzu 3 Figuren in Text und Tafel VI, VII u. VIII.

\section{Einleitung.}

In einer im vorigen Jahre reröffentlichten Arbeit ${ }^{1}$ ) habe ich, in Anschluss an die friiheren Mittheilungen $B$ a bu ch in's ') und Grenaeber's ${ }^{3}$ ), anf Grund eigener, hanptsïchlich mit der Golgi'schen Methode angestellter Untersuchungen den Nachweis fülhren können, dass die Netzhaut von Eledone und höchst wahrscheinlich die sämmtlicher dibranchiaten Cephalopoden einen höchst einfachen Bau aufweist: sie besteht, abgesehen von ibrem Gehalte an unbedeutenden ${ }_{n}^{\text {Stutzzellen }}$ ", aus einer einfachen Lage langausgezogener, palissadenförmig neben einander stehender Zellen, die sich durch den direkten Uebergang ihres proximalen zugespitzten Endes in eine Nervenfaser bestimmt als typische Sinnesnervenzellen kundgeben. Die aus ihrer Verlängerung hervorgehenden Fasern, die „Retinalfasern ${ }^{4}$, wic ich sie zu nemen vorschlage, sieht man zu stïrkeren Bïndelchen gesammelt in den Sehlappen eintreten. Was hier mit ilneu geschieht, dariiber standen mir damals keine befriedigenden Erfahrungen \%u Gebote, anch vermisste ich in der Litteratur alle einschlägigen Angaben; aber bei der ganzen Sachlage, im Ztrsammenhalt mit allen sonstigen neueren Erfahrungen auf dem Gebiete der Anatomie des Nervensystems, musste ich es als höchst wahrscheinlich hinstellen, dass sie im Seblappen ein freies, wahrscheinlich verzweigtes Ende finden.

1) M. v. L e n hos sék, Zur Kenntniss der Netzhaut der Cephalopoden. Zeitschr. f. wissensch. Zoologie, Bd. LVIII, 1894, S. 636-660.

2) A. B a b u c h i n, Vergleichend-histologische Studien. 1. Ueber den Bau der Cephalopodenretina. Würzburger naturw. Zeitschrift. Bd. V. 1864. p. 127.

3) H. G r e n a c h e r, Abhandilungen zur vergleichenden Anatomie des Anges. I. Die Retina der Cephalopoden. Abhandl. d. Naturf. Gesellsch. zu Halle. Bd. XVI, 1886, S. 207. 
Nichts lag nun näher, als die Zuriickführung dieser in der Cephalopodennetzhaut verwirklichten Verhältnisse auf den Typus eines einfachen Sinnesnervenepithels, wie es uns in klarster Form in der Riechschleimhaut der Wirbelthiere, in cler Epidermis vieler Wuirmer ( $\%$. B. Lumbricus) und Mollusken entgegentritt. Unschwer gelang diese Zuriickfuihrung an der Hand der Annalume, dass die Netzhaut hervorgegangen sei aus einer lokalen Anhäufung von Sinnesvervenzellen, wobei diese gewisse charakteristische Veriinderungen erfuhren theils durch Verlängermng ihrer distalen, der Lichtquelle zugewendeten Hälfte $z u$ cinem längeren lichtempfindlichen stäbchenartigen Forsatze, theils auch dureh Aufnahme von zur Absorption der Lichtstralılen dicnendem Pigment.

In den Betrachtungen, die ich noch weiterhin an meine Befunde knïpfte, bin ich auch dem Versuche nicht aus dem Wege gegangen, die so einfach gebante $\mathrm{Cepl}$ a lo po d e n netzhat mit ler Wirbelthierretina zu rergleichen. Es schien mir, dass aus einem solchen Vergleiche für das Verständniss beider, namentlich aber der so viel complicirteren Wirbelthiernetzhant eine Fördermg hervorgehen miisse. Der Versuch einer solchen Vergleichung schien umsomelr Erfolg zu versprechen, als die beiden zu vergleichenden Oljjekte in den wesentlichsten Punkten ihres Baues, vor Allem in denjenigen, anf dic es bei einem solchen Vergleiche ankommt, als bekannt be\%cichnet werden durften. Ist doch nummehr anch bei der Netzhaut der Wirbelthiere der innere Zusammenhang der Elemente, ein 'Thema, bei dem die Forschung so lange im Dunkeln herumgetappt hatte, dank den an der Hand der Methylenblan- nol der Gol gi'schen Methode angestellten Untersuchungen $T$ a $r^{\prime} t$ u fer $r^{\prime} \mathrm{i}^{\prime}{ }^{1}$ ) und namentlich $\mathrm{Dog}$ iels${ }^{2}$ ) und R. y $\mathrm{Cajal}^{3}$ ) unserem Verständuiss

1) F. Tartuferi, Sulla anatomia della retina. Interuat. Monatsschr. f. Anat. und Physiol. Bd. IV, 1887, Heft 10.

2) Von den zahlreichen Netzhautarbeiten A. Dogi el's seicn hervorgehoben: Ueber das Verhalten der nervösen Elemente in der Retina der Ganoiden, Reptilien, Vögel und S̈̈ugethiere. Anat. Anzeiger, Jahrg. 3, 1888, S. 133. - Ueber die nervösen Elemente in der Netzhant der Amphibien. Daselbst S. 342. - Ueber die nervösen Elemente in der Netzhaut des Menschen. Zwei Mittheilungen im Archiv f. mikrosk. Anat. Bd. 38, S. 317 und Bd. 40, S. 29. - Die Retina der Vögel. Arch. f. mikrosk. Anat. Bd. 44, 1895, S. 622 .

3) S. R a m ón y C a ja l, Die Netzhant der Wirbelthiere. Uehers. von Dr. R. Gre e f. Wiesbaden, Bergmann's Verlag 1894. 
s i che r erschlossen. Und doch sollte ich bald einsehen, dass ein solcher Vergleich einstweilen nicht zur Feststelhung einer bestimmten Parallele, sondern nur zur Aufstellung ron zwei Möglichkeiten der Analogisirung führen könne, ron denen allerdings eine dem Sachverhalte entsprechen muss.

Diese Alternative hatte ich in folgender Weise gefasst:

1. Nach der ersten Möglichkeit stellt die Cephalopodennetzhaut eine ganze Wirbelthiernetzhant dar. Was bei dem Wirbelthier, einem höheren funktionellen Zustande entsprechend, in drei Abschnitte vertheilt, durch eine Kette ron drei Nerveneinheiten (Sehzelle, Bipolare und Ganglienzelle) dargestellt ist, erschiene bei dem Cephalopoden in eine einzige Nerveneiuheit: die ${ }_{n}$ Selizelle" ${ }^{u}$ usammengefasst. Der stabfürmig verlängerte distale Zellabschnitt würde etwa der Stäbchen- und Zapfensehzelle, der proximale Abschnitt, angesichts seines Ueberganges in eine Nervenfaser, der Ganglienzelle der Vertebratenretina entsprechen. Ja, auch das Analogon der die funktionelle Verbindung \%wischen diesen beiden Zellschichten herstellenden bipolaren Zcllen köunte man vom Standpunkte dieser Auffassung ans an der Sebzelle erkennen, und zwar in ihrem durch eine charakteristische Anschwellung ausgezcichneten mittleren Theil, in dem "Stäluchensockel" Gren a cher's.

2. Die zweite Annahme geht dahin, dass die Sely olle der Cephalopodennetzhat nicht derganzen Wirbelthiernetzhant, sondern nur ihrer ersten Zellschicht, ıler Schichte der Stäbchen- und Zapfenzellen („Sehzellen" W. M üller's) gleichzustellen ist, dass die ïbrigen Zellschichten hier fehlen, oder was viel wahrscheinlicher ist, p rox i ma l w ärts indender Netrhaut am nächsten gelegenen Hirntheil verlagert sind. Ich hatte hierbei den Lobns opticns im Ange; hier mussten, wenn die zweite Annahme zutrifft, die weiteren Zellschichten gesucht werden. Ich setzte hinzu: „Eine solche Auffassung ist nicht von der Hand zn weisen, namentlich nicht, wenn man aus eigener Anschauung den merkwürdigen Bau des Lobus opticus kennt, speziell die auffallende Schichtung ihrer Oberfläche, die aufeinander folgenden Körner- und Molekularlagen, in welch letzterer sogar die Spur einer derartigen Stratification nachznweisen ist, wie wir sic in der Molekularlag'e der Wirbelthiernetzhaut sehen. Hier wird blos die genane Erforschung des Lobus opticus Licht und Aufschluss bringen." 
Wenn ich mich damals des Ausdruckes ngenane Erforschung" bedient hatte, so lag mir nichts ferner, als die Genauigkeit der dariber schon vorliegenden Untersnchungen zu bezweifeln. Hensen ${ }^{1}$ ), Clarke ${ }^{2}$ ), Trinchese $\mathrm{e}^{3}$ ), vor allen Andern aber St i ed $\mathbf{a}^{4}$ ), deren Arbeiten mir damals schon bekannt waren, hatten gewiss grossen Eifer auf die Erforschung. der Struktur des Selilappens verwendet. Wenn hier trotzdem wenig erreicht wurde, so liegt dies natïrlich an nichts Anderem als an der totalen Unzulänglichkeit der damaligen Technik. Was man mit gewöhnlichen Färbungen sehen kann, das finden wir in Stieda's Arbeit zum grossen Theile treffend wiedergegeben. Das Ergebniss dieser Untersuchungen für das Verständniss des inneren Gefüges dieses Hirntheiles ist aber zugestandenermaassen sehr gering, es ist gleich Null. Seit St ti ed a's Mittheilung, der letzten ausführlichen Darstellung des Sehlappens der Cephalopoden, ist bekanntlich die histologische Technik unter Anderem durch zwei für die Erforschung des Nervensystems besonder's wichtige Untersuchungsmethoden: die Methylenblat- und die Golgi'sche Methode, bereichert worden. Diese, namentlich aber die letztere schwebte mir vor, als ich eine erneute grïndliche Untersuchung des Sehlappens als ein Bedürfniss hinstellte.

Aus dem Vorstehenden erhellt also, was die Triebfeder bei den Untersuchungen war, deren Ergebnisse im Folgenden dargelegt werden sollen. In der vollen Zuversicht, dass die Go I g i sche Methode, die ja schon so viele Räthsel des Nervensystems gelöst hat, auch hier Licht bringen werde, hatte ich mir vorgenommen, die erste Gelegenheit zu ergreifen, um den Lobus opticus mit Hilfe dieser Methode $z \mathfrak{u}$ erforschen. Diese Gelegenheit bot sich mir bald dar anlässlich eines mehrwöchentlichen Aufenthaltes an der zoologischen Station zn Neapel in den Monaten März und April des v. J. - Es ist mir vor allem

1) v. Hen se $n$, Ueber das Auge einiger Cephalophoren. Zeitschrift f. wissenschaftliche Zool., Bd. XV, 1865, S. 155. - Vergl. S. 201.

2) L. Clarke, On the Structure of the Optic Lobes of the Cuttle-Fish. Philosoph. Transactions, Vol. 157, Part. 1, p. 155. London 1867.

3) Trinch ese, Memoria sulla Struttura del Sistema nervoso dei Cefalopodi. Firenze, 1868.

4) L. S ti e d a, Studien ïber den Ban der Cephalopoden. Zeitsehr. f. wissenschaftl. Zoologie, Bd. XXIV, 1874, S. 84. 
eine angenchme Pflicht, bei dieser Gelegenheit einem hohen grossherzogl. hessischen Ministerium des Innern und der Justiz, durch dessen giitiges Entgegenkommen ich den hessischen Arbeitsplat\% benützen durfte, meinen ergebensten Dank auszusprechen!

Bald gelang es, die schwarze Reaktion an dem Sehlappen hervorzurufen und über einige wichtige Punkte, vor Allem iuber die Endigungsweise der von der Retina herkommenden Fasern in's Klare zu kommen. Ich sah mich bald einer Fiulle von Einzelheiten gegentaber, von denen die gewöhnlichen Färbepräparate nichts ahnen liessen, ja ich möchte sagen ich hatte gleichsam das Gefühl eines Entdeckungsreisenden, der in eine bis dahin ganz unbekannte Landschaft vordringt.

Leider gelang es mir nicht, über alle Punkte vollkommen sichern Aufschluss zu erhalten. Ich bin mir dessen sehr wohl bewusst und werde nicht ermangeln, im Laufe meiner Darstellung auf diejenigen Punkte hinzuweisen, wo noch neue Untersuchungen einzusetzen haben. Die Mängel meiner Darstellung sind aber derartige, dass sie sich an der Hand derselben Methode, deren ich mich bedient hatte, gewiss unschwer ergänzen lassen werden. Auch ist es recht wohl möglich, dass bei einer Nachuntersuchung eine oder andere von meinen Angaben und Auslegungen eine Correctur erfahren wird. Immerhin glaube ich aber durch meine Untersuchungen auf einem Gebiete, wo bisher so viel wie nichts bekannt war, manches Interessante festgestellt und die Arbeit späterer Forscher wesentlich erleichtert zu haben.

Von den verschiedenen Cephalopodenarten, die mir in Neapel in entgegenkommendster Weise in beliebiger Menge zur Verfugung gestellt wurden, habe ich mich hauptsächlich an Eledone gehalten, schon aus dem Grunde, weil sich auch meine vorjährigen Untersuchungen tiber die Cephalopodennetzhaut ausschliesslich auf dieses Thier bezogen hatten. Ich will die vorwiegende Benützung dieses Objektes betonen, da im Bau der Corticalschicht des Sehlappens zwischen den einzelnen Cephalopodenarten gewisse Unterschiede bestehen; namentlich weist Sepia in dieser Hinsicht Differenzen gegen Eledone auf, doch sind sie untergeordneter Art und man wird in der Hauptsache nicht fehl gehen, wenn man die auf den folgenden Blättern mitzutheilenden Thatsachen, soweit sie Prinzipielles enthalten, auf 
alle dibranchiaten Cephalopoden ausdehnt. Wie die Verhältnisse bei Nautilus liegen, wo nach Hensen's Angabe ein Lobus opticus überhaupt nicht vorhanden sein soll, ist schwer zu sayen. Zuletzt will ich noch bemerken, dass ich bei meinen Untersuchungen ans technischen Grtinden kleineren, noch nicht völlig a ugetrachsenen Exemplaren ron Eledoue den Volyug gegeben habe.

\section{Allgeneine Orientirung.}

Legt man das Gehirn ron Eledone ron oben her dureh vorsichtiges Abprïpariren der Weichtheile des Kopfes und durch Entfernung der Scheitelpartie des Kopfknorjols blos, so erblickt man zu beiden Seiten der nittleren Hirutheile je ein ansehnliches weisses Gebilde, von Bohnenform, nit dem Hilus nach innen gerichtet, seitlich in unmittelbarem Anschlnss an den Augapfel, mit dem es durch zahlreiche Nervenbündel verbunden ist. Diese Nervenbündel entspringen fast in der ganzen Ausdehnung des Gebildes und legen sich, während sie von imen nach aussen ziehen, flach auf dessen Oberfläche auf, so dass es mit Ausnabue des Hilus und dessen unmittelbarer Ungelunng von den Bündeln fast ganz bedeckt ist und erst nach deren Abtragung in seiner richtigen Form zur Ansicht gelangt.

Dieses Gebilde ist das Sehganglion oder der Seh. lappen, Ganglion opticum seu Lobusopticus, von alters her so genannt wegen seines Anschlusses an den Augapfel. Wenn aber durch diese Bezeichnung, die funktionell vollkommen berechtigt ist, die Vorstellung erweckt werden könnte, als sei das Organ ein Bestandtheil des p e ri p h e ris c h e n Sehapparates, so muss auf der andern Seite wieder betont werden, dass es seiner ganzen Lage und seinem Aussehen nach in morphologischer Hinsicht mit ebensoviel Berechtigung als e in Theil d es Gehirns bezeichnet werden kann.

Steht es doch in engster Verbindung mit den iibrigen Hirntheilen durch Vermittelung einer kur\%en starken Comissur and mag es in funtioneller Hinsicht noch so gerechtfertigt sein, den Sehlappen nach $v$. U e $x \mathrm{k} u ̈ l l^{\prime} \mathrm{s}^{1}$ ) Vorgang den ubrigen, die eigentlichen centralsten Hirnvorgänge tragenden Theilen des

1) J. v. Uexk ü 11 , Physiologisehe Untersuchungen an Eledone moschata. Zeitsehrift für Biologie, Bd. XXXI. N. F. XIII, 1894, S. 584. 
Gehirns als ein "peripherisches Ganglion" gegeniiberzustellen, so liegt hierfïr in morphologischer Hinsicht keine zwingende Veranlassung vor. Dem durch physiologische Vorstellungen nicht beinflussten Auge des Anatomen stellt sich der Sellappen recht eigentlich als ein Theil des Gehirns dar und zwar als der mächtigste Abschnitt, fast als die $\mathrm{H}$ a uptmasse des Ge hir n s. Seine kräftige Entwicklung weist augenscheinlich auf die wichtige Rolle hin, die bei den Cephalopoden die optischen Reize in dem Mechanismus der Nervenvorgänge spielen; man darf annelumen, dass hier die durch das Sehorgan eindringenden Erregungen den wichtigsten Faktor abgeben, auf dem sich die reaktiven Lebensäusserungen anfbanen.

Zieht man den Sehlappen etwas vom Gehirn ab, so erkennt man, dass aus dem Hilus ein starkes, sich kegelförmig gegen das Gehirn verschmälerndes Nervenbindel hervortritt, das sich sofort in das Gehirn einsenkt. Dies ist der Tractus opticus (Hensen) oder Pedunculus ganglii optici (Stieda). Am Hilus hinter dem Ansatze des Stieles, dorsal gelegen, füllt dem Beobachter ein stecknadelkopfgrosses, rundliches, scharf abgesetztes Knötchen auf, ein kleines Ganglion, das lange aus unzutreffenden Voraussetzungen als Ganglion olfactorium bezeichnet wurde, bis $S t$ i e d a diese Bezeichnung durch den schlichteren, aber wenigstens nicht unrichtigen Namen Ganglion pedunculi ersetzte.

Um sich iber den inneren Aufbau des Sehlappens zu orientiren, wird man natürlich zuerst den Weg der gewöhnlichen histologischen Technik einschlagen, $d$. h. Quer- und Längsschnitte aus dem gehärteten Objekt anfertigen und sie mit den herkömmlichen Färbungsmethoden behandeln. Auch ich hatte mich zunächst in ausgiebiger Weise dieser Methoden bedient, wobei ich zur Härtung Alkohol, Müller'sche Flüssigkeit, Formol und Sublimat, zur Färbung Hämatoxylin, Karmin, Magentaroth und Thionin benützte.

Das erste, was an solchen Präparaten, sowohl an Längswie an Querschnitten auffällt, ist die Trennung der inneren Struktur in eine schichtenartig gebaute $R$ indenzone und eine mehr unregelmässig netzförmig beschaffene $M$ arkzone. Die Abgrenzung der beiden Zonen gegeneinander ist übrigens bei Eledone nicht so scharf, wie bei Sepia; während bei letzterer ein heller, aus Nervenfasern bestehender schmaler Streifen die 
Grenze bezeichnet, finden wir bei Elerlone einen fast ummittelbaren Uebergang von Rinde und Mark ineinander.

Die Rinde zeigt nun durch ihre schon 1847 von Delle Chi a je abgebildete Schichtung einen Bau, wie er sonst meines Wissens weder im Centralorgan der Cephalopoden noch in dem von andern Wirbellosen wiederkehrt, einen Bau, der in frappantester Weise an gewisse Strukturverlualtnisse des Nervensystems der Wirbelthiere erinnert, so namentlich an den Sclichtenban des Riechlappens, der Kleinhirninde, des Ammonshorns, vor Allem aber - und dies sei gleich betont - an den Ba u der Netzha ut. Die Zahl der streifenförmigen, parallel miteinander an der ganzen Oberflaiche hinlaufenden Schichten beträgt drei; die iussere und innere davon fesseln den Farbstoff ausserordentlich lebhaft, während die mittlere, die gegen diese beiden scharf al)gegrenzt ist, in der Regel fast ungefärbt bleibt. Schon bei schwacher Vergrösserung erkennt man, dass die dumkle Färbuṇّ der äusseren und immeren Schichte anf der Gegenwart von yahlreichen dicht gredrängt stehenden sehr chromatinreichen kleinen rundlichen Bildungen berulut. Wir laben hier, mu durch $A n$ knüpfung an einen bekannten Ausclruck sofort die Sachlage zu

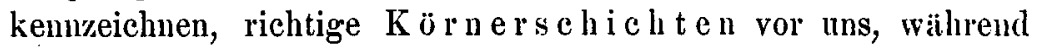
die mittlere Schichte durch ihr Aussehen die Bezeichnnng Mole$\mathrm{k} u \mathrm{lar} \mathrm{ch}$ icht verdient. Letztere ist etwas breiter als die beiden anderen einzeln. An der Konvexität des Sehlappens bleiben sich die drei Streifen iberall gleich breit, ilıre Grenzlinieu iiberall gradlinig, gegen den Hilus zu aber tritt eine Verschmïlerung aller drei Schichten, namentlich aber der äusseren Kernschichte ein; unmittelbar an Rande des Hilus endigt die verschmälerte Molekularlage abgerundet und über ihrem abgerundeten Ende gehen die beiden Körnerlagen in einander iiber.

Indem ich die beiden dunkel gefärbten Bänder als Kürnerschichten bezeichnete, habe ich wissentlich einen veralteten, in seiner urspringlichen Bedeutung nicht melr festzuhaltenden 'Terminus gebraucht. Heutzutage wird wohl niemand mehr daran denken, in den Kügelchen, die an Färbeschnitten derartige Schichten zusammenzusetzen scheinen, etwas anderes zu erblicken als Zellkerne und zwar nicht etwa nackte protoplasmalose Kerne, sondern Kerne, die wie alle anderen Kerne des Organisunus von einem richtigen Zellkörper umfasst sind, der nur bei den gewöhnlichen 
Färbungen nicht recht zur Ansicht gelangt. Diese hentzutage geradezn triviale Erkenntniss ist keine so alte Weisheit, wie man meinen sollte. Es ist noch nicht lange her, dass man diese Zellkerne vielfach für „freie Kerne" oder sogar für „Kürner", d. h. für merkwürdige, sich dem Zellbegriffe gar nicht unterordnende Gebilde gehalten hat. Aus dieser Zeit, die erst mit dem Einsetzen der Golg i-Periode definitiv ihr Ende fand, stammt jener Ausdruck. Freilich hat es immer Forscher gegeben, dic, eigentlich mehr instinktiv als anf Grund direkter Beohachtungen, den richtigen Sachverhalt erkannt hatten. Zu diesen Forschern grehört auch Stieda, denn schon 1874 hezeichnet er in der angefiihrten Arbeit unsere beiden Körnerschichten als „äussere und innere Schicht der Nervenzellen", obgleich er sie in seinen Figuren natürlich so abbildet, wie man sie an Färbepräparaten sieht, d. h. als nackte Kerne. Da aber cin Auslruck, der an sich schlecht ist, umberlenklich weitei gefülurt werden darf zur Bereichnung eines Gegenstandes, wem cinmal dic richtige Anffassung sich so allgemein Bahn gebrochen hat, dass ein Missverständniss nicht mehr zu befürchten ist (vergl. das Wort ${ }_{n} / 1$ elle"), so glanbe ich, dass min den Namen , $\mathrm{K}$ ö 1 u e r auch hier weiterhin beibehalten kann, um so mehr, als dic hicr in Betracht kommenden Zellgebilde gegenüber viclen auderen Nervenzellen in der That ausser ihrer Kleinheit noch durch eine besondere Eigenschaft ihres Protoplasmas eine in sich zus ammenh $\ddot{i}$ ge ende Einheit darstellen. Diese Eigensehatt besteht in der auffallend schwachen oder vollkommen mangelnden Färbbarkeit ihres Zellkörpers, eine Besonderheit, dic in der Abwesenheit jener merkwitrligen, in den Nervenzellen so weitverbreiteten chromophilen Einlagerungen begründet ist, die bei den meisten Nervenzellen das deutliche Hervortreten des Zellkörpers am Farbenbilde bedingen. In diesem Sinne, $d$. h. als Collektivbezeichnung für eine bestimmte Nervenzellengattung hat anch $\mathrm{N}$ is s ${ }^{1}$ ) nenerdings den Ausdruck Körner gebraucht.

Nicht weniger obsolet als der Ausdruck Körnerschicht ist das Wort Molekularlage. Es gibt das Bild wieder, das die fragliche Schicht bei den zur Darstellung ihrer Struktur höchst ungeeigneten

1) Fr. Nissl, Ueber die Nomenklatur in der Nervenzellenanatomie und ihre nächsten Ziele. Neurologisches Centralbl. Jahrg. 14, 1895, S. 69. 
grewöhnlichen Färbungen darbietet. In der That erscheint sie hier vielfach wie aus kleinen molekülartigen Kömchen, Knötchen, Pïnktchen zusammengesetzt. Erst die Golgi'sche Methode zeigt mit voller Deutlichkeit, wie es um diese Schicht bestellt ist; sie enthüllt sie als ein äusserst dichtes Gewirre feinster Fäserchen, als eine "plexif orme Schicht", ebenso wie dies bei der Punktsubstanz der Wirbellosen, bei den Molekularschichten der Netzhaut der Fall ist. Auch hier hat Stied a schon vor mehr als 20 Jahren das Richtige getroffen, indem er sagt: „Die Untersuchung bei starker Vergrösserung, sowie an frischen Präparaten zeigt, dass es sich hier nicht um eine granulirte Substanz etwa im Sinne der Nervenzellen der Wirbelthiere, auch nicht um cinc sogenannte Punktsubstanz im Sinne einiger Autoren, sondern um ein äusserst feines, sehr dichtes Netz der allerfeinsten Fäserchen handelt". Wenn aber Stie d a betont, dass hier keine Punktsubstanz vorliege, so könnte diese etwas unklare Fassung eines richtigen Gedankens zu dem Missverständniss führen, als handle es sich hier um eine ganz andere Gewebsart als diejenige, welche in centralen Nervensystem der Wirbellosen vielfach noch heutzutage mit diesem Namen belegt wird. Eine solche Meinung wäre vollkommen unrichtig. Es liegt hier im Wesentlichen das Gleiche vor. Hier wie dort handelt es sich um ein dichtes Gemenge von Dendriten, Stammfortsätzen und ihren Nebenästchen, von Faserverästelungen, und wie ich es nachweisen werde können, anch von Gliazellenfortsätzen.

Eine gewisse Eigenart kommt unserer plexiformen Schicht gegenüber der Punktsubstanz, wie wir ihr in anderen Theilen des Gehirns von Eledone begegnen, nur insofern zu, als hier eine merkwürdige parallele $\mathrm{Schichtang}$ der ganzen Lage in die Erscheinung tritt, eine Erscheinung, die, soviel ich weiss, in der Punktsubstanz nirgends zur Beobachtung kommt. Es ist das jene Schichtung, die ich schon in meinem vorjährigen Aufsatze an der oben citirten Stelle erwähnt hatte; sie war schon Stieda bekannt. An Alkoholpräparaten ist davon kaum was zu bemerken, sie tritt erst an Präparaten hervor, zu deren Fixirung Chromsalzgemische oder Salpetersäure verwendet wurden. Die besten Bilder liefert aber in dieser Hinsicht soviel ich sehe die Behandlung mit dem bei der Golgi'schen Methode zur Anwendung kommenden Bichrom-Osmium-Gemische. Es handelt 
sich um eine Glickerung der plexiformen Schicht in weitere Unterschichten, die sich theils durch abwechselnd dunklere und hellere Beschaffenheit, theils auch durch stellenweise schärferes Hervortreten einer fibrillären Zusammensetzung auch am Farbenbilde von einander unterscheiden. Worin die Bildung dieser Schichten begrundet ist, wird sich erst im Laufe unserer Darstellung ergeben; hier kann zunächst nur der Eindruck geschildert werden, den man an den Färbepräparaten von diesen Verhältnissen erhält.

Geht min von der an die äussere Körnerschicht grenzenden Fläche aus, so erkemnt man zunächst als erste Lage in der plexiformen Schicht 1) einen sehr. schmalen a uffallend h e llen s a um, damn 2) cine breite Lage, die sich durch dunkleren Ton und durch die Gegenwart einer horizontalen zarten Streifung gegen die Umgebung absetzt. Aus den späteren Ausfiihrungen wird hervorgehen, dass in letzterer Lage ein sehr dichtes Geflecht feinster welliger, in horizontaler Richtung verlaufender Fäscrehen vorliegt; so mag dieser Schicht gleich hier der ilur gebiurende Name nä us serer Horizontalp lexus" beigelegt werden. Ab und zu sicht man die Schicht in drei Abtheilungen, einen äusseren und inneren dunkleren Randstreifen und einen mittleren helleren zerfallen. Auf den dunklen z̈usseren Plexus folgt nun 3) der ansehnlichste Theil der plexiformen Zone, die IIttelzone, wie ich sie benennen nö̈chte. Sie zeigt eine etwas hellere Beschaffenheit und weist an manchen Präparaten, wenn auch undentlich, eine senkrechte Streifung auf, die theilweise durch die darin aufsteigenden Blutgefässe, theilweise aber auch unverkennbar durch zarte, sie senkrecht durchziehende Fäserchen bedingt ist. Das untere Viertel der plexiformen Schicht etwa sehen wir 4) wieder von einem dunkleren, den äusseren Plexus an Breite etwas übertreffenden Streifen in Anspruch genommen, der eine ähnliche Zusammensetzung hat, wie das äussere Geflecht und demgemäss den Namen in nerer Horizontalplexus verdient; nur scheint den Elementen dieses Geflechtes schon nach dem Aussehen an Färbepräparaten eine dichtere Anordnung und eine etwas grobfaserigere Beschaffenheit zuzukommen. Auch hier tritt uns ab und zu eine weitere Gliederung in zwei Randstreifen und ein mittleres, etwas helleres Band entgegen. Gegen die innere Körnerlage grenzt 
sich diese Schicht häutig, aber nicht constant wieder 5) durch einen ganz schmalen helleren Saum ab.

Wem sollte hier nicht die grosse Aehnlichkeit auffallen, die die geschilderten Verhältnisse mit der merkwürdigen Stratification der inneren plexiformen Schicht der Netzhaut der Wirbelthiere aufweisen? Bei letzterer ist die fragliche Schichtung bekanntlich schon von einigen älteren Histologen, zuerst wohl von Wagner im Jahre 1868 gesehen und von manchen, wie $\%$ B. Ranvier ${ }^{1}$ ), auch im Wesentlichen richtig gedeutet worden; abei erst die neuere Zeit brachte uns nach diesen unvollkommenen allgemein gehaltenen Andeutungen in Dogral's und Ramón y Cajal's Arbeiten genaueren Aufschluss ïber ihre Anordnung und ihr Zustandekommen. Es wird sich zeigen, d as s die Bildung der Unterschichten in der plexiformen Sehicht des Sehlappens der Cephalopoden auf ganz ähnliche Ursachen zur ückzuführen ist, wie sie in der Vertebratenretina jene Unterschichten be dingen.

Solltc die folgende Darstellung den Gang meiner Untersuchungen getreu einhalten, so wäre dasjenige zuerst zu beschreiben, was ich aus den Färbepiäparaten über die einzelnen Schichten herauszulesen im Stande war, dann erst wären dic Ergebnisse der Golgibilder anzuschliessen. - Indess scheint mir dem Interesse des Lesers viel mehr gedient zu sein, wenn ich ihm meine Befunde ohne Rücksicht auf die Reihenfolge und Peripetien ihrer Gewinnung gleich in inhaltlich geordneter, abgerundeter Form vorlege.

\section{Retinalfasern und ihre Endigung.}

Wir treten sofort in den wichtigsten Theil unserer Befunde ein, indem wir das Verhalten der von der Netzhaut entspringenden Fasern and die Art ihrer Endigung in's Auge fassen. Eine ganz systematische Darstellung hätte hier freilich etwas weiter anszuholen, d. h. von der Beschreibung der Sehzellen der Netzhaut und ihres Uebergangs in die fraglichen Fasern auszugehen, und so die ganze erste Nerveneinheit, das ganze "Teloneuron ${ }^{\text {" }}$ im Zusammenhang zu betrachten. Indessen will ich hiervon, um

1) L. Ranvier, Technisches Lehrbuch der Histologie, übersetzt von Nicati und v. Wyss, Leipzig 1888, S. 899. 
nicht bekanntes zu wierlerholen, Abstand nehmen und in dieser Beziehung auf meine vorjährige Arbeit verweisen.

Wir knüpfen also gleich an das Bild an, das die Retinalfasem anf der Oberfläche des Sehlappens rarbieten, wo sie sich, wie schon eingangs erwähnt, zu derben makroskopischen Bündeln ordnen. Nur die kürzesten von diesen Bündeln, d. h. diejenigen, die den konvexen Rand des Sehlappens zum Eintritt beniitzen, dringen in das Innere dieses Hirntheils sofort senkrecht ein; alle anderen müssen eine kiirzere oder längere Strecke auf der Oberfliche des Lobus opticus binlaufen. Dieser Umstand hat Stieda veranlasst, eine besondere Retinalfaserschicht am Sehlappen zu unterscheiden. Ein solches Vorgehen scheint mir deshalb nicht gerechtfertigt, weil diese Fasern eigentlich noch nicht zum Bestande des Sehlappeus gehören, vielmehr sich diesen nur im freien Kontakt anlegen; der Sehlappen fängt meiner Auffassung nach erst mit der äusseren Körnerschicht an. Die oberflächlichen Retinalbündelchen weisen zahlreiche längliche Bindegewebskerne anf, die wohl in der Hauptsache dem sie ciuscheidenden und unter sich verknüpfenden Bindegewebe angehören; da man diese Kerne aber an Querschnittsbildern der Bündelchen auch in Inneren derselben vorfindet, wie ich abweichend von $S t$ i e d a betonen muss, so muss wohl auch eine Art Endoneurium vorhanden sein, das ins Innere der Bündel zwischen die einzelnen Nervenfasem hineindringt. Die Kerne sind unschwer von den anders geformten Kernen der hier vorhandenen Blutgefässe zu unterscheiden. Was mit diesem Bindegewebe auf der Oberfläche des Sehlappens geschieht, konnte ich nicht mit Bestimmtheit feststellen, sicher scheint mir nur, dass es sich nicht in den Sehlappen hinein erstreckt; wenigstens vermisst man von der äusseren Grenze des Organes an die beschriebenen Kerne vollkommen. An vielen Stellen schien es mir, als wäre die Oberfläche des Sehlappens gegen die aufliegenden Retinalbündel durch eine zarte, mit schmalen Bindegewebskernen besetzte bindegewebige Haut abgegrenzt. Hierin könnte man die Fortsetzung jenes Peri- und Endoneuriums erblicken.

Die Elemente der Retinalbündelchen sind kernlose Füserchen. $O b$ eine Schwann'sche Scheide an jeder Faser vorhanden ist, wie es von mancher Seite für die Nervenfasern der Wirbellosen im Allgemeinen angenommen wird, konnte ich nicht 
entscheiden; meine Beobachtungen sprechen eher dagegen als dafür. Die Fasern selbst lassen sich mit keiner Färbemethode auch nur annähernd so schön darstellen, wie mit der Golg $\mathrm{i}$ schen. Sie präsentiren sich an solchen Präparaten als relativ starke glatte Fasern, die ausserlalb des Ganglions eine ziemlich gedrängte Lage und einen recht geraden parallelen Verlauf erkeunen lassen.

Das Verhalten im Sehlappen ist nun Folgendes: Zunächst trennen sich die gröberen Bündel bei ihrem Eintritt in eine Anzahl feiner sekundärer B it ndel und diese senken sich unter bogenförmiger Krümmung in den Sehlappen zwischen die obersten Zellen ein, sic stark auseinander drängend, so dass die oberflächlichste Schicht der äusseren Körnerlage ein stark aufgelockertes Aussehen aufweist. Aber schon etwas tiefer tritt eine weitere $A$ uffaser ung der Retinalbündelchen ein. Die Fasern vertheilen sich nun sehr raseh gleichmässig und ziehen einzeln zwischen den Elementen der äusseren Körnerschicht gegen die plexiforme Schicht hin. Das kommt nun auch darin rum Ausdruck, dass fast schon von der Mitte der Körnerschicht an die Anordnungr der Körner eine nahezu gleichmässige, gerarle nur andeutungsweise in dem Sinne des Verlaufes der Retinalfasern gestreifte ist. Mit dieser Auflösung der Retinalbündelchen in ihre Elemente hört auch an gewöhnlichen Färbeschnitten die Möglichkeit ihrer weiteren Verfolgung vollkommen auf: die Golgi'sche Methode kommt hier zur Geltung. Was sie zeigt und wie klar sie die hier in Betracht kommenden Verhältnisse zur Ansicht bringt, habe ich hauptsächlich in Fig. 1, Tafel VI zur Anschanung zu bringen gesucht.

Es schien mir vielfach, als wïrden die Fasern von ihrer Einbiegung in die äussere Körnerschicht an etwas an Dicke znnehmen. Auch nach ihrem Eintritt weisen sie das Bild glatter, nur stellenweise mit knötchenartigen Varikositäten besetzter Fasern auf.

Sie durchziehen nun senkrecht die Körnerlage, doch ist ihr Verlauf selten ganz gestreckt, vielmehr beschreiben sie fast immer wellenförmige oder auch mehr zackige Krümmungen, die, wenn auch vielleicht durch die mit der Hürtung einhergehende Schrumpfung des Organs etwas gesteigert, in der Hauptsache doch wohl als präformirt anzusehen und auf den Umstand zurückzu- 
führen sind, dass die Fasern sich hier durch eine dichtgedrängte Lage von Zellen hindurchzuwinden und hierbei vielfach den einzelnen Zellen auszuweichen haben. Der streng senkrechte Verlauf ist vielfach anch dadurch beeinträchtigt, dass die Bündelchen bei ihrer Auffaserung von einem Punkte aus divergirend auseinanderweichen.

In der beschriebenen Weise erreichen nun unsere Fasern die plexiforme Schicht. Sehr bald nach ihrem Eindringen in diese, schon im Gebiet der ersten Unterschicht: jenes schmalen hellen Saumes, fällt nun eine merkwürdige Erscheinung an ihnen auf: sie bilden alle eine plumpe kegelförmige Verdickung, deren Basis gerade der Grenze zwischen dem hellen Saum und dem äusseren horizontalen Plexus angehört. Schon jetzt mag darauf hingewiesen werden, dass wir hier den überraschendsten Anschluss an die Verhältuisse der Zapfenfasern in der äusseren plexiformen Schicht der Wirbelthiernetzhant haben. Ein Unterschied gegenïber dem Verhalten der letzteren besteht nur darin, dass diese Verdickung, wenigstens im Sehlappen vollkonmen ausgewachsener Thiere, nicht wie bei der Zapfenfaser das Ende der Faser bezeichnet; denn man sieht von der Mitte ihrer Basis noch einen Ast hervorgehen, der senkrecht in tiefere Lagen der plexiformen schicht hinunterzieht. Der Ursprung dieses absteigenden Astes erfolgt mit einer Rauligkeit, die, sich ebenfalls kegelförmig an die Basis des oberen Kegels anschliessend, der ganzen Verdickung oft die Form eines Doppelkegels verleiht, wobei allerdings nur die obere im Bereich des hellen Saumes gelegene Hälfte die Gestalt eines ganz regelmässigen Kegels aufweist.

Die Verdickung kommt typisch einer jeden Faser z $u$ und bildet eine sehr auffallende Erscheinung. Haben sich viele Retinalfasern mit ihren Anschwellungen dicht neben einander imprägnirt, so erhält man das Bild eines starken schwarzen Streifens, theils in der unteren Hälfte des hellen Saumes, theils im äusseren Plexus gelegen. Das ganze Verhalten dieser Verdickung an Golgipräparaten ist, wie aus der Tafel ersichtlich, ein derartiges, dass man es erklärlich finden wird, dass ich sie auf den ersten Blick für imprägnirte Zellen gehalten habe. Erst die nochmalige genaue Prüfung von Färbepräparaten hat mich über den richtigen Sachverhalt aufgeklärt, indem von den Ver- 
dickungen an solehen kaum etwas zu sehen ist; sie sind nänlich fast ganz achromatisch; selbst die Protoplasmafärbumgen lassen sie beinahe ungetärbt.

Eine weitere Analogie mit dem Verhalten des unteren Endes der Zanfenfasern ergiebt sich in der Gegenwart zahlreicher allerfeinsten Fibrillen, die von der geschilderten Verdickung entspringen. Sie gehören ganz dem äusseren Plexus an und zwar nelımen sie nicht dessen ganze Dicke in Anspruch, sondern nur ungefähr seine äussere Hälfte, dadurch oft eine weitere Gliederung. des äusseren Plexus bedingend. Es handelt sich um so zarte Fäserchen, dass man sie in ihrem genauen Verhalten nur mit stärkeren Vergrösserungen untersuchen kann, schon deshalh, weil sie sich nie schwar\% imprägniren, sourlern in hellhraumer Farbe; es sind dies die zartesten Fibrillen, die ich an Golgipräparaten jemals gesehen habe. Sie entspringen theils an der Basis des oberen Kegels, theils auch an der Anfangsrauhigkeit des absteigendes Astes und zeigen in ilırer Anordnung cine grosse Regelmässigkeit, eine Anordnung, die sich am anschanlichsten durch den Vergleich mit cinem mässig auf eine Unterlage aufgedtückten Pinselehen kennzeichnen lässt. Dic äussersten Fäserchen entspringen an den Seitenspitzen der Kegelbasis uml sind am weitesten ausgebogen; je mehr nach innen cntspringend, desto kürzer werden sie. Alle endigen ungetheilt mit freien Spitzen oder Endknötchen, streng an der nnteren Gron\%linie ihres Gebietes, manche in der Weise, dass sie sich noch ein kurzes Stückchen an dieser Linie horizontal umkrimmen. Eine anastomotische Verbindung mit den Verästelungen anderer Zellen kommt nicht vor.

Diese zarten Fibrillenpinselchen tragen wesentlich bei zur Bildung des ätısseren horizontalen Plexus, namentlich in dessen äusserer Hälfte. Man kann von vornherein sagen, dass ihnen eine grosse funktionelle Bedentung zukonımt und dass dic Gegend, in der sie sich ausbreiten, die Haupteinwirkungsstelle der Retinalfasern auf die Elemente der Sehlappenrinde darstellen muss.

Was den schon oben erwähnten absteigenden Endfortsatz betrifft, so entspringt er, wie gesagt, immer mit einer ziemlich ansehnlichen Verdickung, verdünnt sich aber bald in dem Maasse, dass man ihn kaum mehr als eigentliche Fortsetzung des 
Retinalfaserstanmes, sondern mehr als einen absteigenden Zweig der Endverästelung auffassen möchte. Man sieht ihn streng senkrecht durch die Mittelzone einwärtsziehen. In Bezug auf dic Stelle seiner Endigung habe ich sehr verschiedene Bilder erhalten und erkannte erst im Fortgange meiner Untersuchungen, dass in diesen Verschiedenheiten Altersunterschiede vorliegen. Im Sehlappen noch nicht völlig entwickelter Thiere sieht man die Fasern stets schon inmerhalb der Mittelzone oberhalb deren unterer Grenze zugespitzt endigen, manchmal gleich unter dem äusseren Plexus. Da die Mehrzahl meiner Präparate, wie erwälnt, jungen Thieren entnommen waren, so hielt ich dies lange für das normale Verhalten und habe daher diesen absteigenden Fäserchen eine sehr geriuge Bedeutung beigelegt. Eines Bessern wurde ich erst belehrt, als ich in zwei Fällen im Sehlappen von erwachsenen Thieren gelungene Impräguationen der Retinalfasern erlielt (s. Fig. 1, Taf. VI). Hier präsentirten sich die Aeste etwas anders. Zumächst erschienen sie im Allgemeinen etwas stärker, obgleich noch immer bedeutend zarter als der Stamm ihrer Fasern. Auch theilten sie sich manchmal in zwei Aeste, gleich unter der Verdickung oder etwas weiter unten. Als wesentlichster Unterschied ergab sich aber, dass die Fasern hier den unteren Plexus fast immer erreichten, um erst darin zu endigen. Die Endigungsweise erschien verschieden. Entweder liefen sie sofort in eine freie Spitze aus, oder sie bildeten ein kleines schmächtiges Endbiischelchen; in einer dritten Reihe vou Fällen theilten sie sich gabelförmig in zwei Aeste, die horizontal auseinanderweichend an der oberen Grenze des äusseren Plexus eine kurze Strecke horizontal dahinzogen, unn frei zu endigen. Für jedes dieser drei Verhalten wird man in Fig. 1 Beispiele finden. Somit scheint es, dass die Retinalfasern beim erwachsenen Thier auch auf das Gebiet des inneren Plexus einzuwirken geeignet sind, wenn es auch nach der ganzen anatomischen Sachlage nicht fraglich sein kann, dass ihr Hauptwirkungsgebiet a uch im reifen Zustande dem äussern Plexus angehört.

Ueberblicken wir nun das Mitgetheilte, so lïsst sich als Wesentlichstes die Thatsache hervorheben, dass die Retinalfasern, wie ich das schon in meiner friheren Mittheilung vermuthungweise ausgesprochen babe, in der 
plexiformen Schicht ein freies, in ciner bestimmten, sehr typischen Weise verzweigtes Ende finden. Alle ihre Endüste laufen mit freien Spitzen aus und nur durch Kontakt kann somit die Uebertragung der Lichtreize anf die andern Zellelemente des Sehlappens erfolgen.

\section{Centrifugale peripherische Fisern.}

Mit den soeben abgehandelten typischen Retinalfasern sieht man noch ein zweites System von Fasern in das Innere des Seblappens eindringen, allerdings in weitans spärlicherer Zahl, die ein wesentlich verschiedenes Verhalten zeigen (s. die rothen Fasern in Fig. 6, Taf. VII). Sie endligen nämlich nicht wie die Retinalfasern in der plexiformen Schicht, sondern durehsetzen nicht nur die Rinde, sondern anch dic ganze Markschicht, und man kann sie als unverästelte und der Scitenäste ent. behrende Fasern bis zur Gegend des Hilusver. folgen. Ja auch hier dürften sie noch nicht ilur Ende erreichen; nie konnte ich an der Stelle, wo sie aufhörten, eine Znspitzung oder andere anf eine wirkliche Endigung hinweisende Erscheinungen wahrnehmen, vielmelur ist an meinen Präparaten die Art ilres Aufhörens stets eine derartige, dass das scheinbare Ende mit Bestimmtheit auf einen Mangel der Reaktion zurickgefiihrt werden kann. Summire ich die Eindriicke, die ich erhielt, so scheint es mir am wahrscheinlichsten, dass diese Fasern nach Durchsetzung des ganzen Sellappens anf dem Wege des Pedunculus opticus indie Centralgangliendes Gehirnseindringen. Auch sie sind bei ihrem Eintritt in den Sehlappen zn kleinen Bündelchen zusammengeordnet, doch liegen hier die Bündelchen sporadisch, in relativ grösseren Abständen von emander. Auch bewahren die Bündelchen ihre compacte Beschaffenheit während ihres ganzes Verlaufes durch den Sehlappen. Die Dicke der Fasern ist verschieden. Es finden sich recht ausehnliche darunter, aber auch ganz zarte gehören nicht zu den Seltenheiten. In der Mehrzahl der Fälle durchsetzen sie senkrecht die Rinde und laufen auch in der Markschicht in gerader radiärer Richtung gegèn den Hilus weiter fort, allerdings überall unter Beschreibung von kleinell zackigen Krümmungen, die ja ubberhaupt allen Fasergebilden des Sehlappens eigen sind. Nur diejenigen Fasern, die unweit vom Hilns den Sehlappen betreten, 
zeigen vielfach das Verhalten, dass sie die Rinde schief durchsetzen; einer solchen Stelle ist die linke Hälfte der Figur 6 entnommen. In einigen Fällen konnte ich auch beobachten, dass dicse Fasern im Bereich des innern Plexus vorübergehend in die horizontale Richtung umbiegen, um erst in einiger Eutfernung wieder die senkrechte Richtung einzuschlagen und durch die innere Körnerschichte lindurch im Marke weiterzuziehen.

Wie sollen wir nun diese Fasern deuten? Einen Zusammenhang mit Zellen des Sehlappens konnte ich bei ihnen nie feststellen; ein solcher ist wohl allem Anscheine nach nicht vorhanden, da ja manche Fasern fast bis zum Hilus verfolgt werten kounten. Wie schon oben ausgeführt, gehen sie wahrscheinlich in die Centralpartie des Gehirns ein, aber wie sie sich hier verhalten, blieb durchaus unergriundet. Ebensowenig gelang es, sic distal ausserhalb des Sehlappens weiter zu beobachten; also weder über ihr peripherisches noch aber über ihr centrales Verhalten stehen mir direkte Beobachtungen zur Verfügung und ich bin somit durchaus nur auf $\mathrm{M} u \mathrm{th}$ mass $\mathrm{u} \mathrm{g}$ en angewiesen. Die erste Möglichkeit, die hier in Betracht gezogen werden könnte, wäre die, dass es sich um eine zweite Gattung von Retinalfasern handelt, um Forsätze von bestinmten der Retina angehörenden Zellen. Bei näherer Ueberlegung muss man aber eine solche Annahme als unwahrscheinlich bei Seite lassen. Die Netrhaut von Eledone besteht ans einer einzigen und in wesentlichen gleichartigen Zellenform. Finden wir auch in dem Verhalten des unteren Theiles der Zellen kleine Verschiedenbeiten, Differenzen, die mich in meiner früheren Arbeit sogar zur Aufstellung von zwei Zell-Typen, einem Lumbricus- und einem Riechzellentypus, veranlassten, so sind diese Unterschiede doch von sehr unscheinbarer Art, wïhrend wir mit Recht annehmen dürfen, dass, wenn einzelne Retinalfasern einen von dem der übrigen so prinzipiell verschiedenen Verlauf besitzen wïrden, dies anch in der ausgeprägten Verschiedenheit der dazu gehörigen Ursprungszellen zum Ausdruck kommen milsste.

Wenn so ausgeschlossen werden kann, dass diese Fasern in der Netzhaut entspringen, so wäre es doch immerhin möglich, dass sie einen peripherischen, distal vom Sehlappen gelegenen Ursprung haben, nicht etwa aus Ganglien, denn solche finden sich in der Ungebung des Anges bestimmt nicht, sondern aus 
Sinnesnervenzellen der Epidermis, in welchem Falle sie als sensible centripetale Nervenfasern aufzufassen wären. Dass die Cephalopoden in ihrer Epidermis dergleichen Zellen beherbergen, ist sehr wahrscheinlich, schon aus dem Grunde, weil bei anderen Mollusken solehe epidermale Nervenzellen mit Bestimmtheit nachgewiesen sind; auch glaube ich in einem Falle an einem $\mathrm{Golg} \mathrm{i}$ Präparate eines Tentakels von Eledone eine derartige Zelle wahrgenommen zu haben. Indess muss man sagen, dass es bei dieser Annahme nicht reclit erklärlich wäre, warum solche Fasern ilıren Weg gerade durch den Lobus opticus nehmen sollten, da sie doch nach allem, was ich gesehen habe, nicht in diesem selbst, sondern einwärts davon im centraleren Theil des Gehirns ihr Ende erreichen.

Nach reiflicher Ueberlegung scheint mir also die Annalme an wabrscheinlichsten, dass wir es hier mit centrifugalen Fasern zu th un haben, d. h. mit Nervenfasern, die ihre Ursprungszellen im Gehirn besitzen, die in ihrer peripherischen Vertheilung für Auge und Orbitabestimmt sind und ans diesem Grunde, d. h. um ihre Endpunkte auf dem kürzesten Wege zu erreichen, durch den Lob. opt. hindurchziehen. Was die Funktion der Fasern betrifft, ob sie motorischer oder sensibler Natur sind, so lasst sich mit grosser Wahrscheinlichkeit annehmen, dass beide Faserarten unter ihnen vertreten sind; vielleicht hängen die erwähnten Kaliberunterschiede mit einer derartigen funktionellen Verschiedenheit zusammen. Ich glaube aber doch, dass die Mehrzahl davon sensibler Natur ist und zur sensiblen Innervation der verseliedenen Bestandtheile des Bulbus dient. Dass aber auch motorische Fasern darunter vertreten sind, dafür liefert die Physiologie einen indirekteu Beweis (vergl. v. Uexküll a. a. O.S. 600). Diese motorisehen Fasern können freilich nicht im Bulbus selbst endigen, denn das Cephalopodenauge ermangelt der Binuenmuskeln vollkommen, sondern innerviren offenbar die das Auge änsserlich bewegenden Muskeln und vielleicht auch die Hautmuskulatur, die die augenlidartigen Falten in der Umgebung der Augenöffnung berregt.

\section{Aeussere Körnerschicht.}

Schon eine flüchtige Betrachtung der äusseren Körnerschichte an Färbeschnitten ergiebt, dass in der Anordnung und Grösse 
der Körner d. h. der Zellkeme $\%$ wischen den tieferen und oberflachlicheren Lagen dieser Schichte e in a us gesprochener Unterschied besteht. Wälurend in der äusseren Hälfte die Körner durch die eindringenden Retinalbündel anfgelockert, unregelnässig zerklüftet erscheinen, finden wir sie in der inneren Hälfte in dichterer und mehr gleichmässiger Anordnung. Wem Stied a auch in der inneren Hälfte die Kerne in parallele Lüngsreihen geordnet schildert, so kamn ich dies für Eledone nicht bestätigen. Der Uebergang der einen Anordnung in die andere ist allerdings kein plötzlicher, vielmehr findet von aussen nach imen cine allmähliche Verdichtung statt. Ein zweiter nicht weniger prägnanter Unterschied besteht in der verschiedenen Grösse der Kerne. Die innere Schicht beherbergrt hauptsächlich sehr kleine, rundliche Kerne mit so dichtem Chromatingerüst, dass selbst an feinsten Schnitten von der Kernstruktur kaum etwas wahrzunehmen ist. Gegenüber diesen ganz dunkeln sehr kleinen Kernen tritt in der inmeren Hälfte eine zweite Art, die etwas grössere und hellere Kerne umfasst, znrück. In der äusseren Hälfte fehlt die ganz kleine Kerngattung vollkommen, hier finden wir ausschlicsslich etwas grössere hellere, gegen die Oberfläche hin allmählich grösser werdende Kerne. Vom Zellkörper ist an den meisten Färbungen bei allen diesen Kernen nichts zu sehen.

Ganz auf der Oberfläche tritt in sporadischer Anordnung eine besondere Zellgattung auf, die sich von den Körnern einerseits durch ansehnliche Grösse, andererseits dadurch unterscheidet, dass ihr Zellkörper anch bei den gewöhnlichen Fürbungen in die Erscheinung tritt.

Ander Hand der Silbermethode ergebensich nun alle Körner und a uch die letrtgenanten grösseren Elemente als Nervenzellen. Allerdings liegt hier eine besondere Art von Nervenzellen vor, eine Gattung, bei der nicht alle die typischen Bestandtheile, die wir z. B. an den Nervenzellen des Centralnervensystems der Wirbelthiere keunen, zur Entwicklung gelangen, Elemente, die sich mehr an die unvollkommenen Nervenzellen anschliessen, wie sie der Netzhaut der Wirbelthiere eigen sind. Allen kommt cine unipolare Form zu, wobei der Fortsatz stets einwärts gegen die plexiforme Schicht zieht.

Archiv f. mikrosk. Anat. Bd. 17 
Auf Grund der Golgi-Bilder gewinnt die Unterscheidung der soeben nach Färbepräparaten geschilderten drei Zellsorten eine festere Grundlage. Davon lassen sich freilich zwei als ${ }_{n}$ Körner" der dritten als eine einheitliche Gruppe gegeniiberstellen. Betrachten wir nun diese Zellengattungen cinzeln.

\section{Oberflächliche grosse Zellen.}

Eine besondere Stellung nehmen die oberflächliche $n$ grossen Zellen oder ${ }_{n}$ Riesenzellen ${ }^{4}$ ein. Es sind das die oben erwähnten auffallend voluminösen Elemente, die nan auf der Oberfläche in sporadischer Ordnming vorfindet. Sic bilden durchaus keine zusammenlüngende Lage, auch entbehrt ihre Anordnung der Regelmässigkeit, bald findet man sie zn zweien oder dreien dicht neben einander, bald wieder einzeln in weiteren Abständen. Zumeist liegen sie gerade an der Oberfläche des Sehlappens, mit der oft abgeplatteten Basis ihres kegelförmigen oder birnförmigen Zellkörpers einen Theil der Oberfläche bildend, mit der Spitze nach unten gerichtet; doch können sie auch eine tiefere Lage einnehmen, in verschiedene Ebenen der Körnerschicht hineinrlieken, ja manchmal so tief, dass sie mit ihrem Fortsatzpole die Grenze der plexiformen Schicht erreichen, doch gehört eine solche Lage zu den Seltenheiten. Die regelmässige Stellung ist die senkrechte, doch findet man sie namentlich bei den ganz auf der Oberfläche gelegenen Zellen sehr oft mit der Längsaxe horizontal oder schief gestellt, was unverkennbar durch den entsprechenden Verlauf der Retinalbündelchen, zwischen die sie eingesprengt sind, veranlasst ist. Auch die Grösse dieser Elemente wechselt etwas. Man findet ganz anselnnliche Exemplare dieser Art von etwa 30-40 $\mu$ Länge oder noch grössere, dann wieder etwas kleinere, die sich mehr an die grösseren Körnerzellen anschliessen.

Der $\mathrm{K}$ ern erscheint an Färbepräparaten stets ganz rund, auffallend chromatinarm, mit einem grossen oder zwei oder drei kleinen Kernkörperchen. Der Z e 11 kö r p e r (s. die umstehende Fig. 1) stellt sich an den mit Alkohol oder Sublimat fixirten und mit Thionin oder anderen basischen Anilinfarbstoffen gefärbten Präparaten als ans $\mathrm{zwei} S \mathfrak{b}$ stanzen bestehend dar; einer ungefärbt bleibenden Grundmasse und einer in diese eingebetteten färbbaren Subst anz". Doch anch letztere fesselt den Farbstoff durchaus nicht 
Histologische Untersuchungen am Sehlappen der Cephalopoden. 67

mit jener Lebhaftighkeit, wie bei manchen dem Centralnervensystem angehörenden Zellen. Auch handelt es sich hier nicht um morphologisch bestimmt definirbare etwa körner- oder stäbchenartige Einlagertungen, nicht um Schollen, sondern mehr um umregelmässige wolkenartige zerfliessende Massen, die sich bald zu grösseren Ballen anhäufen, bald eine netzförmige Anordnung erkenuen lassen. In der dem Fortsatze entsprechenden Hälfte scheint die färbbare Substanz inmer in etwas grösserer Menge angehäuft zn sein. Den Keln selbst sehen wir öfters von einem breiten hellen Hof umgeben. Desgleichen Labe ich sehr oft in unmittelbarer Beriihrung mit dem Kern zwischen diesem und dem Fortsatz ein rundliches regelmässig abgegrenztes helles Gebiet angetroffen. Vielleicht liegt hier die Andeutung einer Sphäre vor, wie sie in allerletzter Zeit in manchen Nervenzellen nachgewiesen werden konnte. Hierfïr schien mir anch der Umstand zu sprechen, dass der Kern, in vielen Fällen wenigstens,
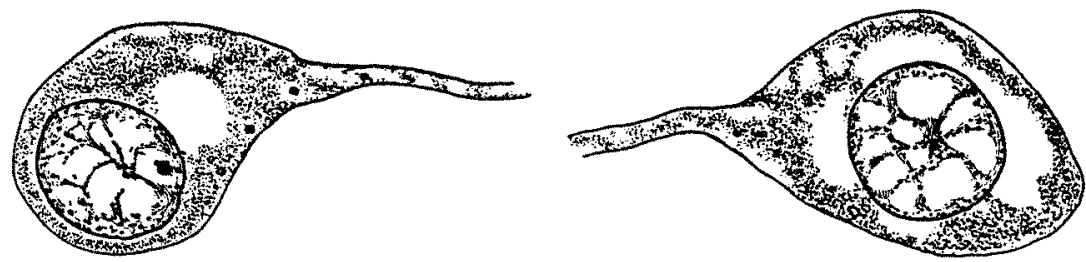

Fig. 1.

Zwei grosse Nerrenzellen von der Oberfläche des Sehlappens. Sublimat-Thionin.

deutlich eine excentrische gegen das stumpfe Ende verlagerte Stellıng erkennen liess. Ob nun jener helle Kreis wirklich einer Sphäre entspricht und ob er etwa noch ein Centrosom einschliesst, das wird sich durch die Anwendung der zur Centrosomenfärbung geeigneten Methoden, vor allem der M. H e id e nhai n'schen, eruiren lassen. Erwäbnenswerth scheint mir noch die Thatsache, dass jene flockigen Massen sich auch in den unter birnförmiger Zuspitzung entspringenden Fortsatz erstrecken.

Mit dem Mitgetheilten ist das an gewöhnlichen Präparaten Erkennbare so ziemlich erschöpft. Hier setzt nun die Gol g ische Methode in vortrefflicher Weise ein. Bloss mit ihr gelingt es, über die Verïstelungsweise und die Bedeutung dieser Zellen eine richtige Vorstellung zu erhalten. Aus einer grösseren 
Anzahl von Präparaten babe icl auf Fig. 2, Taf. VI mehrere in gelungener Weise imprägnirte hierher gehörige Zellen zusammengestellt, vielleicht in etwas dichterem Nebeneinander, als sie jemals auf einem Schnitt getroffen sein können. Die Golgri-Präparate bestätigen nun in Bezug auf die Zellform und die Einzahl des Fortsatzes das, was die sonstigen Präparate zeigen. Während man an Färbeschnitten den Fortsat $\%$ gleich an der Zelle aus deu Augen verliert, kamn man ihm hier bis in die feinsten Spit\%en seiner Verästelung folgen. Er zieht senkrecht durch die äusseren Körner herunter; liegtt der Zellkörper mit der Längsaxe mehr horizontal, so muss dem senkrechten Verlaufe natiirlich cine Umbiegung voransgehen. Er erscheint stets ziemlich derlo und nur mit schwachen Krümmungen versehen.

In Bezug auf das weitere Verhalten des Fortsatzes is t allen Zellen gemeinsam, dass er nicht in eine richtige längere Nervenfaser ïbergelit, sondern sich schon innerhalb der Rinde und zwar in der plexiformen Schicht in eine weit ausgebreitete aber nicht selır reichliche Verïstelung auf zweigt. Die näheren Einzelheiten dicser Verïstelung lassen sich wohl am besten durch Aufstellung von drei Unterformen kennzeichnen:

Bei Typus a), dem einfachsten, sehen wir den Fortsat» ung etheilt durch dengrösten Theil der plexiformen Schichthindurchziehen biszu dem dunklenStreifen, den wiroben alsingerenhorizontalen Plexus be ze i chnet haben; hier, an dessen obcrerer Grenze oder mehr schon im Plexus selbst trennt er sich Y- oder T-förmig in zwei Aeste, die horizontal auseinanderweichen und eine oft ansehnliche Strecke im oberen Theil des Plexus dahinziehen. Während dieses Verlaufes gehen diese Theilungsäste wiederholt weitere Theilungen in immer feiner werdende Aeste ein, die schliesslich alle mit feinen Spitzen frei ohne Verbindung mit anderen Zellelementen auslaufen. Neben der horizontalen Verästelung geben die im inmeren Plexus verlaufenden Fasern von Stelle zu Stelle noch senkrechte, sowohl auf- wie absteigende collateralartige Aestchen ab, die oft an ihren Ursprungsstellen zackige Vorsprünge an der Faser veranlassen. Die aufsteigenden können bis in den äusseren Plexus emporziehen, wo sie zugespitzt, oft mit einem zierlichen Endbäumchen endigen; die etwas spärlicheren absteigenden kann man eine kurze Strecke 
durch die innerc Körnerschicht hindurch in die äussersten Lagen der Markschicht verfolgen.

Viel häufiger begegnen wir den Typus b), der uns in verschiedenen unbedentenden, der Beschreibung kaun werthen Moditicationen entgegentritt. Das wesentlichste Merkmal ist hier, dass sich der Fortsat $\%$ schonim Bereich des ä useren Plexus in eine Anzahl von Aestentheilt; diese Aeste können nun entweder Y-förmig divergirend sofort durch dic tieferen Lagen der Molekularsehicht hindurch nach dem inneren Plexus hinstreben, Im darin in ähnlicher Weise wie bei Typus a in einer horizontalen, wit auf- und absteigenden Collateralen versehenen Aushreitung zn endigen, oder sie können nach ihrem Ursprung im äussern Plexus zunächst die horizontale Richtung einschlagen und eine kïmere orler längere Strecke in diesem verlaufen, um sich erst in ciniger Entfernung von ihrer Theilungsstelle absteigend in dic senkrechte Richtung umzukrimmen und den inneren Plexus zu erreichen, wo sie dann mit feinen Spitzen, öfters anch noch weiter getlıcilt frei auslanfen. Von den herizontalen Abschnitten der beiden Theilungsïste im äusseren Plexus sieht man eine Anzahl zarter collateralartiger absteigender Fasern nach dem inneren Plexus hermnterziehen. Sehr oft sieht man an den in dem äusseren Plexus verlanfenden Abtheilungen der beiden Theilungsäste, orler auch an der Theilungsstelle des noch ungetheilten Stammes selbst e in e Anz a h l feiner varik ös er k urzer Fibrillen entspringen; auch bei Typus a) kommt, wie dies nachträglich bemerkt sein mag, an dem durch den äusseren Plexus hindurch\%iehenden Stïek des Fortsatres manchmal ein solches Fibrillenbuischel zur Beobachtung.

Typus c) kennzeichnet sich dadurch, dass die The il ung des Stammfortsatzes schon innerhalb der Körnersehichte, manchmal unmittelbar unter dem Ursprung aus dem Zellkörper erfolgt. Die Aeste schlagen gleich eine spitzwinklig divergirende Richtung ein, geben während ihres Verlaufes durch den äusseren Plexus ebenfalls sehr häufig einige büschelförmige variköse Reiserchen ab, dringen dann bis in den inneren Plexus hinunter, wo sie unter genau denselben Umständen, wie die Zellen vom Typus a und b endigen, d. h. nnter Aufsplitterung in eine Reihe sich im Plexus flächenhaft ausbreitender Aeste und unter Abgabe gegen die äusseren Körner hin aufsteigender sowie auch gegen das Mark 
hin absteigender Zweigchen. Bezügliclı dieser letzteren absteigenden Aeste kann ich nicht umhin, die Möglichkeit anzudeuten dass sie vielleicht in grösserer Zahl vorkommen und dass sie auch im Mark einen längeren Verlauf besitzen, als es an den Gol g i-Präparaten, die dieser Untersuchung zu Grunde liegen, den Anschein hat. Es sind das so zarte Aestchen, dass man sich leicht denken kann, dass sie in Wirklichkeit in grösserer Anzahl vorhanden sind, namentlich wenn man noch berïcksichtigt, dass sie in einer Ebene liegen, die der Einwirkung der Reagenzien schon etwas schwerer zugänglich ist.

\section{Aeussere Körnerzellen.}

a) Grössere Gattung.

Die grösseren von den äusseren Körnerzellen gehören, wie schon erwähnt, bauptsächlich der äusseren Hälfte der äusseren Körnerschicht an. Sie verdienen den Namen ngross" nur in Verhältniss zu der gileich zu beschreibenden, der inneren Hälftc eigenthümlichen Körnergattung; im Verhältniss zu der soeben behandelten grossen Zellkategorie sind es kleine Elemente. Das Verhalten des Kernes wurde schon oben beschrieben. Er tritt auch an Golgi-Präparaten (Fig. 3, Taf. VI), an denen sich diese Zellen oft imprägnirt zeigen, häufig als brauner Fleck in die Erscheinung; an solchen Zellen erkennt man dann deutlich, dass der Zellkörper den Kern nur in Form eines schwachen Saumes umgiebt. Die Form des Zellkörpers kommt hier mit grosser Deutlichkeit zur Ansicht. Man kann diese Zellen in Allgemeinen als birnförmig bezeichnen, doch ist die Form etwas plumper als die von Zellen, die sonst durch diesen Namen charakterisirt werden; namentlich ist der Uebergang des Körpers in den nacl unten gerichteten Zellfortsatz ziemlich plötzlich. Bei ihrer dichtgedrängten Lage ist es leicht erklärlich, dass sie vielfach Spuren des gegenseitigen Kontaktes aufweisen in Form von Abplattungen oder schwachen napfartigen Vertiefungen. Sehr häufig kommt eine Abplattung dem dem Fortsatze gegenüberliegenden Ende zu. Die typische Stellung ist auch bei diesen Zellen die senkrechte, aber manche Zellen lassen von dieser normalen Lage eine Abweichung erkennen. Verhältnissmässig am häufigsten begegnen wir einer schiefen, ja manchmal fast ganz horizontalen Lage an den in der Nähe der Oberfläche gelegenen Zellen, was sich auch bier leicht aus der Einwirkung der Retinalfaserbündel ableiten lässt. 
Der Fortsatz ist im Verlualtniss zum kleinen Zellkörper als derb zu bezeichnen. Naturlich bleibt er an Stärke weit hinter den viel kräftigeren Fortsätzen der oberflächlichen grossen Zellgattung zurück. Er zieht manchmal gestreckt, häufiger leicht gewunden durch die äussere Körnerlage hindurch in die plexiforme Schicht. In Bezug auf sein Verhalten darin kommt eine gewisse Mannigfaltigkeit zum Ausdruck. Am einfachsten liegen die Verhältnisse bei dem Typus, den dic Zellen a, b und $\mathrm{c}$ der Fig. 3 darbieten. Der Fortsatz bildet im Bereich des äusseren Plexus ein zartes, a us varikösen feinen Fibrillen best e hendes $B$ ii s chelchen und zieht clann stark verdünnt in die Mittelzone hinunter, um ungefähr in deren Mitte zugespitzt zu endigen. Das Büschelchen unterscheidet sich durch horiz o ntale $\mathrm{A}$ u sbreitung der Fibrillen von den geschilderten Retinalfibrillen, die eine ganz andere charakteristische blumenkelchartige Anordnnng zeigen. Auch gehören die zarten Fibrillen des Körncrellenfortsat\%es mehr der imeren Hälfte des äusseren Plexus an, während dic der Retinalfasem, wie geschildert, mehr dessen äussere Lage in Anspruch nehmen. Immerhin ist diese Trennung nicht so scharf, dass nicht eine a us gi ebige Verf le cht $\mathrm{n}$ g beider Fibrillengattungen stattfände. An Zartheit erreichen die fraglichen Füdehen die Fibrillen rer Retinalfasern nicht. Fast immer unterliegt der Fortsat\% gerade an der Stelle, wo er diese feinen Aestchen entspringen lässt, einer $\mathrm{T}$ h e il $\mathrm{u} \mathrm{n} g$ in zwei oder drei Aeste, die entweder nahe beieinander oder auch weit auseinandergespreizt sich in die Mittelzone senken. Immer sind diese absteigenden Aeste ziemlich zart, varikös, und stets endigen sie mit fieien Spitzen.

Die andere Form, die durch die übrigen grösseren Körnerzellen der Figur 3 repräsentirt wird, kennzeichnet sich zunächst durch das regelmässige Vorhandensein mehrerer absteigender Aeste und durch stärkeres Auseinanderweichen derselben, vor allem aber dadurch, dass die absteigenden Aeste ein tieferes Nivea erreichen. Sie ziehen in der Regel bis zum inneren Plexus herunter, betreten aber dessen Gebiet seltener. Das häufigere Verhalten ist, dass sie an seiner oberen Grenze eine kurze Strecke in horizontaler Richtung nach beiden Seiten hin auseinanderziehen. Oft ist die Zahl dieser absteigenden Aeste auch etwas grösser; sie kann drei oder vier betragen. Das feine Aestchen- 
büschel im äusseren Plexus stellt sich bei dieser Sorte in der Regel etwas reichhaltiger dar. Diese Fibrillen entspringen entweder an dem ungetheilten Fortsatze, knapp an der Theilungsstelle, oder wenn die Theilung schon an der oberen Grenzc des äusseren Plexus erfolgt, von den Anfangsstiicken der beiden Theilungsschenkel. Ist eine ausgiebige Imprïgnation der grösseren Körner und ihrer absteigenden Fortsätze eingetreten, was gar nicht so selten der Fall ist, so präsentirt sich nicht nur der äussere Plexus vermöge der geschilderten Fibrillen wirklich als solcher, d. b. als ein Gewirr feinster Fädchen, sondern auch die Mittelzone erscheint namentlich in ihrer äusseren Hälfte von zahlreichen Fäserchen durchzogen, die hauptsächlich senkrecht parallel mit einander verlaufen, deren Regelmässigkeit aber durch vielfache während des Absteigens der Fasern erfolgende Theilungen beinträchtigt wird. Einen selteneren Fall habe ich in Zelle $f$ der Fig. 2, Taf. VI wiedergegeben. Hier theilt sich der Fortsatz schon im Bereich der äusseren Körnerschicht in zwei Schenkel, von denen ein jeder unten im äusseren Plexus sein eigenes Fibrillenbiischel und seine eigenen absteigenden Aeste besitzt.

\section{b) Kleinere Gattung.}

Die kleinere Gattung der Körnerzellen (Tafel VI, Zellen $d, e, f)$ gehört, wie beschrieben, ansschliesslich der inneren $A b$ theilung der äusseren Körnerschichte an. Der Z ellkö r per zeigt hier häufig ein mehr rundliches plumpes Aussehen, womit die regelmässig runde Form des Kernes tibereinstimmt. Auch hier sehen wir den Kern nur von einer dünnen Protoplasmaschichte umhüllt. Der Fortsatz ist feiner als bei der grösseren Gattung, auch ist er weniger geschlängelt, natürlich viel kürzer als bei den mehr answärts gelegenen Körneru. Er erreicht schon im äusseren Geflechte der plexiformen Schicht se in Ende, indem er in einige zarte kurze wurzelfädchenartige Zweigchen, vier oder mehr an der Zahl, zerfällt. Dieses kleine Endbüschelchen bleibt an Reichhaltigkeit und Ausdehnung der Zweige weit hinter den in derselben Lage befindlichen Fibrillen der grösseren Gattung zurück. Es handelt sich um sehr einfache kleine Endpinselchen. Ein absteigender Fortsatz, d. h. eine Verlängerung des Fortsatzes über den äusseren Plexus hinaus konnte hier nicht nachgewiesen werden. 
Wir übergehen zunächst die plexiforme Schicht, da eine Schillerung dieser nicht möglich ist, bevor alle Zellengattungen, die sich durch Fortsatzverästelungen an ihrer Bildung betheiligen, beschrieben sind. Diese Zellen gehören theilweise zwei noch zu beschreibenden Schichten, nämlich der inneren Körnerschicht und der Markschicht des Sehlappens an. Erst nach der Erledigung. dieser Schichten kann mit Erfoly an eine Betrachtung der plexiformen Schicht gegangen werden.

\section{Innere Körnerschicht.}

Färhepräparate lassen anch bei dieser Lage einen Aufhau aus dicht nebeneinander stehenden Kernen erkennen; vom Zellkörper sieht man an Färbungen ebensowenig, wie bei der äusseren Körnerschicht. Während aber bei letzterer wenigstens in ihrer unteren Hälfte die Anordnung der Körner eine fast gleichmässige ist, sehen wir die inneren Körner sehr regelmässig zu senkrechten $I$ ä̈ngreihen geordnct, eine Gruppirung, die besonders an sehr diumen Schnitten zur Ansicht kommt und sich in der Richtung nach dem Mark lin allmählich ausgeprägrter darstellt. Fast unmerklich gehen die Längsreihen in die netz. förmig angeordneten Zellenzïge des Markes über. Diese verschiedene Anordnung bildet bei Eledone die Hauptabgrenzung zwischen beiden, während bei Sepia wie schon erwähnt eine besondere helle Zwischenlage vorhanden ist.

Die Kerne, die diese Schicht bilden, erscheinen ebenso wie die der äusseren Körnerlage als recht kleine Elemente von rundlicher Form, theils mit sehr dichtem, theils mit mässig lockerem Chromatingerïst. Gegen die Markschichte hin sieht man sie allmählich etwas grösser und lieller werden und auch eine etwas lockerere Anordnung annehmen, wodurch die innere Körnerschicht gleichsam als ein Spiegelbild der äusseren erscheint. Um die Analogie noch überraschender zu machen, fehlen anch an der Uebergangsstelle zu dem Marke eine Anzahl besonders grosser Zellen mit färbbarem Zellkörper nicht. Diese grösseren Elemente, die übrigens an Umfang und auch an Zahl hinter den oberflächlichen grossen Zellen der äusseren Körnerschicht zurückbleiben, bilden hier ebensowenig wie dort eine zusammenhängende Lage; auch hier liegen sie sporadisch, unregelmässig vertheilt, auch hier lassen sie Niveauschwankungen erkennen, wobei sie 
aber nic bis an die Grenze der plexiformen Schicht heranriicken. $\mathrm{Da}$ sie allseits von kleinen Körnerzellen dicht ungeben sind, treten sie nicht besonders auffallend hervor und man wird sic erst bei aufmerksamer Untersuchung dieses Grenzgebietes bemerken. Der Zellkörper zeigt ungefälır dieselben Verhältnisse, wie sie oben für die oberflächlichen grossen Zellen geschildert wurden. Anch hier liegt im Zelleib eine Vermischung einer schwach fürhharen und einer den Farbstoff etwas stärker in sich aufnehmenden protoplasmatischen Substanz vor. In einer Beziehung sind sie aber von den äusseren grossen Elementen wesentlich verschieden: sie lassen eine ganz andere Form erkennen. Schon an den Färbepräparaten lässt sich feststellen, dass sie nicht unipolar sind, wie jene, auch nicht etwa spindelförmig bipolar, sondern in der Regel eckig, unregelmässig nultipolar. Schon Stieda kannte diese grossen Nervenzellen; sie scheinen bei Sepia in grösserer Zahl vorhanden $z \mathfrak{n}$ sein und eine zusammenlı̈̈ngende, von der Umgebung scharf abgegrenzte Reihe zu hilden.

Gehen wir mun zu den Bildern über, die man an Gol gipräparaten von den Elementen der inneren Körnerschicht erhält (Fig. 4, Taf. VI). Die erste kle inere Zellgat $\mathrm{tung}$, die eigentlichen , inneren $\mathrm{K} \ddot{\mathrm{n}} \mathrm{r}^{\circ} \mathrm{er}^{u}$, gelangen unschwer zur Inprïgnation, wenn auch seltener mit allen Fortsätzen. Auch hier markirt sich der Kern nicht selten als brauner Fleck, auch hicr umfasst der Zellkörper nur als schmaler Saum die Zelle. Ein wesentlicher Unterschied gegenüber den äusseren Körnern tritt uns darin entgegen, dass dicse Zellen so viel ich sehe nie unipolar, sondern $\mathrm{zum}$ mindesten bipolar, sehr oft aber a u eh multipolar sind. Mit der Zahl der Fortsätze wechselt natürlich auch die Gestalt des Zellkörpers. Bei dem bipolaren Typus liegt eine Spindelform vor, doch ist sie sehr selten regelmässig, vielmehr nimmt die Zelle eine unregrelmässige verschobene asymmetrische Form an. Man findet die spindelförmige Zelle sehr oft mit der Längsaxe horizontal gestellt. Die multipolaren Formen weisen natirlich eine mehr e ckige Gestalt auf.

Von den Fortsätzen imprägnirt sich am leichtesten der in seinen Verhältnissen ziemlich constante a u fs teigende Fortsatz, der einen typischen Dendriten darstellt. Diese seine Eigenschaft ergibt sich sehr bestimmt aus seiner knorrigen rauhen 
Beschaffenleit. Er ist der stärkste von allen, entspringt immer ans einer regelmässigen Zuspitzung des Zellkörpers, zieht senkrecht hinauf, bildet beim Eintritt in die plexiforme Schicht oft eine kleine Knickung und erfäht fast immer im Bereich des inneren Plexus eine mässige Verdickung, die hauptsächlich auf die Gegenwart von Varicositäten zurïckzuführen ist. Hier gibt nun der Fortsatz eine Anzahl seitlicher, relativ kurzer vari cöser A est chen ab, verschieden an Zahl, 3, 4 oder anch mehr jederseits, die sich nun horizontal mit zierlichen welligen Biegungen im inneren Plexus ausdehnen, an dessen Bildung sie jedenfalls den Hauptantheil haben. Sehr oft sind sie an ihrem Ende noch weiter aufgefasert. Im allgemeinen sind sie als etwas gröber za bezeichnen, als die feineren Fibrillenbildungen des äusseren Plexus, daher auch das gröbere Aussehen des inneren Geflechtes in Vergleich zu dem äusseren. Besonders derbe Seitenfibrillen sicht man oft an der oberen Grenzlinie des Plexus verlaufen.

Der St a mm dendrit erschöpft sich nun aher mit diesen Seitenästchen nicht, viehmehr sieht man ihn, allerdings bedentend zarter werdend, sich durch die mittlere Zone senkrecht emporschlängeln, durch den äusseren Plexus hindurch die ä us se e Körnerlage betreten, darin noch weiter gegen die Oberfläche aufsteigen, um dann in verschiedener Entfernung von der Oberfläche, manchmal ganz in deren Nähe, häutiger aber schon in tieferen Schichten mit einer freien Spitze zu endigen. I m Bereich des äusseren Plexus gibt der Fortsatz manchmal, aber nicht constant, ähnliche, nur viel spärlichere S e i t e nfibrillen ab, wie im inneren Geflecht.

Die übrigen Fortsätze der inneren Körnerzellen weisen alle ein anderes Gepräge auf: sie sind viel zarter, kürzer und ganz glatt. Die Natur dieser Fortsätze blieb mir lange unklar. Erst durch Untersuchung vieler solcher Zellen gelangte ich zur Ansicht, dass einer davon die Bedeutung eines $\mathrm{Ner-}$ venfortsatzes hat, die anderen aber trotzihrer glatten Beschaffenheit als dendritenartige Nebenast e hen anzuse hen sind. Die als Dendriten anzusprechenden sieht man zumeist schon in der Nähe der Zelle einfach ungetheilt oder höchstens in zwei, drei Aeste getheilt frei auslaufen. Der Nervenfortsatz entspringt bei den bipolaren Zellen 
stets von dem dem aufsteigenden Dendriten regenïherliegenden Pole, also wenn die Zelle senkrecht steht an der unteren, wenn sie horizontal liegt von einer der seitlichen Spitzen. Er ist ansserordentlich zart und vereinigt sich mit anderen seinesgleichen und mit den noch zu beschreibenden in die Sehlappenrinde aufsteigenden zarten Fäserchen zu zierlichen radiären Bündelchen, die durch die innere Könerschicht hindurch in das Mark hinunterziehen und darin oft eine längere Strecke in der Richtung des Hilus zu verfolgen sind. Aus den Fortsätzen dieser Zellen bestehen zum grössten Theil die hellen Strassen, die die Zellreihen der inneren Körnerschicht von einander tremnel. Wie gesagt, gelingt die Inpräignation des Neuriten bei weitem nicht hei jeder Zelle. Da ich ihn aber an mebreren Zellen nit voller Bestimnitheit beobachten und eine ziemliche Strecke verfolgen konnte, andererseits aber fast an allen Zellen ein senkrechter, nach unten gerichteter Fortsatzstumpf wahrnehmbar ist, so glaube ich mich zul der Annahme berechtigt, dass allen inneren Körnerzellen ein solcher Nervenfortsat z z u kmmt und dass im Falle des Fehlens eines solchen blos eine mangelhafte Reaktion im Spiele ist. Somit sind die inneren Körnerzellen als mononeıritische dendritische Elemente aufzufassen, die ihren anffallend zarten Fortsatz in die Markschicht entsenden und die zwei Dendritengattungen besitzen: eine Anzahl glatter, kurzer und einen einzigen langen rauhen, aufsteigenden, in der plexiformen Schicht unter typischer Verästelung endigenden Dendriten. Ob der Nervenfortsatz bis in den Hilus und durch diesen hindurch in den Pedunculus lobi optici und das Gehirn verläuft oder ob er schon in der Markschicht endigt, in Verknüpfung mit den darin gelegenen Nervenzellen, liess sich nicht positiv entscheiden, aber nach der ganzen Sachlage muss ich es für wahrscheinlich halten, dass wenigstens der grössere Theil dieser Nervenfortsäte schon in der Markschicht des Sehlappens sein Endeerreichtd. h. die Bestimmung hat, die Sehimpulse von der Sehlappenrinde her auf die Zellender Markschicht zu ïbertragen.

Viel seltener gelang es, die zweite Zellgattung, nämlich die an der unteren Grenze der inneren Körnerlage befindlichen grossen Elemente zu schwärzen. (Fig. $4 h, i$.) Soviel ich sehe, unterscheiden sie sich im Wesentlichen nur durch die grös- 
seren Dimensionen ihres Zellkörpers und ihrer Ausläufer von den kleineren Körnerzellen. Alle ihre Fortsätze, sowohl die Dendriten, wie auch der absteigende Nervenfortsat\% sind etwas derber, die seitlichen Dendriten etwas länger mul ranher, der aufsteigende Hauptdendrit viel kräiftiger.

\section{Mark.}

Das Charakteristische für die Markschicht besteht in der merkwïrdigen Anordnung von weisser und graner Substanz. Scharf getrennt sehen wir beide, doch ist ihre gegrenseitige Anordnumg keine schichtenartig. albwechselnde, sondern die zu kompakten Strängen angeordneten Nervenzellen lassen eine $11 \mathrm{etz}$ för mi g c Grup pirung erkennen; die Lücken fült die weisse Substanz aus, ganz aus Fasermassen bestehend und daher den Farbstoff nur wenig aufnehmend, während die Zellenbalken durch lebhafte Färbung schon bei schwacher Vergrösserung in Form einer netzförmigen Zeichnung deutlich hervortreten.

Die Anordnung des Netzes und der Zellbalken unterliegt in der Richtung von der Rinde gegen den Hilus hin einer Veranderung. Unmittelbar unter den inneren Körnern weist das Zelinetz ein viel dichteres Gefüge auf, die weisse Substanz tritt hier noch sehr in den Hintergrund. Die Veränderungen gegen den Hilus hin lassen sich in erster Reihe auf den bemerkenswerthen Umstand zurückführen, dass die weisse $S$ ubstanz rehr rasch eine gewaltige $\mathrm{Z} u$ uhme erfährt. Mehr and mehr tritt die graue Substanz zurück, die Zellbalken erscheinen nun an sich zwar etwas breiter, aber durch die ansehn. lich vermehrte weisse Substan\% viel weiter auseinander gedrängt, die Maschen des Netzes von länglicher Form, gegen den Hilus hin orientirt, grösser, bald hört auch der netzförmige Zu. sammenhang der Zellbalken unter sich auf und statt eines Reticulums sehen wir nun das Bild von sternförmigen oder unregelmässig gestalteten, allseitig von der weissen Masse umgebenen Zelleninseln. In der Nähe des Hilus schwindet die graue Substanz vollends und jetzt tritt die weisse Masse aus dem Hilus als Pedunculus hervor.

Die genaue Untersuchung der Zellenstränge an Färbepräparaten ergibt zunächst die Thatsache, dass ihre Axe sehr oft ron Blutgefïssen eingenommen wird, anf die sich die Zell- 
schichten scheidenartig auflagern. Dies ist aber, wie betont sein mag, durchans nicht bei jedem Balken der Fall. Die Zellen zeigen eine dicht gerlrängte Lagerung, ja sie schliessen sich geradezu in epithelartiger Anordnung aneinander. Im Allgemeinen sind sie grösser als die Zellen der inneren Körnerschicht, anch unterscheiden sie sich durch die $F \ddot{a} r^{\circ} b$ barkeit i hres Zellkörpers von diesen wie auch von den äusseren Körnern. Sie sind ïbrigens nicht von gleicher Grösse. Fast in jedem Balken sieht man einzelne grössere Elemente von eckiger Form hervortreten, oft dic benachbarten Zellen an Umfang. stark überragend. Besonders ge gen d en Hilus hin fesseln da und dort a uf allend grosse Zellen den Blick, Zellen, die sich manchmal zu den sie umlagernden kleineren Markzellen verhalten wie etwa ein nicht ganz reifes $\mathrm{Ei}$ zu den es umhïllenden Granulosazellen. Ueber die Fortsätze und die eigentliche Form aller dieser Elemente geben natürlich Färbeschnitte keinen Aufschluss.

Was die die Lücken des Zellnetzes ausfïllende we iss e Substanz betrifft, so lässt sich dartiber an Färbungren nur soviel feststellen, dass sie einen feinfaserigen, an vielen Stellen auch mehr geflechtartigen Bau aufweist und nur sehr spärliche Zellkerne enthält, die \%. Th. den Kernen von Blutgefässen entsprechen, z. Th. versprengten sporadischen Nervenzellen angehören und z. Th. auch Bindegewebskerne darstellen. Je mehr sich die weisse Masse gegen den Hilus zu vermehrt, desto geflechtartiger wird die Anordnung ihrer Bündel, desto ausgesprochener tritt eine bindegewebige Zwischenmasse auf. An Golgipräparaten gelingt es nicht selten, dieses an sich wohl spärliche mit einer ${ }_{n}$ Neuroglia" ${ }^{4}$ wohl nicht identische Stützsystem zu färben: es präsentirt sich in Form von derben parallelen welligen braun imprïgnirten Bündeln, die sich an die Blutgefässe anzuschliessen scheinen.

Aus dem Hilus quillt nun der Peduncul us oder Tractus opticus als starkes Büdel herror; es senkt sich bald in das Gehirn ein, um sich darin in eine Anzahl von Bündeln zu vertheilen, deren weitere Verfolgung nicht in dem Plane dieser Arbeit liegt. Wenn Stieda angibt, dass der Pedunculus anf seiner Oberfläche von einer Lage von Nervenzellen bedeckt ist, so kann ich dies für Eledone nicht als zutreffend bezeichnen. Hier liegt die Sache 
folgendermaassen: der Pedunculus füllt mit seinem Ursprung nicht den ganzen Umfang des Hilus ans. Sein Ursprung unfasst an Längsschnitten des Ganglions nur dessen mittleres Drittel. Die frei bleibenden Hilustheile werden nun von einer besonderen mebrschichtigen Lage von Nervenzellen bedeckt, die zwar mit den balkenartig angeordneten Zellsträngen der Markschicht direkt zusammenhängen, sich aber von ihnen doch durch die etwas verschiedene Beschaffenheit ibrer Zellen unterscheidet. Sie sind nämlich durchschnittlich grösser als die im Innern des Markes befindlichen, und zwar je näher zur Oberfläche, desto voluminöser und dann erscheinen sie von typischer Birnform mit der Spitze nach dem Mark gerichtet. Am Rande des aus dem Mark austretenden Stieles hört aber diese Zelllage wie abgeschnitten auf, den Pedunculus selbst sebe ich an meinen Präparaten, unter denen sich auch eime liickenlose, mit Hämatoxylin gefärbte Schnittseric des Kopfes von Eledone befindet, vollkommen nackt.

Das kleine $\mathrm{G}$ ang $\mathrm{l}$ i o n ped unculi, das schon eingangs crwailunt wurde, hat mit dem Ganglion opticum keinen eigentlichen organischen Zusammenhang, vielmehr ist es gegen den Hilus des Sehlappens hin durch eine bindegewebige Zwischenschicht getreunt. Es besteht aus einer, aus birnförmigen Zellen zusammengesetzten Rinde und aus einer von "Punktsubstallz" gebildeten Markschicht, die sich gegen den Pedunculus in Form eines Hilus offnet. Aus diesem Hilus tritt ein Nervenbündelchen hervor, das sich dem Pedunculus centralwärts anschliesst.

Fassen wir num die Bilder in's Auge, die man von der Marksubstanz und ihren Elementen an der Hand der Golgi's c h e n M e t h od e erhält (Taf. VII, Fig. 5). Imprägnationen des Markes gelingen unschwer, dennoch ist es nicht leicht, über ihre Verhältnisse Klarheit zu gewinnen, denn eine grosse Complication herrscht hier, namentlich weisen die Fasermassen eine ausserordentlich verwickelte Beschaffenheit auf. Was zunächst die Zellen betrifft, so ist hier ein Unterschied. zn treffen zwischen kleineren und grösseren Markzellen.

1. Die kleineren sind in ihrer typischen Form unipolar, die Spitze aus dem Zellenbalken heraus in die weisse Substanz gerichtet (s. z. B. die Zellen $a, b, c, f$ ). Indessen zeigt die Verästelungsweise dieses Fortsatzes, dass diese Unipolarität nur eine scheinbare ist. Es handelt sich nämlich unr nm die Zusammenfas- 
sung der in der Mehrzahl vorhandenen Dendriten zu einem einheitlichen Stamme; sehr bald theilt sich die Spit\%e der birnförmigen Zelle in eine Anzahl von nach allen Richtnugen auseinauderflatternden Fortsätzen, in 2-4 oder noch melır, die sofort die weisse Substan\% betreten, ja lüufiger eigentlich schon darin entspringen. Sie erscheinen alle von ganz gleicher, glatter Beschaffenheit, dennoch geben sich die meisten durch ihre weiteren Theilungen und durch ihr baldiges zugespitztes Aufhören als ${ }_{\text {"Dendrite }}$ " zu erkennen. Sie sind aber nicht alle als solche auf\%ufassen: sehr häufig macht sich imerhalb der Verästelung. ein ebenfalls zarter und glatter Fortsatz bemerkbar, der keiner weiteren Theilung unterlicgt, die andercn Zweige anch an Lïnge iibertrifft, also nach allem Anschein den Werth e ines $\mathrm{Neu-}$ riten besitzt. In den allerdings sporadischen Fällen, wo ich ihn eine längere Strecke von der Zelle weg zu verfolgen vermochte, sah ich ihn zunächst dic Richtung des Hilus cinschlagen. Somit haben wires auch bei der Melir\%ahl der Markzellen mit Mononeuriten zu thun, die ihren Nervenfortsaty wahreheinlich durch Hilus und Pedunculus hindureh in die mittleren Centren des Gehirns entsenden. Die umregelmässige Anordnung der Zellen, die wechselnde Abgangsweise des Nervenfortsatzes und die Schlängelungen seiner ersten Verlanfsstrecke erklären es hinlänglich, weshalb man ilın nur bei der kleineren Zahl von Zellen zu Gesicht bekommt.

$\mathrm{Ob}$ alle Zellen wirklich nur mit einem einzigen Nervenfortsatz ausgestattet sind, möchte ich nicht mit Bestimmtheit beantworten. Die Zunahme der weissen Substanz gegen den Hilus hin ist eine so rapide, dass man in der That versucht sein künntc, anzunehmen, dass wenigstens ein Theil der Zellen durch Entsendung mehrerer Fortsätze an dieser Zunahme betheiligt ist. Indess mit Bestimmtheit habe ich in keinem einzigen Falle die Gegeuwart von zwei oder mehr typischen Nervenfortsätzen nachweisen können und somit wäre eine solche Annahme einstweilen keiner weiteren Berücksichtigung werth, um so weniger, da sich ja die allerdings sehr auffallende Vermehrung der Fasermassen nach dem Hilus hin auch an der Hand der Hiulfshypothese erklären liesse, dass neben den a a dem Sehlappen entspringenden Faseruauch noch solche Fasergebilde 
in der weissen Substan\% vorhanden sind, die a u $\mathrm{Ner}$ renzellen des Gehirns kommend in der Markschicht des Sehlappens in Contakt mit deren Zellen durch freie Verästelung ihr Ende erreichen. Besteht in Bezug auf die Anordnung der optischen Centra eine Analogie zwischen Cephalopoden und höheren Crustaceen, so dürfen wir auch aus den Befunden Betbe's ') einen Beweis filr die Existenz solcher Faserverïstelungen entnehmen. B e the gelang es nämlich, am Gehirn von Carcinus maelas Zellen naclızuweisen, die ihren Nervenfortsatz in den Pedunculus opticus und durch diesen hindurch zum Sehganglion senden, offenbar behuf's freier Endigung.

Ich möchte noch auf die Thatsache besonder's hinweisen, dass die Zellbalken gerade nur den Zellkörper der Markzellen in sich fassen: Die gesammte Verästelung der Zelle gehört der weissen Substanz an. Letztere besteht also nicht nur aus eigentlichen Nervenfasern, sondern auch aus Verästelungen von als Dendriten aufyufassenden Fortsätzen, ebenso wie ja das auch in der weissen Substanz vieler niederer Wirbelthiere, Cyclostomen, Selachier, Knochenfische, Amphibien und Reptilien der Fall ist²).

Dieser Schilderung ist aber noch hinzuzufügell, dass durchaus nicht alle kleinen Markzellen uni- oder richtiger pseudo-nnipolar sind, es ist keine Seltenheit, hierhergehörige Zellen zu finden, bei denen die Ausläufer schon getrennt vom Zellkörper entspringen. Relativ häufig ist $\%$. B. eine Form (s. die Zellen $d, h, j)$, wo ausser den aus der Zuspitzung des birnförmigen Zellkörpers entspringenden Aesten gerade gegenüber auf der anderen Seite noch ein unvermittelt von der- Convexität der Zelle sich ablösender zweiter Ast, und zwar scheint es der Nervenfortsatz $z \mathbf{u}$ sein, vorbanden ist.

Eine besondere Art von kleineren Körnerzellen tritt uns in jener Zellgattung entgegen, die ihren Nervenfortsatz nicht gegen den Hilus, sondern gegen die Rinde hinaf entsenden, also Zellen mit aufstei-

1) A. B e th e, Studien über das Centralnervensystem von Carcimus maelas. Archiv f. mikrosk. Anatomie Bd. 44, 1895, S. 606.

2) Vergl. hierüber: M. v. Lenhossék, Der feinere Bau des Nervensystems im Lichte neutester Forschungen, II. Aufl. 1895, S. 250-253. 
gendem Nervenfortsatze. An Färhepräparaten lassen sich diese Elemente nicht diagnosticiren, da sich ihr Zellkörper nicht von dem der andern Markzellen unterscheidet. Anch an Golgi-Bildern ist es gerade nur das Verhalten des Nervenfortsatzes, was ihnen den Charakter einer besonderen Zellgattung. verleiht. Eine gelungene Imprägnation dieser Zellen, d. h. cinschliesslich des Verlaufes ihres Nervenfortsat\%es, gehört zu den Seltenheiten. An den wenigen Zellen, bei denen mir gleichzeitige Imprägnation von Zellkörper und Fortsatz gelungen war, zeigte der Zellkörper in Form und Verüstelungsweise gegenüber den anderweitigen Markzellen keine Besonderheit. Auch hier liessen sich neben dem Neuriten einige glatte, schwach verästelte Dendriten unterscheiden. Isolirte Imprägnationen des Nervenfortsatzes dagegen, ohne die dazugehörige Zelle, gehören zu den allerhäufigsten Befunden (s. die blauen Fasern in Fig. 6, Taf. VII). Man sieht die fraglichen Fortsätze als glatte, zarte Fasern oft gar nicht so spärlich unter sanften Schlängelungen in der Bahn der das Mark radiär durchsetzenden Faserbündel gegen die Rinde hin aufsteigen, die innere Körnerschicht durchsetzen and die plexiforme Schicht betreten, um darin ihr Ende zu erreichen. Freilich ist hier grosse Vorsicht geboten, damit man unsere Fasern unit den theilweise auch sehr zarten auf S. 62-64 beschriebenen centrifugalen peripherischen Fasern nicht verwechselt. Ist das Verhalten in der plexiformen Schicht nicht zu eruiren, so ist die Unterscheidung iiberhaupt nicht möglich. Nur dann ist eine Diagnose der fraglichen Fortsätze auch in diesem Falle nicht ausgeschlossen, wenn unsere aufsteigenden Neuriten, wie dies manchmal der Fall ist, während ihres a f steigenden Verlaufes Collateralästchen abgeben: an den centrifugal-peripherischen Fasern kommt etwas Derartiges nämlich nie vor.

Die Erforschung der Endigungsweise dieser anfsteigenden Fäserchen ist dadurch beträchtlich erschwert, dass sich gleichzeitig mit ihnen auch fast immer das ganze Fasergewirre des inneren Plexus, in den unser Fortsatz eintaucht, sei es, nm in ihm zu endigen, sei es, um ihn nur zu durchsetzen, reichlich imprägnirt. Immerhin ist es mir gelungen, mehrere Stellen zu finden, wo diese Fasern mitsammt ihren Endigungen isolirt zur Ansicht gelangten. Ich sah ihre Endigungen unter verscbiedenen Formen erfolgen, aber 
stets in Gestalt cincr freien Veräistelung im Bereich der plexiformen Schicht. Die schönste Endigungsweise stellt jene Form dar, die in der Faser $a$ der Figur $6 \mathrm{zur}$ Ansicht gebracht ist. Die Faser zerfällt i m B creich derMittel to ne in ein schönes geveihartiges welliges Endbäumclien, dessen sehr zarte Verästelungen ein stark varicöses Aussehen darbieten. Bei einer zweiten, etwas häufigreren Form (Faser $b$ ) erfolgt die Endigung schon innerhalb des inneren Plexus entweller quastenförmig mit einigen kumen Aestchen oder in der Weise, dass sich die Faser T-fömnig in zwei Schenkel theilt, die eine kiirzere oder längere Strecke in dem Plexus horizontal auseinanderlaufen, um dann zuletzt einfach frei zu endigen. In einer dritten Reihe von Fällen schien mir die Faser bis in das Gebiet des änsseren Plexus zu gelangen, um erst darin ihr Ende zu erreichen. Der Nervenfortsatz der hier beschriebenen Zellgattung kann also in allen Lagen der plexiformen Schicht endigen.

2) Die grösseren Zellen des Marklagers lassen stets eine ausgesprochen multipolare, unregelmässig stern. förmige Gestalt erkennen. Die Verzweigung ist so viel ich sehe häufiger einseitig gegen den Hilus als gleichmässig nach allen Seiten oder etwa gegen die Oberfläche hin gerichtet. Auch hier liess sich ron den Aesten einer öfters bestimm t als $\mathrm{Nerven-}$ fortsatz erkennen, nicht nur durch die Verhältnisse seines Verlaufes, sondern auch durch seine zarte und glatte Beschaffenheit, die hier dadurch den Werth eines Kennzeichens erhält, dass die anderen Fortsätze, die Dendriten viel derber erscheinen als bei den kleineren Markzellen und auch mehr ein richtiges dendritenartiges, rauhes, höckeriges Ausselıen besitzen, wenn auch nicht in so charakteristischer Weise, wie wir das an den centralen Nervenzellen der Wirbelthiere sehen; sie theilen sich öfters und erstrecken sich häufig über sehr weite Gebiete des Markes aus. Auch hier gehört die Verästelung der Dendriten ausschliesslich der weissen Zwischenmasse an.

3) Eine besondere Gattung von grossen Markzellen scheinen die in den tiefsten Lagen der Markschicht oft unweit rom Hilus befindlichen ${ }_{n}$ Riesennerven-

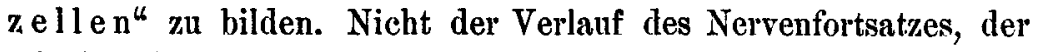
wie bei der vorstehend geschilderten Gattung durch Pedunculus 
und Hilus den Sehlappen zn verlassen scheint, auch nicht ihre Grösse ist es, wodurch ihnen eine so besondere Stellung gegenüber den anderen grösseren Zellen des Markes einzuräumen ist, sondern die Gegenwart eines sehr starken, dendritenartigen a ufsteigenden Armes, der den langen Weg oft von der Gegend des Hilus bis zur Oberfläche des Sehlappens nicht scheut, um in der Rindensubstanz unter freier baumförmig ausgebreiteter Verästelung sein Fnde zu erreichen. Hier muss ich freilich bekennen, dass ich den Zusammenhang dieses Fortsatzes mit dem Zellkörper der fraglichen Zellgattung thatsächlich nur ein einziges Mal und auch da nicht mit voller Sicherheit gesehen habe - auch in diesem einen Falle liess sich nicht genau feststellen, ob zwischen Zelle und Fortsatz ein direkter Zusammenhang oder nur ein zufälliges Uebereinanderlagern vorhanden war. Es handelt sich also hier umeine erschlossene, nicht um eine direkt beobachtete Thatsache, aber Alles, was ich gesehen habe, spricht mit einiger Wahrscheinlichkeit für diesen Zusammenhang. Aus welchen Zellen sollten denn auch diese kräftigen aufsteigenden Aeste entspringen, die man bei gelungener Imprïgnation in der Gegend beginnen sieht, in der jene umfangreichen Elemente liegen. Volle Sicherheit massen hier freilich noch weitere Untersuchungen bringen.

Die Fortsätze selbst, von denen hier die Rede ist, gelangen mit der Go $1 \mathrm{~g}$ i'schen Methode besonders leicht zur Imprägnation. Sie bilden durch ihre sehr grobe, dicke Beschaffenheit besonders auffallende Gebilde, die den Blick sofort auf sich ziehen (s. Taf. VI, Fig. $1 a, b$, Fig. $4 k, l$ ). Man kann sie als die stärksten Faserbildungen des ganzen Sehlappens kennzeichnen. Man sieht sie von der Gegend des. Hilus oder ron etwas tiefer gelegenen Punkten her radiär nach der Oberfläche hin streben, wobei sie ein knorriges Aussehen darbieten und zahlreiche kleine Zacken beschreiben; dieses ihr Aussehen und Verhalten rechtfertigt es, wenn wir sie als $D$ e $\mathrm{ndr}$ it e n auffassen, ohne freilich dies mit Entschiedenheit vertreten zu können. Schon während ihres Verlaufes durch das Mark, bäufiger aber schon in der inneren Körnerschicht geben sie eine Anzahl von varikösen, sich zwischen den Zellen hindurchwindenden und dann frei endigenden Nebenäst e n ab. Diese Seitenäste sind bald kürzer, wie 
bei Zelle $a$ der Figur 1, ball länger, wie bei Zelle $b$. Unter charakteristischem zackigem Verlaufe erreichen unsere Fasern die plexiforme Schicht. Ihr Verhalten darin habe ich in einer grösseren Anzabl von Figuren auf Tafel VI und VII zur Darstellung gebracht. Es handelt sich um mächtige, weit ausgebreitete A ufzweigungen, wohei die Hauptausbreitung und Verästelung dem inneren Plexus angehört. Aber diese reichen Verästelungen bilden eigentlich keine Endverzweigungen, denn der Stamm des Fortsatzes selbst erreicht d amit nicht sein Ende, sondern dringt noch unter senkrechter Durchsetzung der ganzen plexiformen Schicht und Körnerschicht, manchmal wic bei Faser $k$ Figur 4 in zivei gleich starke Aeste getheilt, bis zur Oberfläche des Sehlappens, his zur Retinalfaserlage empor, um erst hier zu endigen.

Was die Einzelheiten dieser Verästelung und dieses Verlanfs betrifft, so wird man schon aus der Verglcichung der in den genannten Figuren dargestellten Fasern erkennen, dass hier eine gewisse Mannigfaltigkeit herrscht. In ler Regel weist der schon an sich starke Dendrit im Bereich dles inneren Plexus noch eine weitere Verdickung anf. Auch fehlt hier nur selten eine starke seitliche $\mathrm{Kn}$ ick ung, indem die Faser zunächst seitlich abweicht, um dann aber noch innerhalb des Plexns wieder in die ursprüngliche Verlaufslinie zurtickznkehren. Von ler ganzen in dem in neren Plex us g e bi e te gelegenen Strecke lösen sich Seitenäs te ab, in der Regel nicht zahlreich, aber zumeist relativ stark und weit ausgedehnt. Sie sind varicös, von knorriger, unregelmässiger Beschaffenheit. Eine weitere Theilung dieser Zweige ist sehr gewöhnlich. Während sie sich horizontal im innern Plexus hinschlängeln, geben sie fast immer noch zartere a uf teigende A es te ab, die von der Horizontalfaser immer an der Stelle eines zackigen Vorsprunges entspringen und senkrecht durch die Mittelzone hindurch in den äusseren Plexus emporziehen, wo man sie dann in verschiedener Weise endigen sieht, bald einfach zugespitzt, bald auch in ein kleines einfaches Endbäumchen zersplittert, oder T-förmig in zwei nicht sehr lange, horizontal auseinanderweichende Aeste getheilt.

Der S t a m m f o r t s a t z geht aber wie gesagt in diesen Verästelungen noch nicht völlig auf, vielmehr sehen wir ihn aus dem inneren Plexus durch die Mittelzone hindurch in den 
ä usseren Plexus eintreten, wo er oft wieder einige Seit enästchen abgiebt, dann dartiber hinaus noch die Lage der äusseren Körner his zur Oberfläche senkrecht, ohne von seiner Breite viel einzubüssen, durchsetzen. Er erreich t stets di e $\mathrm{Oberfläche;} \mathrm{sein} \mathrm{Verhalten} \mathrm{hier} \mathrm{ist} \mathrm{aber} \mathrm{ein} \mathrm{Punkt,} \mathrm{der}$ bei weiteren Untersuchungen noch besondere Berïcksichtigung: erheischt, denn es ist mir nicht gelungen, in dieser Hinsicht zu einem gan\% sicheren Ergebniss zu gelangen. Nach allem, was ich gesehen habe, scheint es mir am wahrscheinlichsten, dass sich der Fortsatz hier in die horizontale Richtung umbiegt, eine kurze Strecke oberflächlich hinzicht und dann ba ld e i f a c h. zugespitzt an der 0 berfläche, bald bakenförmig ein wenigin die Lage der ä usseren Körner zur ickgekr it mmt endigt.

\section{Plexiforme Schicht.}

Jetzt erst wird es möglich sein, von dem Aufbau der plexiformen Schicht ein richtiges Bild zu entwerfen, nachdem die Elemente, die sich durch die Verästelung ihrer Ausläufer an ihrer Bildung betheiligen, einzeln abgehandelt sind. Bevor wir aber auf die Betrachtung der Entstehungsweise der Geflechte eingehen wüden, müssen wir doch zuerst gewisse, allerdings spälliche Zellen in's Auge fassen, die d och dieser Schicht ei g e $n$ thü mlich sind. An Färbepräparaten ist es nämlich keine Seltenheit, namentlich wenn der Schnitt etwas dick ausgefallen ist, versprengte Kerne in geringer Anzahl in der plexiformen Schicht wahrzunehmen. Ein Theil davon nun giebt sich sofort als $z u$ den in dieser Schichte aufsteigenden und sich verästelnden Blutgefässen gehörig zu erkennen. Indessen begegnet man doch auch Kernen, die man kaum auf Blutgefässe zurückführen kann. Solche kommen nun allerdings in sehr spärlicher Zahl vor; man trifft sie hauptsächlich an der in neren Grenzlinie des äusseren Plexus an. Schon nach Betrachtung der Kerne bin ich zur Ansicht gekommen, dass hier irgendwelche $\mathrm{Nervenze}$ l l e $\mathrm{n}$ im Spiele sein mitssen. In dieser Annahme wurde ich bestärkt, als in einem einzigen Falle die Imprägnation einer solchen, isolirt in der plexiformen Lage gelegenen Zelle gelang. Sie präsentirte sich als multipolar, 
ihre Ausläufer nach allen Seiten hin, sowohl aufwärts gegen die äusseren Körner, wie auch abwärts in tiefere Schichten entsendend. Im Ganzen erschienen diese Zellen von kleinen Dimensionen; ein besouderer Nervenfortsatz trat unter den A esten nicht hervor. Dies war aber auch der einzige Fall, wo es mir gelungen ist, eine solche Zelle mit Hülfe der Golgi'schen Methode zum Vorschein zu bringen. Welche Bedeutung diesen Zellen zukommt, konnte ich nicht entscheiden; auf alle Fälle handelt es sich um sehr sporadische Elemente und vielleicht geht man nicht fehl, wenn man in ihnen Zellen erblickt, die, eigentlich zur äusseren Körnerschicht gehörend, durch eine Zufälligkeit der Entwicklung in die plexiforme Schicht verlagert sind. Kommen doch solche versprengte Zellen, die die Schicht, der sie eigentlich angehören sollten, verlassend sich in eine benachbarte Lage verirren, anch in der Netzhaut der Wirbelthiere da und dort vor (versprengte Bipolaren, versprengte Spongioblasten, „nervöse Spongioblasten", d. h. versprengte Ganglienzellen). Es ist aber doch auch möglich, dass eine besondere Zellgattung, entsprechend vielleicht den "horizontalen Zellen" der Vertebratenretina, vorliegt.

Viel konstanter tritt uns eine zweite, der plexiformen Schicht recht eigentlich angebörende Zellgattung entgegen. Es h a n d elt sich um. Gliazellen, offenbar von ektodermaler A bkunft, ein Befund, der mich selbst iberraschte. Soviel ich weiss, ist bis jetzt mit der Golg $\mathrm{i}$ 'schen Methode ein typisches Gliaelement im Nervensystem der wirbellosen Thiere nicht nachgewiesen. Höchstens könnte hier eine Zeichnung von Retzius ${ }^{1}$ ) herangezogen werden, die aus dem Banchstrange des Regenwurms eine gliartige Zelle erkennen lässt. Die Imprägnation dieser Elemente gelingt nicht leicht und scheint gewissen Zufälligkeiten unterworfen zu sein. Am zahlreichsten erhielt ich sie geschwärzt, oder richtiger gebräunt, an einem Präparat, zu dessen Fixirung statt doppeltchromsauren Kalis Formol in $10 \%$ iger Lösung benützt wurde. Trotz der Schwierigkeit der Imprägnation dieser Zellen erhielt ich doch an den vielen Präparaten, dic ich bei meinen Untersuchungen angefertigt hatte, mehrere imprägnirt,

1) G. Retzius, Biologische Untersuchungen, Neue Folge, III, 1892, S. 15 und Fig. 2, Tafel V. 
wovon einige in Fig. 7, Taf. VII zur Ansicht gebracht sind. Am schwierigsten gelangt zur Darstellung der Zellkörper selbst, während die Verästelung der Silberbehandlung rugänglicher zu sein scheint.

Der Zellkör per dieser Zellen liegt in der Regel an der Grenze zwischen innerer Körnerschicht und plexiformer Schicht, oft schon mehr in das Gebiet der letzteren hineingertickt, in welchem Falle man ihn in der beschriebenen schnılen weissen Zone findet. Sehr bezeichnend ist der Umstand, dass der in der Regel längliche Zellkörper mit der Längsaxe horizontal gelagert erscheint. Er ist um ein geringes grösser als die inneren Körnerzellen und anch von unregelmässigerer Form; die Unregelmässigkeit der Gestalt wird noch dadurch ausgeprägter, dass eine tadellose Imprägnation der Zelle selten gelingt. Nachdem ich den Zellkörper nach Form und Lage an Golgi-Präparaten kennen gelernt hatte, wurde ich auch an anderen Präparaten auf die dazu gehörigen Z ellkerne anfmerksam. Sie unterscheiden sich von denen der inneren Körner"zellen durch ihre oberflächlichere, oft wie gesagt schon der plexiformen Schicht angehörende Lage, durch ihre längliche Form, wobei sie quergestellt sind, und durch ihre grösseren Dimensionen. Von dem Zellkörper geht nun, und zwar von einem der Pole unter rechtem Winkel senkrecht aufsteigend, nur an Golgi-Präparaten sichtbar, ein ziemlich starker Ast hervor, der sich sehr bald in eine merkwürdig buschige, stachelige, mehr oder weniger dichte Verästelung auflöst, die sich nach oben hin durch die ganze Breite der plexiformen Schicht bis zur unteren Grenze der äusseren Körnerlage erstreckt. Die Dichtigkeit des Busches ist eine verschiedene. Ich erhielt Zellen geschwärzt, bei denen die Verästelung recht einfach erschien, Zellen bei denen der aufsteigende Fortsatz erst im Bereich des äusseren Plexus sich in seine Verästelung aufsplitterte, aber auch Zellen, bei denen diese Verzweigung gleich von der Zelle an in dichtester Weise vor sich ging, ja bei denen die buschige Verästelung gerade im inneren Plexus am dichtesten erschien (s. Zelle $b$ ). Von allen Sorten sind Beispiele auf der Fig. 7 wiedergegeben. Freilich ist dabei immer damit zu rechnen, dass die weniger dichten Formen nur auf einer weniger vollkommenen Imprägnation beruhen. Ein besonders dicht verästeltes Exemplar ist in der Zelle $b$ dargestellt. 
Der ganze Typus dieser Bäumchen ist ein anderer, als der der Nervenzellenverästelungen. Es handelt sich nicht um jene frei ansgebreiteten welligen Verzweigungen, wie wir sie bei den Nervenzellen sehen, sondern um einen dichten, starren, sich auf ein verhältnissmässig schmales Gebiet beschränkenden Busch. Auch ist bezeichnend, dass diese Zellen sich nie in der satten schwarzen Farbe wie die Nervenzellen imprägniren, sondern stets in hellerem bräunlichem Tone. Viele von den Aesten endigen schon während des aufsteigenden Verlaufes, die Hauptmasse der Zweige erreicht aber die obere Grenze der plexiformen Schicht, um sich hier in sehr charakteristischer Weise st re $\mathrm{ng}$ in e in er geraden Linie ander unteren Grenze der Körner anzusetzen. Sehr oft erkennt man, dass schon innerhalh des äusseren Plexus alle hindurehtretenden Fasern eine Verdi ckung erleiden, sie werden hier rauher, mit Varikositäten beset\%t. Konstanter aber sind die sehr starken ke ulenförmigen Anschwellungen, die die Fasern an ihren Endstiicken innerhalb des weissen Streifens erkennen lassen und die sehr an die Endverdickungen erimnern, die die Ependymfasern und die Fortsätze der peripherisch gelegenen Astrocyten (Spinnenzellen) auf der Oberfläche im Centralnervensystem der Wirbelthiere aufweisen. Nur sind die hier vorliegenden Verdickungen verhältnissmässig ansehnlicher. In der Regel zeigen sie eine dreieckige Gestalt oder Kolbenform, seltener erscheinen sie mehr tellerförmig ausgebreitet. Diese Endknötchen dienen offenbar dazn, die Lücken, die die durch den weissen Saum hindurchtretenden Fasergebilde zwischen sich ïbrig lassen, auszufüllen.

Sollte der Leser fragen, woher ich die Berechtigung schöpfe, die in Rede stehenden Zellen ohne weiteres als nicht nervös, sondern als Stützzellen zu bezeichnen, so kann ich nur sagen, dass mich hierzu ausser dem Mangel eines Nervenfaserfortsatzes

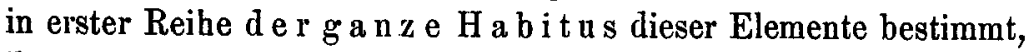
ihre Aehnlichkeit mit den sicher als Gliazellen erkannten Elementen aus verschiedenen Theilen des Centralnervensystems der Vertebraten, so namentlich aus der Klein- und Grosshirmrinde (vergl. z. B. die Abbildungen von $\operatorname{Retzius}^{1}$ ) und $\mathrm{Sala}$ y $\left.\mathrm{Pons}^{2}\right)$ ).

1) G. Retzi u s, Biolog. Untersuchungen. N. F. 14, 1894, Taf. XI.

2) Cl. Sala y Pons, La Neuroglia de los Vertebrados. Barcelona 1894, Fig. 8 und 9. 
Auch mit den Mä 11 e r'schen Śtützzellen der Netzhaut, wie sie etwa R. y Cajal in der Fig. 3 und 4 seines grossen Retinawerkes abbildet, weisen sie einige Aehnlichkeit anf.

Es ist merkwürdig, dass es mir gerade nur in der Molekularschicht gelungen ist, dergleichen Zellen nachzuweisen und zwar in so strenger Beschränkung auf ihre Grenzen; ich halte es auch nicht für wahrscheinlich, dass solche auch in anderen Theilen des Sehlappens vorkommen. Jedenfalls kommt der Verästelung dieser Stützzellen auch ein wesentlicher Antheil an der Bildung der plexiformen Schicht zu.

Führen wir nun die einzelnen Abtheilungen der plexiformen Schicht auf die sie zusammensetzenden Elemente zurück. Der äussere helle Saum verdankt seine sehr helle Beschaffenheit dem Umstand, dass er der feinen Fasergeflechte, wie sie in den andern Schichten vorhanden sind, ganz entbehrt. Die hindurchziehenden Nervenfortsätze oder Nervenfasern geben in dieser Schicht keine Seitenfibrillen ab. Zahlreiche Fasergebilde nehmen ihren Weg durch diese Lage, so die Retinalfasern, die absteigenden Fortsätze der oberflächlichen grossen Zellen sowie der grösseren und kleineren Körnerzellen, die aufsteigenden Dendriten der inneren Körnerzellen und gewisser tiefgelegener grosser Markzellen, schliesslich die centrifngalen peripherischen Nervenfasern. Die Lücken, die zwischen all diesen Fasergebilden ubrig bleiben, werden; wie oben schon erwähnt, ausgefüllt durch die unregelmässigen Varikositäten und Endkeulen der Stützzellenfortsätze.

Der äusere horizontale Plexus geht in erster Linie hervor aus den feinen Seitenzweigehen der Retinalfasern und der äusseren Körnerzellen; geringen Antheil an seiner Bildung haben noch die nicht ganz konstanten Seitenfibrillen, die die absteigenden Fortsätze der grossen oberflächlichen Zellen sowie die aufsteigenden Dendriten der tiefen grossen Markzellen bilden. Alle diese Fäserchen zeigen eine mehr oder weniger horizontale Verlaufsrichtung. Die erstgenannten Fibrillen bilden hauptsächlich seine äussere, die anderen seine innere Lage. In physiologischer Hinsicht wird wohl die Hauptbestimmung dieses Plexus im Herstellen von funktionellen Beziehungen zwischen diesen beiden Fibrillengattungen liegen.

Die Mittelzone hat als Hauptbestandtheil senkrecht in 
dichter Anordnung herunterziehende Fibrillen und zwar die absteigenden Endäste der Retinalfasern, sowie diejenigen der grösseren Körnerzellen. Auch die oberflächlichen grossen Elemente liefern durch ihre derben absteigenden Arme einen Beitrag zu dieser Schicht. Sie wird weiterhin durchsetzt durch die aufwärts ziehenden Verlängerungen der Dendriten der inneren Körnerzellen, sowie der grossen tiefen Markzellen. Eine grosse Komplikation erwächst ihr durch die Nervenfasern, die von bestimmten Markzellen (Zellen mit aufsteigendem Nervenfortsatz) ausgehend, sich in ihr in unregelmässige Endbäumchen auflösen. Schliesslich wird sie noch durchzogen von den centrifugalen Nervenfasern, sowie von zahlreichen aufsteigenden Capillaren.

Der innere Plexus bezieht seine Elemente einerseits von den auf der Oberfläche der äusseren Körnerschicht gelegenen riesigen Nervenzellen in Form der weitausgebreiteten mächtigen Verüstelungen ihres absteigenden Fortsatzes, andererseits von der inneren Körnerschicht und dem Mark in Form jener seitlichen Fibrillenbiischel, die deren aufsteigende Fortsätze in dieser Schicht aus sich hervorgehen lassen. Die ersteren verästeln sich mehr in der äusseren, die letzteren mehr in cler inneren Zone des inneren Plexus, daher manchmal, wie schon elwähnt, zwei dunkle Randstreifen hervortreten. Eine weitere Komplikation erfährt das Geflecht durch die darin ausgebreitete Verästelung vieler aufsteigender Nervenfortsïtze, sowie auch dadurch, dass in seine obersten Schichten sich die absteigenden Endästchen der kleinen Körnerzellen und der Retinalfasern hineinsenken, sich oft noch durch Umbiegungen in die horizontale Richtung an der Plexusbildung betheiligend. Hier ist die Stelle, wo die Bestandtheile der inneren Körnerschicht und des Markes die von der Netzhaut kommenden Erregungen in sich aufnehmen, theils direkt von Seiten der Endspitzen der absteigenden Zweigchen der Retinalfasern, theils indirekt und zwar wohl in erster Reihe von den Verästelungen der grossen Körnerzellen. Ueber den inneren feinen Saum ist nicht viel zu sagen. Er kommt wie der äussere helle Saum zu Stande durch Fehlen aller Seitenfibrillen. Als eigens ihm angehörende Elemente erkennen wir nur die Zellkörper der Gliazellen, die aber, wie geschildert, manchmal etwas tiefer, schon den inneren Körnern entsprechend, gelagert sind.

Die Fortsätze der Gliazellen durchsetzen in allen Schichten 
alle die erwähnten Faserkategorien in komplizirtester Weise und verflechten sich mit ihnen zu jenem dichten Gewirre, das eben die plexiforme Schicht ausmacht.

\section{Schlussfolgerungen.}

Im Vorstehenden ist das empirische Material beigebracht, aus dem ein Verständniss des Hirntheiles, das den Gegenstand unserer Bemühungen bildete, hervorgehen kann. Nach zwei Richtungen hin wird sich hier der Versuch einer Erklärung zu bewegen haben: nach der physiologischen und nach der morphologischen Seite hin, wobei für letrtere Betrachtungsweise die schon eingangs aufgestellte Fragestellung massgebend sein wird, ob und inwieweit im Sehganglion der Cephalopoden Anklänge an den Bau der Wirbelthiernetzhaut nachzuweisen sind.

Eine gesonderte Behandlung dieser beiden Erklärungsrichtungen scbeint mir indess nicht geboten, vielmehr werden die beiden Fragen schon aus dem Grunde in inniger Verschmelzung zu diskutiren sein, weil die funktionelle Stellung, die den einzelnen von uns nachgewiesenen Elementen in der Fortleitung der optischen Reize zugewiesen werden muss, einen wichtigen Faktor bei der Beurtheilung ihrer morphologischen Stellung bei dem Vergleich derselben mit den Elementen der Vertebratenretina abgeben wird.

Es scheint mir hier zweckmässig, abweichend von der sonst in den Naturwissenschaften üblichen Darstellungsweise, das Ergebniss meiner Untersuchungen an die Spitze meiner Ausführungen zu stellen.

Um es kur\% zn sagen: ich bin zu dem Etgebniss gekommen, dass die Sehlappenrinde der Cephalopoden der Wirbelthiernetzhautentspricht, mit Abrecbnung der Sehzellenschichte, d. h. der Stäbchen-und Zapfenzellen, diebei unseren Thieren alseigentliche Netzhaut eine ganz selbstständige, distalwärts hinausgeruckte Lage innehaben, dass also die zweite von den beiden eingangs aufgestellten Möglichkeiten durch meine Untersuchungen bestätigt wurde. Di e Cephal opodennetzhat entspricht also nicht derganzen Wirbelthiernetzhat, sondern nur ihrer ersten Sebicht der "Nearoepithelschicht"Schwalbe's. 
Histologische Untersuchungen am Sehlappen der Cephalopoden. 93

Es ist dies gewiss ein hochinteressantes Ergebniss, umso interessanter, als auch die Wirbelthiernetzhaut dadurch in ein helleres Licht gerückt wird. Auf das Ueberzengendste sehen wir durch unsere Befunde die Thatsache illustrirt, dass in der Vertebratenretina $z$ wei wesentlich verschiedene Dinge zur Bildung einer einheitlichen Membran vereinigt sind: eine Schichte von richtigen epidermalen S in nesu ervenz el l e n und verschiedene Zelllagen, die eigentlich dem Centralnervensystem angehörend e in S t it ck chen nach a usen hin verlagertes Gehirn darstellen. Diese Auffassung ist ja keineswegs neu, sie ist ja schon öfters, zuerst wohl von $H$. M iiller ${ }^{1}$ ), ausgesprochen worden und hat wohl ilren treffendsten Ausdruck in der von $\mathrm{S} \mathrm{c} \mathrm{h} \mathrm{w} \mathrm{a} 1 \mathrm{~b} \mathrm{e}^{2}$ ) eingeführten Unterscheidung einer ${ }_{n}$ Neuroepithelschicht ${ }^{4}$ und einer "Hirnschicht" gefunden, aber einen so frappanten Beweis für ihre Richtigkeit, wie sie uns die Verhältnisse bei Cephalopoden liefern, hat noch Niemand geben können.

Die Ceplalopoden nehmen in Bezug auf die Entwicklung ihres Sehorganes unter den Wirbellosen gewiss eine exceptionelle Stellung ein und es ist daher nicht anzunehmen, dass noch bei vielen anderen Mollusken oder anderen Wirbellosen eine ebenso weitgehende Differenzirung der am Sehact betheiligten Nervenzellenschichten bestehen sollte. Wenn dies jeder Wabrscheinlichkeit entbehrt, so spricht auf der anderen Seite vieles dafür, dass das Princip der hier verwirklichten Einrichtung, wenn auch in viel einfacher Ausfuibrung, in der Anordnung des Sehapparates vieler anderen Formen den maassgebenden Faktor bilde. Das principiell Wichtigste erblicke ich aber darin, dass die Netzhaut ans einer einfachen Schicht von Sinnesnervenzellenzusammengesetzt ist, die an ihrem.proximalen Ende in Nervenfasern ïbergeben, welche dann in einem besonderen Ganglion dureh ihre verzweigten Endigungen auf eine Anzahl von in einer bestimmten, zur Fort-

1) W. Mülle r, Ueber die Stammesentwickelung des Sehorgans der Wirbelthiere. Leipzig 1874, S. XLIX.

2) G. Schalbe, Lehrbuch der Anatomie der Sinnesorgane, Erlaugen 1887, S. 93. 
leitung der Lichtreize geeigneten Weise an einander gegliederten Nervenzellen einwirken.

Wenn durch den Nachweis der räumlichen Trennung von Nervenzellenschichten, die wir beim Wirbelthier so eng aneinandergeschlossen sehen, zwischen Cephalopoden und Vertebraten eine tiefe Kluft vorhanden zu sein scheint, so wird diese Kluft iiberbritckt durch die iberraschende Thatsache, dass es gel in gt, in der Sehlappenrinde von Eledone fastalle Zellgattungen, die in der Wirbelthiernet\%hant die ${ }_{n} H$ irnschichten ${ }^{4}$ Schwalbe's bilden, wiederzufinden. Wir steheneiner anffallenden Uebereinstimmung in vielen Einzelheiten der feinsten Struktur bei sonst so weit a useinanderliegenden Formen ge genüber und werden wieder aufs eindringlichste auf die Gemeinsamkeit der Organisation lingewiesen.

Indem ich nun daran gehe, diese Uebereinstimmung im Einzelnen nachzuweisen, d. h. die Elemente des Lobus opticus durch den Vergleich mit denen der Wirbelthiernetzhaut zil kennzeichnen, trete ich \%ugleich den Beweis an für die Richtigkeit des oben aufgrestellten Satzes, des Hauptergebnisses meiner Untersuchungen.

Betrachten wir also von dem Gesichtspunkte einer solchen Vergleichung aus zunächst die Retinalfasern mitsammt den Zellen, die ihnen zum Ursprunge dienen, d. h. den Sehzellen der Cephalopodenretina. - Es kann nach Allem nicht fraglich sein, dass diese Zellen den ${ }_{n}$ Neuroepithelzellen " der Wirbelthiernetzbant entsprechen. Bei dem Wirbelthier finden wir den unteren Abschnitt der "Sehzellen" zwar stielartig verdünnt und verlängert, was besonders für die Stäbchensehzellen zutrifft, aber wegen der Nähe der nächsten Zellenlage nie zu einer richtigen Nervenfaser ausgezogen. Anläufe zu einer solchen Metamorphose bietet uns allerdings auch' die Wirbelthiernetzhaut dar im Gebiet der Macula lutea und ihrer Umgebung, wo bekamutlich die Neuroepithelzellen unterhalb ihres kernhaltigen Abschnittes sich zur Bildung der ${ }_{n} \mathrm{H}$ enle's chen Faser$\mathrm{schich} \mathrm{te}$ " verlïngern; allein zur Entstehung ron eigentlichen Nervenfasern kommt es auch hier nicht. - Bei den Cephalopoden dagegen veranlasst die beträchtliche Entfernung der näch- 
sten, schon in der Rindenlage des Sehlappens lokalisirten Schicht die Umwandlung des proximalen Zellkörperabschnittes zu einer richtigen, ziemlich langen Nervenfaser. - Stäbchen- und Zapfenzelle der Wirbelthiere verhalten sich also zu den Sehzellen der Cephalopodennetzhaut genau so, wie die s e c un däre n S in nesz e lle n der Geschmacksknospen und Hörnervenendstellen zu den primären Si nnesnervenzellen der Riechschleimhaut. Da lemnach die eine Form durch die andere, sccundäre Sinneszellen durch primäre vertreten sein können, wird hier aufs klarste bewiesen, dass der Unterschied $z w$ is chen den beiden Gattungen nichtso fundamentaler Natur ist. Er scheint im Wesentlichen nur dadurch bedingt zu sein, ob ron der zweiten Nerveneinlseit, anf die die Sinneszelle einzuwirken hat, ein Fortsatz an sie herantritt oder nicht. Im ersten Falle ist ein Ausläufer an der Sinneszelle überflüssig, da die Weiterleitung der Erregung durch die sie umflechtenden Dendritenverästelungen der zweiten Einheit besorgt wird, im zweiten Falle muss aber die Sinneszelle selbst behufs Ankniipfung funktioneller Beziehungen die zweite Nerveneinheit aufsuchen, und zwar thut sie dies durch eine Verlängerung ihres Zellleibes bis an den Standort jener Nervenzellen; sie besorgt also selbst die $\mathrm{Ab}$ leitung der voll ihr aufgenommenen specifischen Sinnesreize in centripetaler Richtung. - Wir sehen hier ferner schön, wie sich unter bestimmten Umständen das Protoplasma ohne weiteres zn einer Nervenfaser umbilden kann. Manches liesse sich hier noch anknüpfen, mit Berticksichtigung namentlich der Entwicklungsweise der Spinalganglienzellen.

Es fragt sich nun weiter, welcher von den beiden Zellgattungen des $\mathrm{Neuroepithelsder} \mathrm{Wirbelthier-}$ netzhaut entsprechen unsere Sehzellen: den Stäbchenzellen oder den Zapfenzellen? Vielleicht drängen sich hier dem Leser Bedenken anf, ob der Verfasser durch eine so sehr ins Einzelne gehende Vergleichung bei so gänzlich verschiedenen Thierformen wie Vertebraten und Cephalopoden nicht etwa zu weit gehe. Dies war auch meine Beftirchtung anfangs, auch ich meinte, dass sich die Parallele mehr in einem allgemeinen Rahmen $z \mathfrak{u}$ halten und von einer solchen Detailfrage abzusehen haben. Indessen traten mir an den Cephalopodensehzellen und ihren Fortsätzen in aufdringlicher Weise 
gewisse Merkmale entgegen, die es mir gegen alles Erwarten nahelegten, zwischen jenen beiden Sehzellenformen bei der Vergleichung eine Wahl zu treffen. Wem sollte nicht die überraschende Analogie auffallen, die die kegelfönnig verdickten unteren Abschnitte der Retinalfasern mit den merkwürdigen, schon von M. S ch n lt \% e nachgewiesenen, neuerdings von $R . y \mathrm{Caj}$ a l a. a. O. mit Hülfe der Golgi'schen Methode so anschaulich dargestełlten dreieckigen Endanschwellungen der Zapfenfaseru erkennen lassen? Um die Uebereinstinmung noch frappenter zu machen, fehlt an jenen Endkeulen bei Cephaloporlen anch ein ganz ähnliches zartes Fibrillenbüschelchen nicht, wie wir es bei den Zapfen, genau wie hier, von der Basalfläche der Endverdickung abgehen sehen. - Nun ist allerdings zu bemerken, dass bei Amphibien und Vögeh (mit Ausnahme der Nachtrögel) auch die Stäbchenfasern solche Endverdickungen aufweisen; indessen ist ein derartiges Verhalten der Stäbchen gerade nur bei diesen zwei Klassen vorhanden, während die Zapfenfasern jene Endkeulen bei keinem Wirbelthier vermissen lassen. Es ist somit vollkommen begründet, wenn wir die Endverdickung als typisches Merkmal den Zapfenzellen zutheilen.

Ich halte alsodie Sehzellender Cephalopoden für Analoga der Zapfenzellen der Vertebraten und möchte, von dieser Anschauung ausgehend, jene spindelförmige Anschwellung, die die langen stäbchenartigen Fortsät\%e der Retinalzellen der Cephalopoden głeich an ihrem Wurzelstück oberhalb der "Grenzmembran" bilden, und die ich in meiner vorjührigen Arbeit als ${ }_{n}$ Stäbchenspindel ${ }^{*}$ bezeichnet hatte, dem verdickten Innenglied der Zapfen gleichsetren.

Eine einzige Einrichtung nur, die wir an den Retinalfasern wabrnehmen, bleibt ohne Analogon bei den Zapfenfasern: es ist dies jener zarte absteigende Ast, der von der Basalfläche der Endverdickung ausgehend noch eine Strecke - im reifen Zustande bis zu dem inneren Plexus - herunterzieht. Denn beim Wirbelthier erstreckt sich das Wirkungsgebiet der Zapfenfasern nie uber die dem äusseren Plexus entsprechende äussere plexiforme Schicht hinaus.

Hier liegt nun allerdings eine wirkliche Besonderheit vor, ein Unterschied, der auch mit einer physiologischen Verschieden- 
heit zusammenlängren diurfte, die einzige wesentlichere Differen\%, die ich zwischen Vertebratenretina und Cephalopodensehlappen feststellen konnte. Beim Wirbelthier mus der Sehimpuls bei seinem Uebergang von den reiza u nellmenden Neuroepithelzellen anf die reizableitenden Ganglienzellen un we iger lich die $\mathrm{Z}$ wischenstation der zwischen beide eingeschalteten Bipolaren passieren; einen direkteren Weg giebt es hier nicht. Anch bei den Cephalopoden ist, wie wir sehen werden, der gewöhnliche Weg der Reizwelle ein analoger, indem sie von den Retinal-

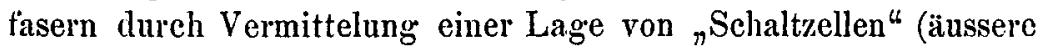
Körnerzellen) auf die den Ganglienzellen entsprechenden inneren Kömerzellen iibertragen wird; aber $n$ eben diesem indirekten Wege scheint auch für die Möglichkeit einerdirekten Uebertragung gesorgtzusein. Zu den Einrichtungen nun, die diese den Cephalopoden eigenthümliche direkte Reiziiberleitung vermitteln, gehören wohl auch die fraglichen zarten absteigenden Aeste. Es ist fü mich nicht zweifelhaft, dass die Ha u ptmenge des Reizes durch den feinen Fibrillenbusch im äusseren Plexus den umständlicheren Weg durch die äusseren Körner einschlägt, aber e $t w$ a $s$ von der Reizwelle mag wobl auch immer in den absteigenden Ast gelangen und durch ihn direkt auf die Verzweigungen der oberen Dendriten der inneren Körnerzellen übergehen.

Beide Endgebilde: der Fibrillenbusch wie der untere Ast sind natürlich als Emissions- oder Transmissionsorga ne, als Telesidendrien des ersten Neurons aufzufassen. Hier wie dort steht es fest, dass die Endigung mit freien Spitzen erfolgt, ohne jede Spur einer anastomotischen Verbindung mit anderen Nervenelementen; di e U ebertragung der Reize von der NetrhautaufdenSehlappenwirdalsoausschliesslich durch einen innigen Contact der Endbäumchen der Retinalfasern mit den Verästelungen auderer Nerveneinbeitengetragen.

In der Wirbelthiernetzhaut treten die unteren Büschel der Neuroepithelzellen in der a ausseren plexiformen Schicht mit den oberen, büschelförmig anfgefaserten Zellfortsätzen der Bipolar- 
zellen in Beziehung: auf diese Zellen ubertragen sie die Erregung behufs Weiterbeförderung cerebralwärts. Bei den Cephalopoden erfolgt diese Uebertragung von den Retinalbisscheln hanptsächlich auf die unteren zarten Fibrillen der ä us s e re n K ör n e rzellen: in diesen, namentlich in der grösseren Gattung derselben möchte ichalso die Analoga der Bipolaren erblicken.

Wenn wir freilich die Form, das ganze Verhalten der beiden in Rede stehenden Zellgattungen \%um Vergleich bringen, so scheint auf den ersten Blick Alles eher gegen als für eine solche Analogie zu sprechen. Bei dem Wirbelthier treten uns ausgesprochen bipolare Elemente entgegen, mit einem gegen die Neuroepithelschichte gerichteten, ohne Frage einem Dendriten entsprechenden receptiven, und einem gegen dic ableitende Zelllage bin gewendeten, den Neuriten darstellenden reizabgebenden Fortsatze; in den äusseren Körnern des Lobus opticus dagegen haben wir unipolare Zellen, nur ein ein\%iger in einer typischen Weise verästelter Fortsatz ist vorhanden.

Und doch fallen bei näherer Betraclitung die Scbranken. Eine Analyse der äusseren Körnerrellen ergiebt, dass jene beiden Bischel, die wir den Enden des oberen und unteren Fortsatzes der Bipolaren angefilgt sehen, das receptive und abgebende, auch hier durch entsprechende Vorrichtungen vertreten sind. Das Receptionsorgan wird hier ohne Frage dargestellt durch jenezarten Reiserchen, die der Fortsat\% im äusseren Plexus abgiebt: durch sie setzt sich die Zelle mit den Retinalfibrillen in geflechtartige reizaufnelimende Verbindung. Von hier läuft die Erregung durch die absteigenden Aeste in den inneren Plexus herunter, wo sie der ableitenden Zellenreihe mitgetheilt wird. Es ist also der absteigende $\mathrm{Zweig}$ als der eigentliche Nervenfortsat\%, seine Endigung als Analogon des Emissionsblischels aufzufassen.

Welche Rolle soll nun aber bei einem solchen Lauf des Erregungsstromes dem Zellkörper 'zugesprochen werden? Anscheinend liegt er ausserhalb der Bahn der Reizwelle und man könnte daher versucht sein, ihm jede Betheiligung an dem Vorgang der Reizubertragung von den Retinalfaserenden anf die tieferen Schichten des Sehlappens abzusprechen.

Ich glaube nun aber, dass durch ein solch' absprechendes 
Urtheil den Zellkärpern der äussern Kärnerzellen ein grosses Unrecht geschehen wüldle. I) Vorstellung, die sich in mir iiber diese Sache allmählich festgesetzt hat, geht vielmehr dahin, dass der Zellleib auch hier wie bei allen anderen Nervenzellen den Hauptfactor bei der Thätigkeit des Nervenelementes bildet; ich bin der Ueberzengung, dass die Zelle mit ihrer Function schon dazu nothwendig ist, um die Fibrillen im ïusseren Plexus zur Reizaufnahme iiberhaupt zu befähigen; im Zellprotoplasma selbst werden dann weiterhin die Reize in eine bestimmte Erregungsform ungeprägt, durch die Thätigkeit desselben wieder durch den Fortsatz zuriick zur Einwirkungsstelle und tiber diese hinaus in die absteigenden Aeste hingeleitet, durch deren Endspitzen sie weiter fortwirken.

In ganz ähnlichem Sinne habe ich mich schon fruiher ein$\mathrm{mal}^{1}$ ) in Bezug auf die functionelle Stellung des Zellkörpers bei einer Zellgattung ausgesprochen, bei der die Verhältnisse merkwhirdig ähnlich liegen, wie hier. Diese Zellgattung ist die pseudo-unipolare Spinalganglienzelle der Amphilsien, Saturopsiden und Säuger. Anch hier liegt die Versuchung nahe, anzunehmen, dáss die Erregung bei der T.förmigen Theilung unter Umgeliung der Zelle von der peripherischen sensibeln Faser direkt anf die Hinterwurzelfaser tiberspringe, aber auch hier habe ich ïberzeugende Beweise dafür anführen können, dass dies nicht anzunehmen sei, dass vielmehr die Zelle an der Fortleitung der Reize wesentlichen Antheil nehme.

Besteht so keine Schwierigkeit, an den äusseren Körncrzellen die functionellen Einrichtungen, die den Bipolaren \%ukommen, und in derselben Verknïpfung, nachzuweisen, so gelingt es allch, ihren anscheinend so sehr abweichenden morphologischen Habitus mit der Form der Bipolaren in Einklang zu bringen, ja ibn gleichsam daraus abzuleiten. Als Ausgangspunkt dieser Betrachtung möchte ich die gar nicht so selten vorkommende Form der Bipolaren heranziehen, bei der wegen der bis an die obere Grenze der inneren Körnerschichte herangeriickten Lage des Zellleibes ein oberer Fortsatz gar nicht in die Érscheinung tritt, sondern das obere, receptive Bischel direkt dem Zellkörper entströmt. In dem grossen Werke von $\mathrm{R}$. y $\mathrm{Caj}$ a I sind

1) Der feinere Bau des Nerrensystems etc. II. Anflage. S. 275. 
mehrere derartige Zellen abgebildet, so Zelle $f$ in Fig. 2 Tafel V, die Zellen $f$ und $g$ in der Fig. 4 derselben Tafel; desgleichen finden wir alich in Dogiel's Arbeiten mehrere hichergehörige Abbildungen, wie die Zelle $f$ Fig. 2 in der Abliandlung "Ueber die nervösen Elemente in der Retina des Menschen" (Archiv $f$. mikrosk. Anat. Bd. XXXVIII). Ein Schritt weiter in den Vorgang des Aufwärtsrlickens des Zellkörpers und die Zelle verlagert sich in die aussere plexiforme Schicht, wobei die receptiven Aestchen numnehr nicht von ihrer oberen, sondern von ihrer unteren Fläche entspringen, von derselben Fiäche, aus deren Mitte der absteigende (Nerven-)Fortsat\% hervorgelit. Auch für diese Form bietet das Cajal'sche Werk ein Beispiel in Zelle $f$ der Fig. 2, Tafel II, sowie auch Dogiel's citirte Arbeit in Zelle $e$ der Figur 2. Steigert sich nun dieser Vorgang, ein Process, den man sich ja leicht construiren und vorstellen kann, und für den ja auch der ${ }_{n}$ Unipolarisirungsvorgang" bei den Spinalganglienzellen ein Analogon bildet, so rlickt der Zellkörper von der Abgangsstelle der Receptivfäserchen noch weiter weg, hiuauf in das Gebiet der äussereu Körner, wobei sich natürlich ein Theil des Zellprotoplasmas zu einer fortsatzartigen schmalen Verbindungsbrlicke ausziehen muss, und wir haben ungefähr das Bild einer äusseren Körnerzelle des Cephalopoden-Sehlappens. Solite sich hier nun aber der Leser von einem gewissen Widerwillen gegeu dergleichen willkurliche Constructionen ergriffen fithlen, was ich ilım gar nicht verübeln könnte, so kann ich zur Berubigung mittheilen, dass das, was hier wie auf constructivem Wege erdacht dargestellt wurde, sich ab und zu an den Bipolaren thatsächlich einleitet, also der Wirklichkeit entlehnt ist. Es kann nämlich wirklich vorkommen, dass die Zelle in das Gebiet des Neuroepithels versprengt wird, in welchem Falle ein Stück des Zellfortsatzes sich natirlich zu einem derben Fortsatze unwandeln muss. Solche ${ }_{n}$ versprengte bipolare Zellen" sind schon von W. Krause, Ranvier, Scbiefferdecker u. A. gesehen worden, aber erst Dogiel hat sie in ihrer Eigenschaft als Bipolare eikannt. Der russische Forscher und R. y Cajal haben von diesen Zellen einige klare Bilder gegeben; ich verweise z. B. auf Fig. 2 der oben citirten Dogiel'schen und Fig. 7 Tafel III der grossen $\mathrm{C}$ ajal'schen Arbeit; in letzterer Figur sind nicht weniger als sechs solche "deplacirte Bipolare" 
zur Ansicht gebracht. Mit Ueberraschung sehen wir hier Zellen, in denen wir annähernd eine Wiedergabe der äusseren Körnerzellen der Cephalopoden erblicken könnten.

Ich habe in der nachstehenden Figur 2 den Vorgang, der aus einer Vertebratenbipolaren eine Cephalopoden-Körner"elle hervorbringt, durch Nebeneinanderstellung einiger Uebergangsformen bildlich darzustellen gesucht; alle diese Formen sind verschiedenen Figuren des $\mathrm{Caj}$ al'schen Werkes nachgebildet.

Ich möchte hier gleich die Existen\% solcher versprengten Bipolaren auch in einem anderen Sinne, nämlich in der Richtung der functionellen Erklairung verwerthen, und zwar zu Gunsten der schon oben vertretenen Ansicht, dass der Zellkörper der äusse-

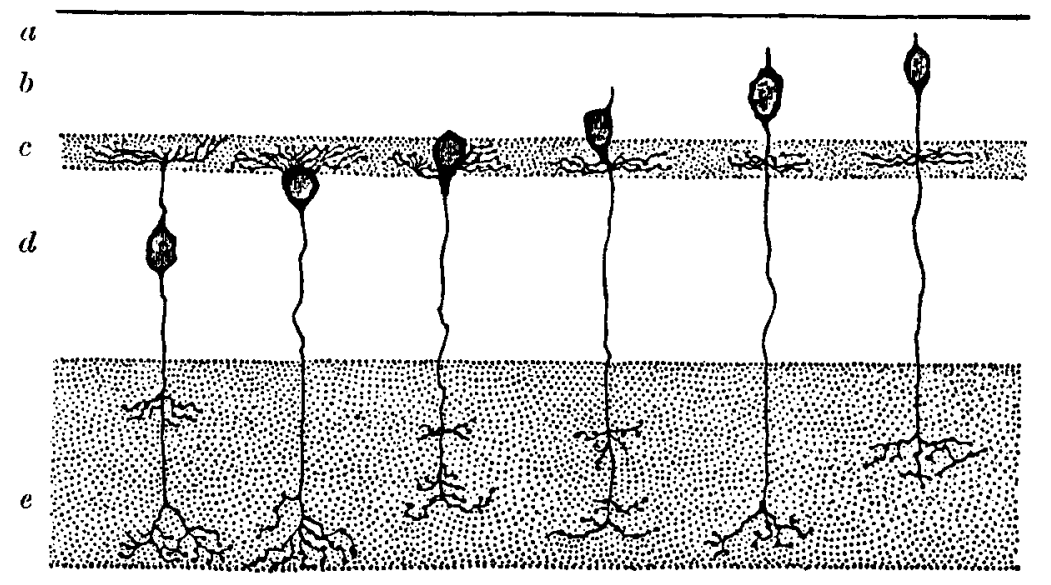

Fig. 2.

Verschiedene Formen von Bipolaren aus der Netzhaut von Wirbelthieren, links normale Formen, links "verlagerte bipolare Zellen“; letztere schliessen sich in ihrer Form ganz an die äusseren Körnerzellen des Sehlappens an. $-a=$ Membrana limitans externa; $b=$ iussere Körnerschicht; $c=$ äussere plexiforme Schicht ; $d=$ innere Körnerschicht; $d=$ innere plexiforme Schicht.

ren Körnelzellen aus der Function nicht ausgeschlossen, sondern anch an den Nervenfunktionen betheiligt ist. Dass bei den gewöhnlichen Bipolaren die Erregung durch den Zellkörper hindurchgeht, kann wohl keinem Zweifel unterliegen. Wenn wir nun nicht annehmen wollen, dass bei den in Rede stehenden deplacirten Zellen ganz besondere, von denen aller anderen Bipolaren abweichende funktionelle Verhältnisse vorliegen, so 
müssen wir daran festhalten, dass der Zellkörper auch bier von der Reizwelle durchsetzt und erfüllt wircl, dass er anch hier ihr weiteres Fortwirken durch eigene Thätigkeit befördert. - Ich schliesse mich vollkommen $\mathrm{R}$. y $\mathrm{C}$ aja $\mathrm{l}$ an, wenn er sagt (a. a. O. S. 134): „In physiologiseher Beziehung ist ein Wechsel in Sitz der retinalen Zellen ohne Bedeutung, vorausgesetzt, dass die Lage der Protoplasmaverzweigungen und die Richtung der functionierenden Fortsätze constant bleiben."

Aus dem Dargelegten ergiebt sich von selbst, dass ich das stück der äusseren Körnerzelle vom Zellkörperbiszur Abgangsstelle der feinen imäusscren Plexus der plexiformen Schicht sich a usbit end en $R$ e is er ch e n nicht für einen Nervenfortsatz, aber auch nicht für einen Dendriten, sondern noch für e in $S t$ ü ck des Zellkörpers selbst halte; erst im Bereich des Plexus hört fürr mich der Zellkörper auf und beginnt der als „absteigender Ast" zum inneren Geflechte hinziehende zarte Nervenfortsatz, während ich die Fibrillen als cellipetale receptive Organe, als Dendriten auffasse.

Es handelt sich in diesem functionellen Verhalten durchaus nicht um eine isolirte Erscheinung, vielmehr liegt hier ein Auschluss an das Verhalten der meisten Nervenzellen bei Wirbellosen vor, und ich habe mit der obigen Därstellung auch meine Auffassung über die Wirkungsweise der meisten Unipolarzellen rler Evertebraten gekennzeichnet. Vergegenwärtigen wir uns, class bei dieser im Nervensystem der Wirbellosen verbreitetsten Zellform der Zellkörper in der Regel abseits, ausserhalb des Gebiets der Nervenverïstelungen liegt. Woher soll nun die Zelle die Impulse für ihre eigene Thätigkeit beziehen, wenn nicht auf dem Wege der ersten Nebenzweige ihres Stammfortsatzes; diese müssen nun cellipetale Aufuahmeapparate sein, den Dendriten der Multipolarzellen entsprechend, und man wird auch hier mit vollem Recht das erste Stitck des Stammfortsatzes bis zur Stelle wenigstens, wo die ersten Nebenfortsätze sich von ihm ablösen, in functioneller Hinsicht als einen stielförmig ausgezogenen Theil des Zellkörpers auffassen dürfen. Ich finde mich in der Auffassung der Nebenfortsätze als Dendriten - eine Ansicht, die ich schon an einer anderen Stelle (Der feinere Bau des Nervensystems, II. Aufl. S. 85) ausführlicher entwickelt habe - in 
Uebereinstimmung mit Retzius; auch Bethe ${ }^{1}$ ) lat sich neuerdings in diesem Sinne ausgesprochen.

Der Leser wird beinerkt haben, dass was hier von den äusseren Körnerzellen gesagt wurle, sich ausschliesslich auf die grössere Gattung derselben beziehen kann. Wie steht es nun aber um die kleineren Elemente dieser Art? Da hier ein absteigender Fortsatz fehlt, können obige Ausfuhrungen für sie nicht Geltung haben. Nun könnte man hier einer jeden functionellen Erklärung anfs bequemste aus dem Wege gehen durch die Annahme, dass in diesen Zellen vielleicht noch unreife nicht völlig entwickelte Elemente vorliegen - beziehen sich doch meine Erfahrungen, wie schon öfters betont, hauptsächlich auf junge Exemplare von Eledone. Allein anch eine andere Deutung ist möglich; man könnte annehmen, dass dle zarten Endästchen, in die der Fortsatz im äusseren Plexus zerfällt, von verschiedener physiologischer Bedeutung sind: einzelne vielleicht receptiver Natur, andere wieder zur Reizabgabe bestimmt, und dass letzteren die Aufgabe zufällt, die von den Retinalfibrillen ubernommene Erregung an jene noch zu schildernden inconstanten Fibrillen abzugeben, dic die Ausläufer der inneren Körnerzellen und gewisser Markzellen in dieser Schicht bilden.

Die grossen oberflächlichen Nervenzellen der äuseren Körnerschichthalte ich ihremganzen Ausseben nacb fü Analoga der Spongioblasten (H. Maller) oder Amakrinen (R. y Cajal) der Wirbelthiernetzhaut. Die Aehnlichkeit ist wirklich auffallend, sie wird sich wohl Jedem aufdrängen, der die von mir in der Fig. 2, Taf. VI dargestellten Zellen mit den Abbildungen, die z. B. Cajal von den Amakrinen gibt, vergleicht. Hier wie dort sehen wir einen plumpen Zellkörper, eine weitausgedehnte, sich bald von einem längeren Stiele flächenhaft ausbreitende, bald mehr in diffuser Weise angeordnete Verästelung; Typus 1) unserer Zellen schliesst sich besonders auffallend an die ,einschichtigen Amakrinen" Cajal's, Typus 2) und 3) an die ndiffusen" an. Dass der

1) A. B et h e, Studien über das Centralnervensystem von Carcinus maenas etc. Archiv f. mikrosk. Anat., Bd. 44, 1895, S. 615. 
Sitz des Zellkörpers hier ein etwas anderer ist, als bei den Amakrinen, wird wohl keinen wesentlichen Unterschied abgeben, sind doch die topographischen Verhältnisse der Schichten hier durch die Verlagerung des Zellkörpers der Bipolaren ganz andere ge. worden. Wenn wir uns an den oben citirten Cajal'schen Ausspruch halten, dass in der Netzhaut die Lage des Zellkörper's in physiologischer Beziehung nicht von so grossem Belang ist, dass vielmehr die Ausbreitungsweise der Fortsätze in dieser Hinsicht den Ausschlag gibt, so werden wir die Analogie als eine vollkommene bezeichnen dürfen, denn das innere horizontale Geflecht, worin der Fortsatz unserer Zellen zur Ausbreitung gelangt, entspricht unverkennbar der inneren Molekularschicht der Wirbelthiernetzhaut.

Von der Gleichartigkeit oder Verschiedenheit der Wirkungsweise dieser Elemente im Vergleich zu den Amakrinen dürfen wir hier unsere Entscheidung nicht abhängig machen, denn die functionelle Stellung der letzteren ist noch durchaus nicht hinreichend klargelegt. Alle hierüber aufgestellten Annahmen tragen zu sehr den Stempel willkürlicher Annahmer an sich. Am schärfsten formulirt hat $\mathrm{R}$. y $\mathrm{Caj}$ a $\mathrm{l}$ seine diesbezügliche Ansicht (a. a. 0. S. 165). Nach ihm sind die Amakrinen an der directen Fortleitung der Sehreize nicht betheiligt; ihre Aufgabe besteht vielmehr darin, in den Elementen, die kettenartig aneinander gegliedert diese Fortleitung besorgen, speciell in der dritten und vielleicht auch in der zweiten dabei betheiligten Nerveneinheit, also in den Ganglienzellen und Bipolaren, durch einen nicht näher definirbaren Einfluss den zur Reizleitung geeigneten Zustand anzuregen und wachzuhalten. Sie selbst empfangen nun aber wieder den Impuls zu dieser Einwirkung vom Centralorgan her, auf dem Wege der von $\mathrm{R}$. y $\mathrm{Caj}$ al histologisch zuerst nachgewiesenen ncentrifugalen" Fasern.

Nichts würde uns histologischerseits daran hindern, die Anschauung des spanischen Histologen auch bei unseren Zellen durchzufuhren. Auch hier giebt es ja wie wir gesehen haben ganz ähnliche centrifugale Fasern, die sich in allen drei Schichten der plexiformen Schicht verästeln und somit auf die oberflächlichen grossen Zellen durch Verflechtung mit deren absteigendem Fortsatze rom Centrum kommende Reize ubertragen könnten, auch hier treten die Endspitzen der Verästelung unserer Zellen in in- 
nigste Beziehungen zu den Dendriten der den Ganglienzellen entsprechenden Elemente. Und doch könnte ich mich dieser Detrtung hier nicht anschliessen, weil sie auf mich den Eindruck der Gezwungenheit machen würde. Die einfachste und richtigste Deutung scheint mir vielmehr die zu sein, dass wir es hier mit Zellen zu thun haben, deren Bestimmung darin liegt, die durch eine beschränktere Zahl von Retinalfasernihnen mitgetheilte Erregung vermöge ibrer umfangreichen Verästelung auf eine grössere Zahl von inneren Körnerzellen und Markzellen z u übertragen und a uszubreiten. Im Speciellen stelle ich mir hierbei ihre Wirkungsweise ganz ähnlich vor, wie ich sie bei den äusseren Körnerzellen dargelegt habe. Bei seinem Durchgang durch den äusseren Plexus wird der Fortsatz umflochten von den benachbarten Retinalbuischeln und empfängt so von ihnen die Impulse, die er.weiter fortzupflanzen hat. Diese Reizaufnahme wird befördert durch die zarten, alleidings nicht hesonders zahlreichen und auch nicht konstanten Fibrillen, die wir an ihm oft im Bereich des Plexus wahrnehmen; aber wenn solche auch nicht vorhanden sind, kann nan sich diese Uebertragung leicht vorstellen, denn was hindert uns, anzunehmen, dass auch der Stamm eines Dendriten, wenn er von Faserverästelungen umstrickt wird, zur Reizaufnahme geeignet ist. Die kräftigen absteigenden Aeste besorgen dann die Ausbreitung der Erregung auf den inneren Plexus, den Hauptsitz der Dendriten der dritten, reizableitenden Nerveneinheit. Wozu dienen aber die zarten Aestchen, die wir manchmal von den schon im inneren Plexus hinziehenden Endzweigen wieder in das äussere Geflecht zurtickbiegen sehen? Auch sie lassen sich erklären im Zusammenhalt mit der Thatsache, dass bei der dritten Nerveneinheit, besonders bei der einen Gattung derselben (den grossen tiefgelegenen Markzellen), der aufsteigende Dendrit oft auch im äusseren Plexus kleine receptive Fibrillen entsendet, zum Beweise, dass er auch in dieser Schicht einige Reize empfängt. Diese Reize könnten nun allerdings diesen Fibrillen direkt von den Retinalbüscheln zugeführt werden, wodurch eine zweite Möglichkeit (vergl. S. 97) einer direkten, verkürzten Leitungsbahn gegeben wäre, aber andererseits können auch die in Rede stehenden aufsteigenden Aeste im Spiele sein, wobei freilich schwer zu sagen wäre, warum 
diese Fasern anstatt gleich im äusseren Plexus selbst an dem die Schicht durchsetzenden Stück des Stammfortsatzes zu entspringen, den Umweg durch die ganze Tiefe der plexiformen Schicht machen.

Mit dieser Stellungnahme in Bezug auf die Funktion der grossen oberflächlichen Zellen ist auch schon die Frage beantwortet, ob ihr Fortsatz als ein Dendrit oder als der Neurit aufzufassen sei. Für die Amakrinen der Wirbelthiernetzhaut hat bekanntlich Cajal die Frage dahin beantwortet, dass der in der Einzahl vorhandene Fortsatz einen Dendrit darstelle. Auf dem Boden unserer Anschauung ist natürlich der Fortsatz unserer, den Amakrinen entsprechenden Zellen bis zu dem äusseren Geflecht der plexiformen Schicht als Dendrit oder richtiger als verlängerter Zellkörper aufzufassen, die absteigenden Theilungsaste als Nervenfortsätze. Dem dendritenartigen Charakter des ersten Stäckes entspricht auch die schon angedeutete Thatsache, dass jene färbbaren Substanzmassen, die wir im Zellkörpcr fanden, sich in dieses Stück hinein erstrecken; handelte es sich hier gleich von Anfang an um einen wirklichen Vervenfortsatz, so wärden diese Schollen höchst wahrscheinlich fehlen, denn wir sehen sie Halt machen an dem Ursprunge des Neuriten in den meisten Nervenzellen der Wirbelthiere ${ }^{1}$ ), und das Gleiche fand ich unlängst auch an den riesigen Nervenzellen von einigen Opisthobranchiern.

Mit der Betrachtung der Elemente der inneren Körnerschicht gelangen wir zur dritten Nerveneinheit, zn derjenigen, der die Ableitung der Sehreize aus der Sehlappenrinde zufällt; alle hier vorhandenen Elemente sind zunächst also in funktioneller Hinsicht mit den Ganglienzellen der Wirbelthiernetzhaut in eine Reihe zu stellen. Aber auch in morphologiseher Hinsicht ist die Aehnlichkeit unverkennbar, freilich bestehen auch gewisse Abweichungen. Dass die inneren Körnerzellen relativ kleine Gebilde sind, kaum grösser als die den Bipolaren entsprechenden äusseren Körnerzellen, bildet keinen

1) K. Sch affer (Budapest), Kurze Anmerkung über die morphologische Differenz des Achsencylinders in Verhältnisse zu den protoplasmatischen Fortsätzen. Neurol. Centralbl. Jahrg. XII, 1893 S. 849. 
wesentlichen Unterschied: findet man doch auch unter den Ganglienzellen der Wirbelthiere, namentlich bei Vügeln und Reptilien, auffallend kleine Exemplare (Cajal). Beachtenswerth ist dagegen der Unterschied, dass hier der Fortsatz keineswegs mit der dem oberen Dendritenbusch der Ganglienzellen entsprechenden Verïstelung in inneren Plexus endigt, vielmehr nach Abgabe dieser Fibrillen noch weiter emporzieht bis in die äussere Körnerlage, wo er dann zwischen clen Zellen in verschiedener Höhe zugespitzt endigt. Wenn nun auch an den entsprechenden Nervenelementen der Wirbelthiernetzhaut, den Ganglienzellen, nichts Analoges nachinweisen ist, so zeigen uns doch wieder andere Elemente der Netzhaut bei Amphibien, Reptilien und Vögeln Verhältnisse, die uns die Gegenwart dieser oberen Verlängerung minder befremdlich erscheinen lassen, ja ihr das Gepräge einer aussergewöhnlichen Erscheinung völlig nelımen. Ich habe hier jenes merkwairdige Anhängsel der Bipolarzellen in Auge, das als "Landolt'sche Keule" oder richtiger „Faser" bekannt ist. Auch bei den mit diesem Fortsatz ausgestatteten Bipolaren schliesst der anfsteigende Zellkörperabschnitt mit dem der äusseren plexiformen Schicht angehörenden receptiven Büschel nicht ab, sondern erstreckt sich darüber hinaus eben in Form der "Landolt'schen Faser" in die äussere Körnerschichte, ja sogar in die Stäbchen- und Zapfenlage, um erst etwas jenseits der Membrana limitans zu endigen. Nach Dogiel's neuesten Mittheilungen ${ }^{1}$ ) scheineu auch an den Bipolaren der menschlichen Netzhaut Andeutungen einer Landolt'schen Faser vorhanden zu sein, wobei dic Aehnlichkeil derselben mit den in Rede stehenden Fortsatzverlängerungen bei Cephalopoden um so grösser erscheint, als die Fasern nicht so hoch hinaufreichen, wie bei den Sauropsiden und Reptilien, sondern wie bei den Cephalopoden schon innerhalb der äusseren Körnerschichte endigen.

Ich habe lange darïber nachgedacht, mit welcher Funktion man die obere Verlängerung des aufsteigenden Dendriten der inneren Körnerzellen in Verbindung bringen könnte, habe aber gar nichts Befriedigendes ausfindig machen können. Das im

1) A. S. D o g i e l, Ueber die nervösen Elemente in der Retina des Menschen. Erste Mittheilung. Archiv f. mikrosk. Anatomie, Bd. 38, Tafel XIX, Fig. 1. 
äusseren Plexus gelegene Sttick kann noch für den direkten Reiziibertragungsweg in Anspruch genommen werden, indem man annehmen darf, dass der Fortsat\% hier direkt von Seiten der Retinalfibrillen Erregungen in sich aufnehnen kann; diese Annahme findet eine Stitze in der Thatsache, dass dem Fortsatz hier mitunter kleine Seitenfibrillen angefügt sind. Aber mit dem letzten, in der äusseren Körnerschicht gelegenen Sttick weiss man wirklich nicht was anzufangen. So lange also nicht Jemand eine plausible Erklärung für die Bestimmung dieses Endstuckes beibringt, glaube ich mich zur Annahme berechtigt, dass hier ein funktionell unwichtiger Anhang vorliegt. In funktioneller Hinsicht hört der Dendrit also schon mit dem ersten oder mit dem zweiten Büschel auf, was noch darüber liegt, ist schon als tiberflüsige ${ }^{\text {Wucherung }}{ }^{u}$ anfzufassen, geradeso wie bei den Rückenmarkzellen der Säuger jene Endspitzen der Dendriten der motorischen Zellen, die in die weisse Substanz hineinragen (Golgi, Kölliker u. A.), in ein Gebiet, wo sie gewiss keine Faserverästelungen finden, von denen sie Reize empfangen könnten. Die glciche Schwierigkeit besteht auch betreffs der funktionellen Deutung der Landolt'schen Keulen der Wirbelthiere. Soviel ich weiss, hat noch Niemand, weder Cajal oder Dogiel noch aber ein Anderer versucht, sie mit einer bestimmten Leistung zu rerkntipfen.

Abgesehen also von dieser einzigen Differenz sowie vielleicht noch von der Thatsache, dass die inneren Körnerzellen manchmal an ihrem Zellkörper noch einige kleine seitliche dendritenartige Anhänge haben, während die Ganglienzellen der Vertebratenretina ausser ihren in die innere plexiforme Schicht eintretenden Dendriten und ihrem Nervenfortsatze keine Ausläufer besitzen, besteht zwischen den beiden Zellgattungen eine grosse Analogie, und namentlich stimmen sie in Bezug anf ihre funktionellen Verkniipfungen ganz uberein. Bei beiden sehen wir den nnteren Pol mit einer Nervenfaser zusammenhängen, die die Erregung centripetalwärts ableitet, auf der anderen Seite vom oberen Zellenende einen starken Dendriten ausgehen, der sich in der plexiformen Schicht verästelt. Das Hauptausbreitungsgebiet des letzteren Fortsatzes ist beim Wirbelthier die innere plexiforme Schicht, beim Cephalopoden der innere Plexus der plexiformen Lage. Die beiden Schichten entsprechen 
sich also; dort wirken auf jene Dendritenaufzweigungen die unteren Endbüschel der Bipolaren ein, hier die absteigienden Aestchen der äusseren Körnerzellen und oberflächlichen Riesenzellen. Ebenso wie beim Wirbelthier sehen wir hier also die Lichtreize durch eine dreigliederige Kette ihren Weg nelımen, bestehend ans einer reizaufnehmenden, reizubertragenden und reizableitenden Nerveneinheit, nu* ist hier die erste davon weit weg von den beiden anderen verlagert; auch scheint, wie schon erwähnt,neben diesem dreigliederigen Wege noch ein einfacherer, zweigliederiger zu bestehen, indem einerseits die Fortsätze der ersten Einheit, die Retinalfasern, vermöge ihrer absteigenden Endästchen wahrscheinlich auch direkt auf die oberen Buischel der inneren Körnerzellen einwirken können, andererseits aber die dritte Nerveneinheit durch ihren aufsteigenden Dendriten direkt mit den zarten Fibrillen der ersten Einheit in Beziehung treten kann.

Die Gegenwart von gröisseren Zellformen in den tiefsten Lagen der inneren Körnerschicht schliesst sich ungezwungen an die Verhältnisse bei Wirbelthieren an, denn auch hier, namentlich bei Säugern, besteht in der Ganglien-

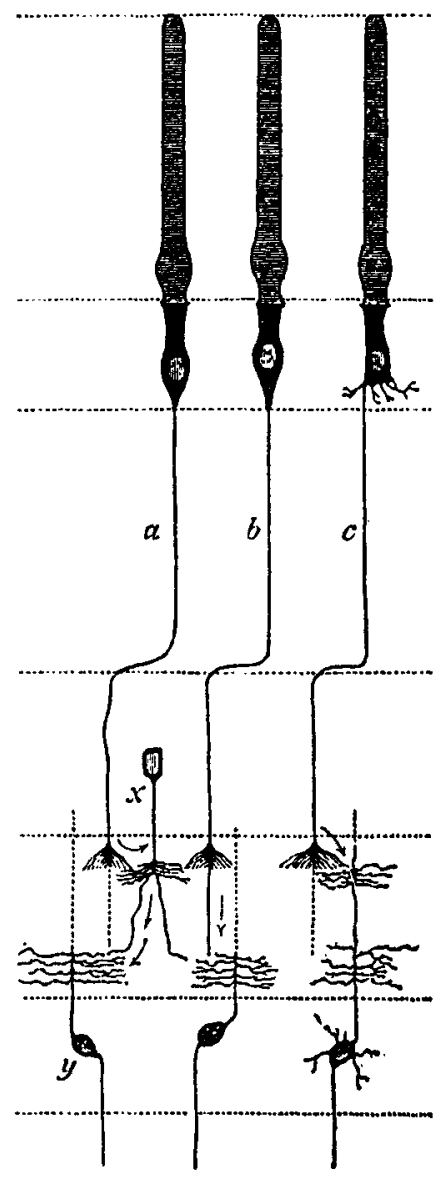

Fig. 3.

Schematische Darstellung der Uebertragung der optischen Reizwelle von den Sinneszellen der Netzhaut auf das Mark des Selllappens. $\quad a=$ indirekter Weg: die Erregung wird im äusseren Plexus der plexiformen Schicht durch die feinen Fibrillen der Retinalfasern auf die receptiven $\mathrm{Fi}$ brillen der äusseren Körnerzellen $(x)$ übertragen, die absteigenden Aeste der letzteren leiten sie in den inneren Plexus, wo sie ron den Fibrillen der inneren Körnerzellen $(y)$ aufgenommen werden. $-b=\mathrm{di}$ - 
rekter Weg, erste Möglichkeit: die Retinalfaser führt durch ihren absteigenden Endast die Erregung direkt den Fibrillen der inneren Körnerzelle zu. $c=z$ weite Möglichkeit: die Erregung wird von den inneren Körnerzellen schor im äusseren Plexus übernommen auf dem Wege der (inkonstanten) Fibrillen, die ihr Fortsat\% in dieser Schiclit abgiebt.

zellenschicht der Netzhaut eine Vermischung von Zellen kleinerer und grösserer Art, wobei die Unterschiede so betrïchtlich sind, dass $\mathrm{Caj}$ al sich veranlasst sieht, einen besonderen "Riesentypus" zu unterscheiden.

Die plexiforme Schicht erscheint uns nach dem (iesagten also als eine Verbindung "zweier funktionell sehr verschiedener Nervengeflechte, von denen das eine die Reizubertragung von der ersten auf die zweite Nerveneinheit, die andere von der \%weiten auf die dritte Einheit besorgt. $Z \mathbf{n}$ einer gemeinsamen ${ }_{n}$ plexiformen Lage sehen wir hier vereinigt, was in der Wirbelthiernet\%haut als $n^{\ddot{a} u s s e r e ~ u n d ~ i n n e r e ~ p l e x i f o r m e ~ s c h i c h t ~ g e t r e n n t . ~}$ besteht. Die doppelte Zusammenset»ung prigt sich in den beiden horizontalen Plexus aus.

Es ist nicht schwer, die unnittelhare Ursache dieser Verschmelzung anzugeben; sie bestelit darin, dass die Zellkïrper der $n^{\circ}$ äusseren Kïmer ${ }^{4}$ und ${ }^{\circ}$ oberflüchlichen grossen Nervenzellen", die beim Wirbelthier als Bipolare und Amakrinen oder zusammen betrachtet als "innere Körnerschichte" eine Scheidewand zwischen den beiden plexiformen Schichten bilden, bier uber die äussere plexiforme Schicht hinans verlagert sind.

Was die sporadischen in der plexiformen Schicht gelegenen Zellen betrifft, so habe ich es bei ihrer Beschreibung als möglich bezeichnet, dass sie verlagerte Körnerzellen darstellen. Indess durfen wir anch eine zweite, ebenfalls schon angedeutete Möglichkeit nicht ausser Acht lassen, und indem ich dies schreibe, drïngt sie sich mir mehr und mehr als die wahrscheinlichere auf. Diese Möglichkeit besteht darin, dass es sich um Analoga der, ${ }_{n} \mathrm{Horizontalzellen}{ }^{4}$, d. h. der bei Wirbelthieren in der äuseren plexiformen Schicht befindlichen sporadischen Nervenzellen handelt. Hierfür liesse sich auch geltend machen, dass 
sie eine ähnliche Lage anfweisen, wie jene Zellen beim Wirbelthier, indem sie sich mit Vorliebe an die untere Grenze des ässeren Plexus halten.

Die "Gliazellen" der plexiformen Schicht sind natïrlich als Analoga den Müller'schen Statzzellen der Wirbelthiere anzusprechen. Ihre ansehnliche Entwickelung fordert geradezu zur Diskussion der Frage heraus, welche Aufgabe sie durch ihre Anwesenheit erfüllen? Von den verschiedenen Ansichten, die über die Bestimmung der ${ }_{n} \mathrm{Glia}$ " im Allgemeinen aufgestellt worden sind, können meines Erachtens iberhatpt nur zwei ernstlich in Betracht kommen. Die eine davon, die ältere, erblickt in den ${ }_{n}$ Gliazellen "Stiltzvorrichtungen zum mechanischen Schutze der Elemente des Nervensystems; sie hat jiingst in $W$ ei gert ${ }^{1}$ ) einen beredten Auhïnger gefunden. Weigert knttpft bei seinen Ausfubrungen an die bekannte Lehre von der Architektur der Spongiosa an und futhrt in anregender Darstellung aus, wie vielleicht flir die Anordnung der "Gliafasern" ebenso wie für die Knochenarchitektur die Gesetze der graphischen Statik maassgebend sein könnten. Für Pedro Ramón ${ }^{2}$ ), R. y $\mathrm{Cajal}^{3}$ ) und $\mathrm{Cl}$. Sala ${ }^{4}$ dagegen sind die Gliazellen (Spongiocyten) Isolirvorrichtungen, zu dem Zwecke allgebracht, das zweckwidrige Uebergreifen der nervösen Reizströme von Faser auf Faser zu verhindern.

Es liegt mir die Absicht fern, in dieser Frage in ihrer allgemeinen Fassung. ein . Votum abzugeben, ich möchte vielmehr das, was ich zu sagen habe, nicht iber den vorliegenden Specialfall ausgedehnt wissen. Was in dem uns vorliegenden Falle zunächst auffallt, und was vielleicht einen Anhaltspunkt fur eine Entsclfeidung in dieser Frage bieten könnte, ist die Thatsache, dass sich hier die "Gliazellen" von den drei Schichten der Seh-

1) C. Weigert, Beiträge zur Kenntniss der normalen menschlichen Neuroglia. Festschrift z. 50jährigen Jubiläum d. ärztl. Vereins za Frankfurt a. M. Frankfurt 1895, S. 125.

2) P. R a m ó n, El encéfalo de los reptiles. Barcelona 1891, p. 10.

3) S. R. y Caja l, Significación fisiologica de las expansiones protoplasmáticas $y$ nerviosas de las células de la sustancia gris. Barcelona 1891, p. 22 und 23.

4) Cl. Sala y Pons, La neuroglia de los Vertebrados. Barcelona 1894, p. 39. 
lappenrinde gerade nur anf die plexiforme Schicht beschränken. Es drängt sich nun gleich die Frage auf: ist diese Schicht stützbedürftiger als die beiden ${ }_{\text {Körnerschichten }}{ }^{\text {oder nicht. Diese }}$ Frage muss nun unbedingt bejaht werden, denn eine Lage, die sich aus einem Gemenge zartester Fäserchen anfbant, wird sich an Widerstandsfähigkeit mit einem Complex dicht gedlü̈ngt stehender Zellen nicht messen künnen. So scheinen auf den ersten Blick die Aussichten für die erste Auffassung günstiger \%u liegen. Indessen wenn wir genauer zusehen, wendet sich das Blatt. Die plexiforme Schicht besteht ihrerseits wieder wie wir gesehen haben aus mehreren Unterschichten, die von sehr verschiedener Dichtigkeit sind. Wührend sich die beiden „Horizontalplexus" durch seln dicht geflochtene Beschaffenlieit auszeichnen, fällt die breite "Mittelzone" durch das Gegentheil auf, sie entbehrt des feinen Fibrillengeflechtes, das die beiden Plexus z dem macht, was sie sind, vollkommen, und man darf annehmen, dass hier neben den Fasergebilden noch eine gewisse Menge einer "Zwischensubstanz" vorhanden sein muss. Wie verllalten sich nun unsere "Gliazellen" in der Vertheilung dieser Verästelung auf die genannten drei Schichten? Sind sie wirklich Stützgebilde, so dürfen wir erwarten, dass sie gerade der Mittelzone ihre Hauptschutz angedeihen lassen, d. h. hier ihre dichtesten Verästelungen bilden. Ein Blick aber auf Fig. T, Taf. VII belehrt uns vom Gegentheil. Die meisten Zellen zeigen die reichste Verzweigung im äusseren Geflecht, ausserdem giebt es noch Zellen, wie Zelle $b$, die im inneren Geflecht einen besonders dichten Busch bilden, mit strenger Beschrinkung auf die Grenzen dieses Geflechtes; auf die Mittelzone ist in der Verästelungsweise der Zellen kaum Rticksicht genommen. Bemerkenswerth sind noch die auffallenden Varikositäten, die die Aeste im Bereich des äusseren Plexus bilden. Die beiden Horizontalplexus sind aber die Schichten, in denen die wichtigsten, die Uebertragung der Sehimpulse vermittelnden Contakte stattfinden, in denen aber zugleich die dichteste Verflechtung aller möglichen Fasern Platz greift. Deshalb spricht mir hier die Pedro Ramón'sehe Hypothese mehr z $\mathbf{n}$; ich stelle mir vor, dass die gesetzmässige Fortpflanzung der Lichtreize durch bestimmte Contakte dadurch gesichert wird, dass die buschigen Gliafaserveristelungen in der Weise in dieses Fasergewirr eingreifen, lass sie zwisehen den- 
jenigen Fasergebilılen, zwisclien denen keine Reiziibertragung stattfinden soll, Isolatoren bilden.

In Bezug auf das Marklager des Sehlappens bin ich nach reiflicher Ueberlegung zu der Ueberzeugung gekommen, dass es, mit den Verhältnissen der Wirbelthiere verglichen, nicht mehr zur "Netzhant" zu rechnen, sondern als ein „p rimäres Centrum" aufanfassen ist, mit anderen Worten; dass es den im Mittelhiln gelegenen optischen Centrender Wirbelthiere, also dem Lobus opticus der Vögel und niederen Vertebraten, den rorderen Vierh i geln etwa der Säuger entspricht. Dies ist gewiss ein merkwürdiges Ergebniss, denn nachdem wir beim Cephalopoden die beim Wirbelthier so eng verbundenen Netzhautschichten weit anseinandergesprengt fanden, tritt uns hier in Gegentheil eine Verschmelzung der Netzhaut mit einem Hirntheil entgegen, der beim Vertebraten von der Retina weit entfernt liegt; es ist, als ob jene Trennung durch diese Verschmelzung compensirt werden sollte. - Man kann also, immer die Verhältnisse bei Wirbelthieren vor Augen haltend, den Lobus opticus der Cephalopoden definiren als ein Sehganglion mit daruber gestulpter Netzhaut, wobei die oberflächlichste Netzhautschicht abgespalten und als eine besondere Membran distalwärts verlagert erscheint.

Was mich zu einer solchen Homologisirung veranlasst, das ist die Beschaffenheit der vielen Nervenzellen, die das Marklager bevölkern. Die itherwiegende Mehrzahl davon stebt nämlich zur Sehlappenrinde nicht in direkter histologischer Beziehung; sie empfangen die Erregung, die sie durch ihren nach dem Hilus hinstrebenden Fortsat\% den medianen Hirncentren zuzuführen liaben, nicht direkt in der Sehlappenrinde, sondern indirekt von ihr in der Weise, dass ihre kurzen Dendriten von den Endigungen des Nervenfortsatzes der inneren Körnerzellen. umflochten werden, ebenso wie wir beim Wirbelthier die Zellen des Mittelhirns oder richtiger ihre Dendriten von den prächtigen baumförmigen Verästelungen der Opticusfasern umflochten sehen (vergl. van Gehuchten 1)). Die Umflechtung erfolgt im Mark-

1) A. van Geh u ch te $n$, La Structure des lohes optiques chez l'embryon de poulet. La. Cellule, t. VIII, 1892, p. 37.

archiv f. mikrosk. Anat. Bd. 47 
lager des Cephalopodensehlappens natirlich innerhalb jener „weissen Substanz", die die Maschen des von den Zellbalken gebildeten Netzes ausfüllt. Jetz.t wird uns erst die sehr complicirte Beschaffenheit, der geflechtartige Charakter dieser Fasermassen verständlich. Sie bestehen nicht nur aus den verästelten Dendriten und den centripetalwärts ziehenden Nervenfortsätzen der Markzellen, sondern begreifen auch die Endarborisationen der Neuriten wohl der meisten inneren Körner\%ellen in sich und noch dazı wahrscheinlich auch verästelte Endigungen von Nervenfasern, die von den Centralganglien kommend im Sehlappenmark frei auslaufen.

Dass wir mit dieser Auffassung das Richtige getroffen haben, dafur ist auch der Umstand ein Beweis, dass im Lichte dieser Homologisirung auch die auf S. 82 beschriebenen ${ }_{n} \mathrm{Zellen}$ mit a ufsteigendem Fortsatze ihre Erklärung finden, d. h. anf entsprechende Elemente beim Wirbelthier zurilckgefthit werden künnen. Die Elemente bei Vertebraten, die ich hier meine, sind jene Zellen des Mittelhirns oder des Thalamus opticus (Cajal), deren Nervenfortsätze im Sehnerven peripheriewärts lanfen, um in der Netzhaut jene freien Endigungen zu bilden, die, schon fruther von v. Monakow ${ }^{1}$ ) auf Grund von Degenerationsergebnissen erschlossen, vor einigen Jahren von $\mathrm{R}$. y C aj a ${ }^{2}$ ) mit Hülfe der Golgi'schen Methode histologisch dargestellt worden sind. Bei Vögeln sind es nach Cajal (Retinawerk S. 111) ndicke Fasern, welche aus dem Sehnerv stammen, die innere plexiforme Sehicht durchsetzen und bis zum Niveau der anıakrinen Zellen aufsteigen; hier zerfallen sie in ein Endbüumchen mit dicken, varikösen und vollstïndig frei endigenden $Z_{w}$ weigen ${ }^{\mu}$. Freilich handelt es sich bei den aufsteigenden Fortsätzen unserer Zellen nicht um ${ }_{n}$ dicke $^{4}$, sondern um recht zarte Fasern, auch ist die Verästelung nicht immer endbäumchenartig, allein das sind wobl nicht wesentliche Unterschiede, nicht Abweichungen, die einen Vergleich ausschliessen könnten. Auch bei den Säu-

1) C. v. Monakow, Experimentelle und pathologisch-anatomische Untersuchungen über die optischen Centren und Bahnen. Archiv f. Psychiatrie Bd. XX, 1889, S. 714.

2) S. R. y Cajal, Sur la fine structure du lobe optique des oiseaux et sur l'origine réelle des nerfs optiques. Internat. Monatsschrift f. Anat. u. Physiol. Bd. VIII, 1891, S 337. 
gern scheinen diese „centrifugalen Fasern" vorhanden zu sein (vergl. Cajal S. 143).

Die Bestimmung der Function dieser Fasern ist sowohl beim Wirbelthier wie hier eine.Sache von grosser Schwierigkeit. Sofern wir uns an das von van $\left(\mathrm{ehuchten}^{1}\right.$ ) und R. y Cajal ${ }^{2}$ ) ausgesprochene, von $\mathrm{Ret} \mathrm{itus}^{3}$ ) und dem $\mathrm{Verf.}{ }^{4}$ ) befürwortete Gesetz der ndynamischen Polarität der Nervenzellen ${ }^{\star}$ halten, d. h. an das Axiom, dass der Nervenfortsatz immer cellifugal, die Dendriten cellipetal leiten, so müssen wir annehmen, dass diese Fasern von ihren Ursprungszellen her der Netzhaut resp. der Sehlappenrinde irgendwelche Impulse zuführen. Welcher Natur sind nun aber diese Impulse? Nach $\mathrm{van} G \mathrm{G}$ h u $\mathrm{chten}$ (Lobes optiques S. 31) haben diese Fasern die Aufgabe, die Netzhaut von der Natur und Intensität der durch den Sehnerven schon dem Gehirn zugeftihrten Erregungen rückläufig in Kenntniss zu setzen (?). R. y Cajal's Auffassung haben wir schon oben S. 104 geschildert. Ich selbst hatte noch (Feinerer Bau des Nervensystems, II. Aufl. S. 128) auf die Möglichkeiten hingewiesen, dass durch die fraglichen Fasern ein Einfluss auf den Contraktionszustand der Zapfen (E $\mathrm{n}$ g e l m a n n, H a m m a ch er) oder die Lage des Pigments ausgeubt wird. Diese beiden letzteren Momente fallen naturlich in unserem Falle weg. - In Ermangelung einer befriedigenderen Auffassung und von der Meinung ausgehend, dass eine auch nicht ganz tiberzeugende Hypothese besser ist als iiberhaupt keine Erklärung, möchte ich mich hier der $\mathrm{C}$ aja l'schen Meinung als der noch immerhin plausibelsten anschliessen, dass die Fasern einen Reiz vom Centrum herauf die Netzhautzu übertragen haben, der fürdie Function der letzteren irgendwie förderlich ist. Nach Cajal's Meinung bedienen sich dabei diese Fasern der Vermitte-

1) A. van Gehuchten, La structure des centres nerveux. La moëlle épinière et le cervelet. La Cellule, Tome VII, 1891, p. 83.

2) S. R. y Cajal, Sobre el papel desempeñado per los expansiones protoplasmáticas y nerviosas de las cellulas centrales. Barcelona 1891.

3) G. Retzius, Zur Kenntniss der ersten Entwickelung der nervösen Elemente im Rückenmarke des Hühnchens. Biol. Innters. Neule Folge V, 1893, S. 54.

4) Der feinere Bau des Nervensystems. 11. Anfl. S. 141. 
lung der Amakrinen. Dies könnte nun allerdings - wenn man Amakrinen bei muserem Objekt durch oberflächliche Rieseuzellen ersetzt - für unser Objekt, die Sehlappenrinde von Eledone, nicht als wahrseheinlich bezeichnet werden. Betrachten wir die Endigungsweise unserer Fasern, so fällt vor allem die Thatsache auf, dass ihre Verästelung ausschliesslich in der plexiformen Schicht erfolgt, also in demjenigen Gehiet, in dem die wichtigsten Contacte der Zellausläufer stattfinden, in dem die Uebertragungen der Reize von einer Nerveneinheit auf die andere vor sich gehen. Nicht auf die Zellkörper scheinen es also jenc Fasern mit ihrer Erregung abgesehen zu haben, sondern gerale auf die Stellen der "Articulationen" der Nerveneinheiten, das L eberspringen der Reizwellen von einem Büschelchen anf das andere scheint durchihren anregenden Einfluss erleichtert $z u$ werden.

Leider muss dieser Vergleich mit einem "Misston" enden, mit der Constatirung eines Unterschiedes, dem ich freilich eine besondere Bedeutung nicht zumessen kïnnte. Um die grossen, weitausgebreiteten Dendriten hancle es sich, die in der Sehlappenrinde eine so auffallende Erscheinung bilden und die wir mit einiger Wahrscheinlichkeit anf grosse Nervenzellen zurilckführen konnten, die in tieferen Schichten des Markes, oft in der Nähe des Hilus liegen. Wenn das Mark, wie wir anzınebmen alle Berechtigung haben, dem Mittelhirnganglion der Vertebraten entspricht, so bleibt unser Befund ohne Analogon bei den Vertebraten, denn wir kennen hier keine Zellen, die, in Mittelhirn gelegen, ihren Nervenfortsat\% centralwärts, einen kriftigen Dendriten aber in die Netzhaut senden.

Freilich ist hier gleich $\mathbf{z u}$ bemerken, dașs die Dendritennatur dieser Fasern nicht ganz als gesichert hingestellt werden kann, ich habe auch in dieser Beziehung an der Stelle, wo ich sie beschrieb, die gehörige Reserve walten lassen. Wer weiss, vielleicht handelt es sich doch um ${ }_{n}$ aufsteigende Nervenfortsätze ${ }^{u}$ einer noch nicht bestimmten Zellenart und entspricht jene mit einem gewissen Vorbehalt ausgesprochene Annahme, die sie als Aeste den grossen „tiefen Markzellen“ zutheilt, Zellen also, die ihren Neuriten, wie mir scheint, in den Pedunculus senden, nicht dem Sachverhalte. - Dies ist möglich, aber einstweilen, bis mir das Gegentheil bewiesen wird, muss ich an der oben auf- 
gestellten Ansicht als an der wahrscheinlicheren festhalten und muss daher versuchen, im Rahmen meiner Auffassung eine Erklärung für diese Zellen zu finden. Diese Erklärung könnte nun darin gesucht werden, dass bier dislocirte und besonders voluminös entfaltete ,innere Körner\%ellen vorliegen. Dass solche Zellversprengungen in der Netzhautstructur vorkommen können, ja sehr häufig vorkommen, beweisen uns die schon oben angeführten Erfahrungen an der Wirbelthiernetzhaut. Ist die Sehlappenrinde wirklich als "Retina" aufzufassen, so darf es uns nicht Wunder nehmen, wenn anch hier solche Zellverlagerungen stattfinden. Dass diese Dislocation in das einem Centralganglion entsprechende Marklager erfolgt, erklärt sich eben daraus, dass dieses Centralganglion hier zur "Retina" ganz andere räumliche Beziehungen aufweist, als beim Wirbelthier. Fragen wir uns zum Schlusse, wozu diese reichlich ausgebreiteten Dendriten dienen könnten, so ergiebt ein Blick auf die Figuren, in denen sie dargestellt sind, dass ihre Bestimmung nur darin liegen kann, Sehimpulse, di e durch eine grössere Anzahl von Retinalfasernder Sehlappenrinde z ugeführt werden, in sich zu sammeln, zu c oncentriren. Sie würden demnach in functioneller Hinsicht in einem gegensätzlichen Verhältniss stehen zu den noberfläehlichen grossen Zellen", denen wir mit einiger Wahrscheinlichkeit als Function die Ausbreitung der in den Sehlappen hineingetragenen Reize zutheilen konnten.

\section{Nachtrag.}

Mehrere Wochen, nachdem ich vorliegenden Aufsatz der Redaction dieses Archivs eingesendet hatte, erschien in No. 12 Bd. XI des Anatomischen Anzeigers eine kurze vorläufige Mittheilung von Fr. Kop s ch über denselben Gegenstand ( $D a s$ Augenganglion der Cephalopoden", A. A. Bd. XI, 1895, S. 361), auf die ich hier mit einigen Worten eingehen möchte; ein ausführlicher Vergleich meiner Befunde mit denen von $\mathrm{Kopsch}$ scheitert an der Kürze der genannten Mittheilung. Wenn ich einerseits mit Vergntugen konstatiren kann, dass wir in der $\mathrm{H}$ a u p s a che einig sind - in der Erkenntniss nämlich, dass die Cephalopodenretina nur der äussersten Schichte der Wirbel- 
thiernetzhaut, nur den Stäbchen- und Zapfenzellen entspricht, ein Sachverhalt, der freilich schon in meiner früheren Cephalopodenarbeit, wenn auch zunächst als Möglichkeit, aber mit allen Attributen der Wahrscheinlichkeit ausgestattet, vorgetragen wurde: so ergeben sich auf der andern Seite in vielen Einzelh e i t e n unserer Darstellungen Abweichungen, die ich mir nicht leicht erklären kann, auch nicht, wenn ich berücksichtige, dass die Untersuchungen von $\mathrm{K}$ op s $\mathrm{ch}$ an einem dekapoden Cephalopoden (Loligo), die meinigen aber an einem octoporlen (Eledone) angestellt wurden. Was mich hauptsächlich iberrascht, ist die abweichende Schilderung, die $\mathrm{Kops} \mathrm{h}$ von der Endigungsweise der "Retinalfasern" (Stäbchenfasern) in der Sehlappenrinde giebt, sowie auch der Unstand, dass die Zellen, die bei Eledone (und nach Stieda auch bei der mit Loligo rerwandten Sepia) fast die auffallendsten Elemente der Sehlappenrinde bilden: die oberflächlichen Riesennervenzellen, bei $\mathrm{Kopsch}$ weder Erwähnung noch bildliche Darstellung finden. Auch vermisse ich eine Erwähnung der Gliazellen der plexiformen Schicht, der „ centrifugalen peripherischen Fasern", der weitausgebreiteten Dendritenbäume der plexiformen Lage und anderer Dinge. Aber mögen unsere vollkommen unabhängig von einander und zur gleichen Zeit ausgefibhrten Untersuchungen in manchen Einzelheiten zu abweichenden. Ergebnissen gefithrt haben, erfreulich ist, dass wir in principieller Hinsicht $\mathrm{zu}$ dem gleichen Resultate gelangt sind.

\section{Erklärung der Abbildungen auf Tufel VI-VIII.}

Sämmtlichen Abbildungen dienten Golgipräparate aus dem Seh lappen von Eledone moschata als Vorlage. Die dargestellten Zellen sind immer aus mehreren Präparaten unter Anwendung eines Zeissschen Zeichenapparates in eine Zeichnnng eingetragen. Um die Bilder nicht zu complicirt zu gestalten, sind in jeder Figur jeweilen nur 1-2 Zellsorten dargestellt worden. Die auf der Oberflache des Sehlappens gelegenen Retinalfaserbündel sind mit Ausnahme der Figur 2 und der schematischen Figur 8 weggelassen.

Fig. 1. Endigungsweise der Retinalfasern in der plexiformen Schicht des Sehlappens. Schichtenfolge: 1 äussere Körnerschicht, 2-6 plexiforme Schicht, 7 innere Körnerschicht, 8 Markschicht. In der plexiformen Schicht: 2 äusserer heller Saum, 3 äusserer horizontaler Plexus, 4 Mittelzone, 5 innerer horizontaler Plexus, 
6 innerer heller Saum. - In $a$ und $b$ sind die mächtigen Verästelungen von drei starken, aus der Tiefe des Markes aufsteigenden, wahrscheinlich von grossen Markzellen herstammenden Dendriten dargestellt, bei $a$ giebt der Dendrit schon in der inneren Körnerschicht Nebenäste ab. $-c$ : eine Körnerzelle mit imprägnirtem Nervenfortsatz; der aufsteigende Dendrit lässt sich bis zur Oberfläche verfolgen, wo er zugespitzt endigt.

Fig. 2. Grosse oberflächliche Nervenzellen der äusseren Körnerschicht. $a=$ erste Gattung, die Theilung des Fortsatzes erfolgt erst in inneren Plexus; $b=$ \%weite Gattung, der Fortsatz theilt sich im äusseren Plexus; $c=$ dritte Gattung, der Fortsatz gabelt sich schon in der äusseren Körnerlage. - In $d, e$ und $f$ sind drei äussere Körnerzellen (grössere Gattung), und zwar solche mit relativ kurzen absteigenden Fortsitzen zur Darstellung gebracht; die bei $f$ vorhandene Besonderheit, dass der Fortsatz sich schon in der äusseren Körnerschicht theilt, gehört $z u$ den Seltenheiten.

Fig. 3. Aeussere Körnerzellen. Mit Ausnahme der Zellen $d, e, f$ gehören alle der grösseren, zahlreicheren Gattung an. Bei den Zellen $a, b, c$ erreichen die absteigenden Aoste den inneren Plexus nicht. $d, e, f^{\prime}=$ kleine Körnerzellen.

Fig. 4. Innore Körnerzellen. Der (absteigende) Nervenfortsatz crscheint bei den meisten nur eine kurze Strecke imprägnirt. Die meisten Zellen von bipolarem Typus. Die Zelleu $a, b, c, d$ unterscheiden sich von den anderen' dadurch, dass ihr autsteigender Hauptdendrit auch im äusseren Plexus einige feine Fibrillen abgiebt. Bei den Zellen $e, f, g$ ist der aufsteigende Dendrit absichtlich nicht dargestellt. $h, i=$ grössere, ausgesprochen multipolare Gattung der inneren Körnerzellen. $k, l=$ Verüstelungen zweier aus tiefen Schichten des Markes kommenden Dendriten.

Fig. 5. Nervenzellen aus dem Marklager des Sehlappens. $a, b, c, f=$ unipolare, $d, h, i, j=$ bipolare, $e, g, k=$ multipolare Zellen.

Fig. 6. Verschiedene Fasergebilde der Sehlappenrinde. Schwarz: Verästelungen der aus tiefen Lagen des Markes kommenden Dendriten; ihre sonst bis zur Oberflache aufsteigende Fortsetzung wahrscheinlich nicht imprägnirt. Roth: centrifugale peripherische Fasern (motorische und sensible Fasern für die Muskeln und Häute des Auges). B la u: Endigungen des Neuriten gewisser Markzellen, die ihren Nervenfortsatz in die Rinde senden; $a=$ baumförmige Endigung desselben in der Mittelzone der plexiformen Schicht; $b=$ Endigung durch einfache Gabelung im inneren Plexus.

Fig. 7. Die Gliazellen der plexiformen Schicht. $a, a, b=$ Zellen, deren Verästelungen schon unweit vom Zellkörper beginnt, in $b$ sehen wir eine besonders dicht verästelte Form, deren Aeste 
120 Michael v. Lenhossik: Histologische Untersuchungen etc.

im inneren und ausseren Plexus noch mit besonderen stacheligen Zweigchen versehen sind. $-c, c_{1}=$ Zellen, deren Verästelung in der Mittelzone beginnt, $d=$ Gliazellen, deren Fortsatz sich erst in der aussersten Schicht der plexiformen Schicht verästelt.

Fig. 8. Schematische Darstellung des Baues der Netzhaut und des Sehlappens von Eledone. In der Netzhaut sind nur einige Sehzellen dargestellt; sie bestehen aus einer (in hellerem Ton gehaltenen) distalen Verlängerung, dem "Stäbchenapparat" und aus dem eigentlichen kernhaltigen Zellkörper. Letzterer giebt bei manchen Zellen an seinem basalen Ende einige kurze protoplasmatische Fïserchen $a b$; bei allen setzt er sich in eime Nervenfaser fort, die als "Retinalfaser“ nach Durchsetzung der knorpeligen (hier gelb angedeuteten) Sklera nach dem Sehlappen hinstrebt. In letzterem endigt sie im Bereich der plexiformen Schicht, theils in deren ausserem Plexus mit einem zarten Fibrillenbusch, theils durch einen absteigenden Ast an der iusseren Grenze des inneren horizontalen Geffechtes. Die Zellgebilde des Sehlappens sind mit verschiedenen Farben dargestellt. In der ßusseren Körnerschicht, für deren Zellen die rothe Farbe Verwendung getunden hat, sehen wir drei Zellgattungen: die oberflächlichen grossen Zellen $(a)$, die grösseren $(b)$ und kleineren $(c)$ äusseren Körner\%ellen. In der plexiformen Schicht sind als autochthone Elemente nur die in violetter Farbe gezeichneten Gliazellen $(d)$ dargestellt worden. Von den blau dargestellten Elementen der inneren Körner. schicht entsprechen die Zellen $e$ der kleineren, die Zelle $f$ der grösseren Gattung der inneren Körnerzellen. Ihr Fortsat\% dringt in die Markzone herunter, um darin mit fieien Veristelungen zu endigen; letztere Endigungsweise ist als $\mathrm{H} y$ p othes $\mathrm{C}$ aufaufassen. In der Markschicht entsprechen die schwarzen Zellen der gewöhnlichen Zellgattung, d. h. den Zellen mit absteigendem Nervenfortsatz, wovon es kleinere $(g)$ und grössere (h) Exemplare giebt. Die grünen Zellen $(l)$ stellen die seltenere Form dar, nämlich die "Zellen mit aufsteigendem Nervenfortsatze ${ }^{u}$. Schliesslich ist ganz unten in hrauner Farbe einc auffallend grosse ,.Riesenzelle ${ }^{\alpha}(i)$ dargestellt, die ihren Neuriten, wie die meisten Markzellen, in den Pedunculus sendet. Wahrscheinlich gehören zu diesen Zellen als aufsteigende Dendriten jene kräftigen Fasern $(k)$, die man von den tieferen Schichten des Markes her in die Rinde aufsteigen und sich darin in Form eines mächtigen Endbaumes verästeln sieht. - Die centrifugalen peripherischen Fasern sind in dieses Schema nicht aufgenommen worden, da sie nicht eigentlich zu dem Bestand des Sehlappens gehören, sondern ihn nur zum Durchgange benützen. 